\title{
Stability and Reactivity of Organic Molecules in Geothermal Reservoirs
}

\author{
Dissertation \\ zur Erlangung des Doktorgrades \\ der Mathematisch-Naturwissenschaftlichen Fakultäten \\ der Georg-August Universität zu Göttingen
}

vorgelegt von:

Martin Breer genannt Nottebohm

aus Itzehoe

Göttingen 2011 
Referent: $\quad$ Prof. Dr. Martin Sauter

1. Korreferent: Dr. habil. Chicgoua Noubactep

2. Korreferent: Dr. Tobias Licha

D7

Tag der mündlichen Prüfung: 14.11.2011 


\section{Abstract}

The present work deals with laboratory studies of tracers for geothermal applications. Analytical methods for the detection of molecules being used as nonreactive tracers are presented and investigations of their thermal stability as well. Furthermore, the synthesis of substances is described which can undergo a reaction by hydrolysis. Additionally, these substances are explored for their application as thermosensitive tracers by lab experiments.

For the characterization of several geothermal reservoir properties, tracer tests are the method of choice. Only by tracer tests it is possible to track flow paths, to estimate reservoir fluid volumes and fluid dwell times, and various other parameters that are essential for the operation of a geothermal reservoir. But the results gained from tracer tests are often distorted or misguided due to a lack of knowledge of the substance behavior in the reservoir. Also, the analytical methods may be incorrect or not sensitive to the substance. Naphthalene sulfonates are widely used as conservative tracers in geothermal applications. In this work, an analytical method was developed and validated that is able to detect different naphthalene sulfonate isomers from highly saline geothermal brines in the sub- $\mu \mathrm{g} / \mathrm{L}$ range. The method bases on high-performance liquid chromatography in conjunction with fluorescence detection and solid phase extraction.

Beside conservative tracers, thermally reacting substances are under investigation by several research groups. These are envisaged to map reservoir temperatures and to describe a thermal drawdown during operation of the geothermal plant. Previous field applications using thermosensitive tracers gave only insufficient results. An applicable thermosensitive tracer has to possess well known reaction kinetics and transport behavior in the reservoir, as well as a sensitive detectability in brines. The investigations presented in this work shows that hydrolysis is a promising reaction for geothermal applications. On the example of phenolic esters it is shown that the kinetics of this reaction can be influenced at least by a factor of 100 by varying the structural characteristics of the ester. All these influences are predictable. Matrix effects such as high salinities of $100 \mathrm{~g} / \mathrm{L} \mathrm{NaCl}$ or the presence of powdered rock showed no effect on reaction kinetics. A strong effect on the kinetics is given by the $\mathrm{pH}$ of the solvent. It could also be shown that the reaction is completely alkaline catalyzed within the $\mathrm{pH}$ range of most geothermal systems. This effect can therefore be included in the reaction equations. However, the reaction is comparatively fast for long-term tracer tests in high temperature regimes. For these applications the findings of this work may be transferred to another class of 
ester substances. Finally, a hydroxynaphthalene sulfoic ester was synthesized and investigated in lab experiments as a example of a practical thermosensitive tracer for geothermal field applications. 


\section{Zusammenfassung}

Die vorliegende Arbeit beschäftigt sich mit Laboruntersuchungen von Markierungsstoffen (Tracern), welche bei geothermalen Fragestellungen Anwendung finden. Hierbei sollen bestehende analytische Methoden auf geothermale Fluide ausgeweitet werden. Weiterhin soll die Stabilität von als konservativ angesehenen Markierungsstoffen untersucht sowie Stoffe entwickelt werden, welche thermosensitive Eigenschaften aufweisen.

Zur Charakterisierung von geothermalen Reservoireigenschaften, welche für die Nutzung des Systems von essentieller Bedeutung sind, stellen Tracertests häufig das Mittel der Wahl dar. Nur hierdurch können Fließwege, Reservoirfluidvolumina, Verweilzeiten und andere Parameter bestimmt werden. Häufig wird dabei die Interpretation des Wiedererhaltes des Tracers aufgrund fehlender Kenntnisse des Verhaltens des Stoffes im Reservoir verfälscht, fehlgeleitet oder gar unmöglich gemacht. Ebenfalls können hierfür fehlerhafte analytische Methoden die Ursache sein. Naphthalinsulfonate sind heutzutage weitverbreitete Tracer bei geothermalen Fragestellungen. Im Rahmen dieser Arbeit wurde daher eine analytische Methode entwickelt und validiert, welche in der Lage ist, verschiedene Naphthalinsulfonatisomere im sub- $\mu \mathrm{g} / \mathrm{L}$ in hochsalinaren Geothermalfluiden zu quantifizieren. Das Verfahren basiert auf Hochleistungsflüssigkeitschromatographie in Kombination mit Fluoreszenzdetektion und Festphasenextraktion.

Neben den als stabil betrachteten Tracern werden zur Zeit von verschiedener Seite Stoffe entwickelt, welche thermosensitive Eigenschaften aufweisen. Dieses soll dazu dienen, die Temperatur innerhalb des Reservoirs abzubilden und einen thermischen Abfall während des Anlagenbetriebes zu erfassen. Bisherige Feldanwendungen scheiterten jedoch im Wesentlichen an der mangelnden Verfügbarkeit geeigneter Stoffe. Hierbei sind ihre kinetischen Eigenschaften, das Transportverhalten im Reservoir sowie eine empfindliche Detektierbarkeit zu berücksichtigen. Innerhalb der in dieser Arbeit durchgeführten Untersuchungen zur Entwicklung von "Thermotracern" zeigte sich, dass die Hydrolysereaktion außerordentlich vielversprechend für geothermale Fragestellungen ist. So ist die Kinetik dieser Reaktion durch verschiedene Struktureigenschaften des hydrolysierenden Esters mindestens um den Faktor 100 beeinflussbar. Ebenfalls sind diese Auswirkungen vorhersagbar. Bei den Untersuchungen zum Einfluss verschiedener Matrixeigenschaften auf die Kinetik zeigte sich, dass hohe Salinitäten oder reaktive Oberflächen keinen Einfluss besitzen. Ein signifikanter Einfluss ergibt sich jedoch durch den pH-Wert der Lösung. Es konnte ebenfalls festgestellt werden, dass die 
Reaktion von pH 5 bis 8 ausschließlich basenkatalysiert ist. Der Einfluss des pHWertes kann somit innerhalb der kinetischen Gleichungen berücksichtigt werden. Innerhalb der untersuchten Ester ergibt sich durch eine relativ rasche Reaktionsgeschwindigkeit eine Limitierung der Stoffe für den langzeitlichen Hochtemperaturbereich. Für diese Anwendungen sollten daher die hier vorgestellten Ergebnisse auf andere Stoffgruppen von Estern übertragen werden. Als erster "Thermotracer" wurde ein Naphtholsulfonsäureester synthetisiert, dessen Reaktionsprodukt bereits als konservativer Tracer bei geothermalen Anwendungen findet. Es zeigte sich, das die Erkenntnisse aus den Hydrolyseuntersuchungen auf diesen Stoff übertragbar sind und diese Substanzen somit für die Feldanwendung eine außerordentlich vielversprechende Stoffgruppe darstellen. 


\section{Danksagung}

Mein Dank gilt an erster Stelle Prof. Martin Sauter für die Übernahme des Hauptreferats. Ohne seine Etablierung von neuen, vielfältigen Schwerpunkten an der Universität Göttingen hätte ich dieses Studium nicht weiter fortführen können und wollen.

Weiterhin danke ich Dr. Tobias Licha für die inhaltlich und zeitlich maßgebliche Betreuung meiner Arbeit. Besonders für die stets anregenden und produktiven Diskussionen, insbesondere während der wesentlichen Phasen meiner Promotion.

Dr. Iulia Ghergut danke ich für inr Vertrauen und die Einblicke in die Probleme realer Feldanwendungen.

Dr. habil. Chiqua Noubactep danke ich für die Übername des Korreferates.

Bei den CTA Anke von Gaza, Mechthild Rittmeier und Florian Deisinger bedanke ich mich für die Unterstützung im Labor sowie bei den HIWI Anne Niedbala und Nicholas Ryan für die Durchführung von Laborversuchen.

Eike Sacher danke ich für die Hilfestellung bei der Synthese.

Ebenfalls bedanke ich mich bei der gesamten Abteilung "Angewandte Geologie" der Universität Göttingen und insbesondere meinen Bürokollegen Karsten Nödler und Mario Schaffer - nicht nur für fachliche Diskussionen und Anregungen. 


\section{Table of Contents}

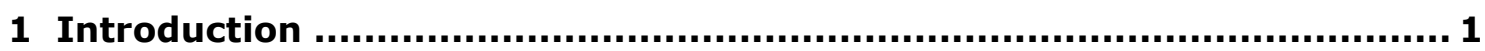

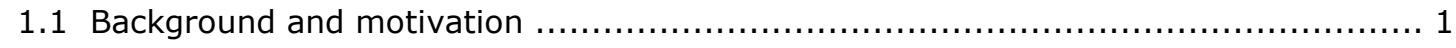

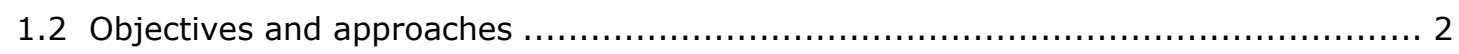

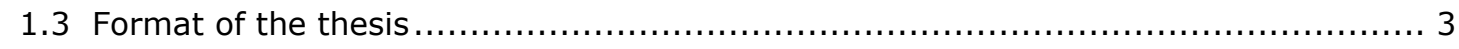

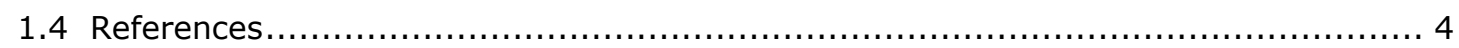

2 Geothermal energy usage - a general overview ................................ 5

2.1 Geothermal reservoir types and applications for its exploitation.......................... 6

2.2 Exploration and characterization methods of geothermal reservoirs ...................... 7

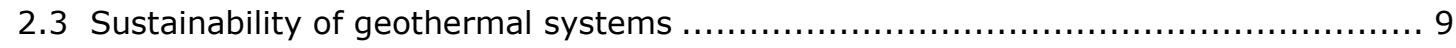

2.4 Tracer techniques in geothermal applications ....................................... 10

2.5 Reactivity and stability of organic molecules and options for using chemical

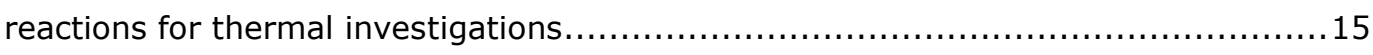

2.6 Analytical methods for the detection of highly polar organic molecules from

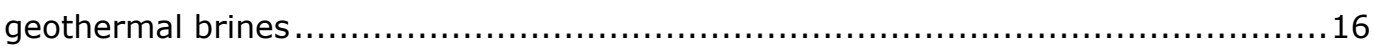

2.7 Synthesis and purification of naphthalesulfonic esters for the use as thermosensitive substances ............................................................ 17

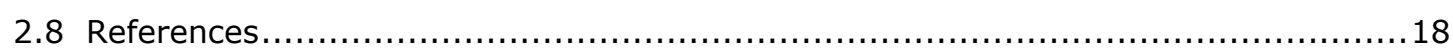

3 Detection of Naphthalene sulfonates from highly saline brines ............ 24

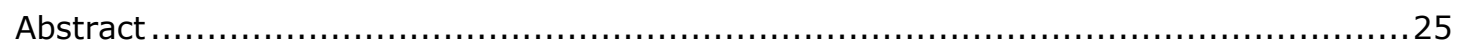

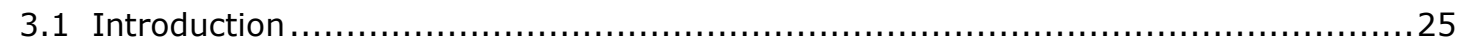

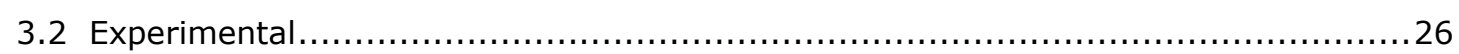

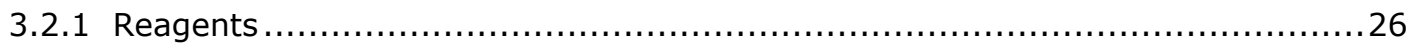

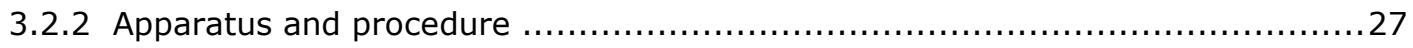

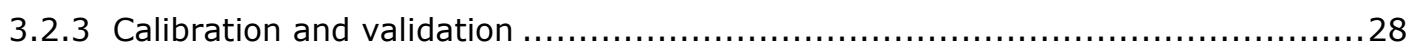

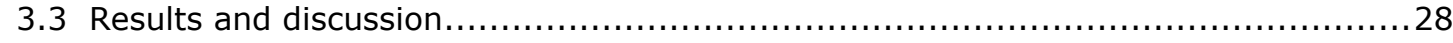

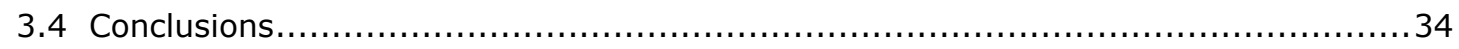

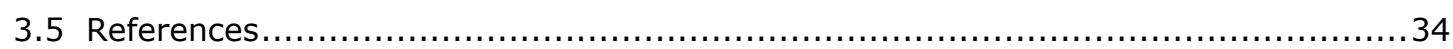


4 Development of Thermosensitive Tracers for Push-Pull Experiments in Geothermal Reservoir Characterization .......................................... 37

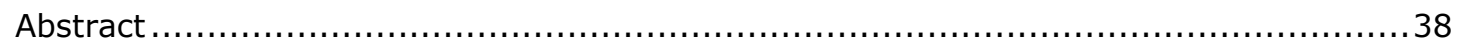

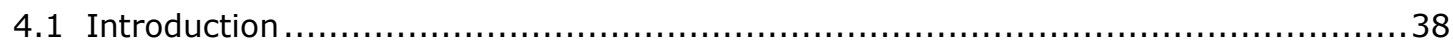

4.2 Hydrolysis constants of phenolic esters measured by HS-SPME-GC-MS................. 39

4.2.1 Experimental Method ................................................................. 40

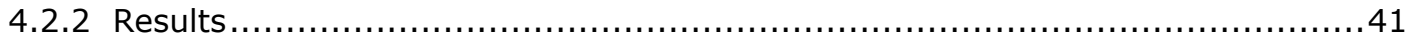

4.3 Thermal stability of naphthalene sulfonates in the presence of oxygen traces ..........44

4.3.1 Thermal batch experiments with individual compounds ...........................45

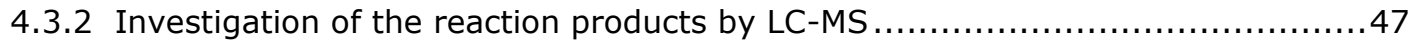

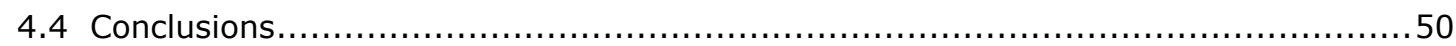

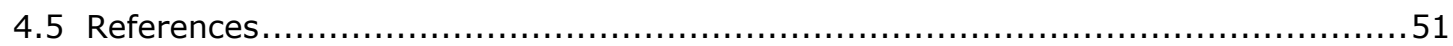

5 Tracer design for tracking thermal fronts in geothermal reservoirs...... 53

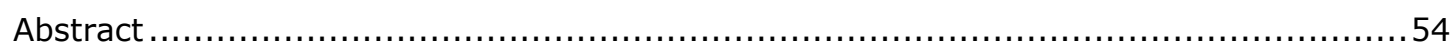

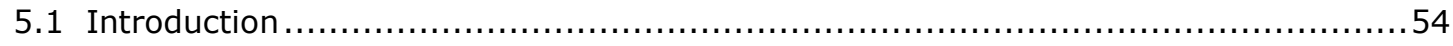

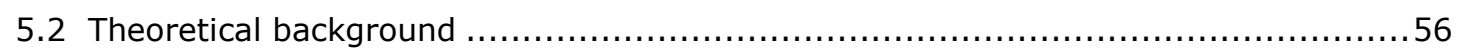

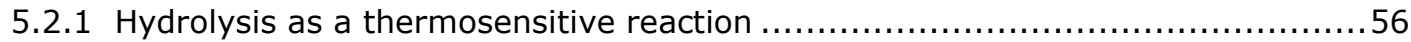

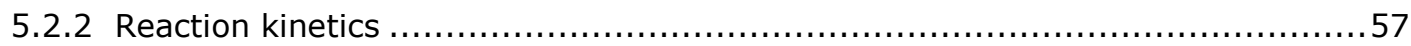

5.2.3 Temperature dependency of reaction kinetics....................................... 58

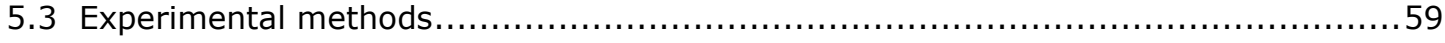

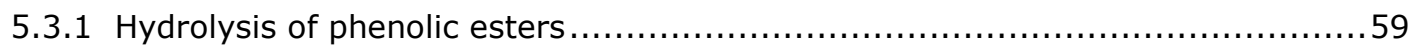

5.3.2 Hydrolysis of hydroxynaphthalene sulfonic esters ..................................61

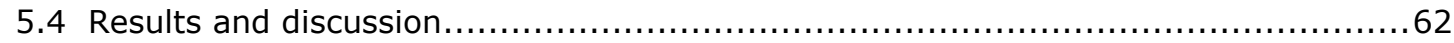

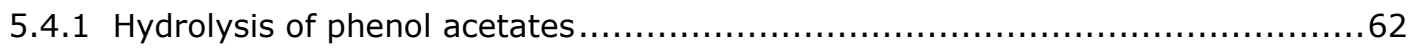

5.4.2 Hydrolysis of hydroxynaphthalene sulfonic esters .................................6 68

5.4.3 Considerations of potentially suitable reactive tracers in geothermal reservoirs .70

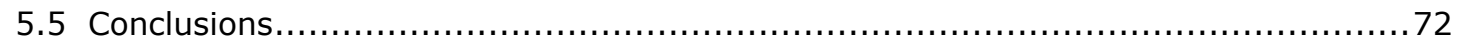

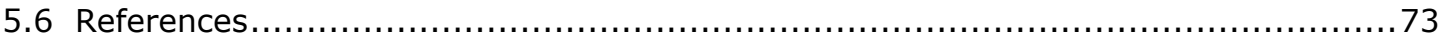

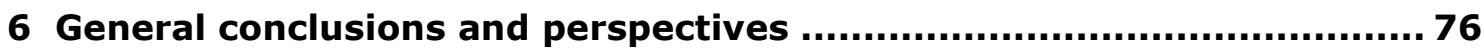

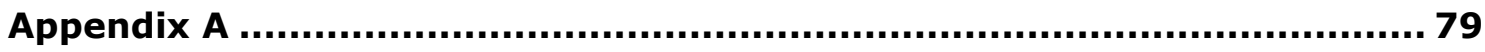

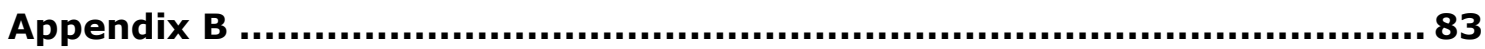




\section{List of Figures}

Figure 1.1: Thermal regime in a typical geothermal reservoir at the beginning of production and after several years of production

Figure 2.1: Classification of artificial tracers in geothermal applications

Figure 3.1: $\quad$ Structures and fluorescence maxima for different naphthalene sulfonates

Figure 3.2: Chromatogram of a $10 \mu \mathrm{g} / \mathrm{L}$ mix-standard consisting of different naphthalene sulfonates

Figure 4.1: Calculation of the first-order rate constant $\mathrm{k}$ for 4 -chloro-3-cresol

Figure 4.2: Hydrolysis constant $\mathrm{k}$ at ambient temperature versus $\mathrm{pK}_{\mathrm{a}}$

Figure 4.3: Decrease in fluorescence of naphthalene sulfonates after $165 \mathrm{~h}$ at $150^{\circ} \mathrm{C}$

Figure 4.4: TIC-Spectrum of 1-NMS before (green line) and after the stability test (black line)

Figure 4.5: Investigated reaction products of different naphthalene sulfonates after $24 \mathrm{~h}$ and $66 \mathrm{~h}$ at $150^{\circ} \mathrm{C}$

Figure 4.6: Proposed and identified reaction products of the thermal degeneration of naphthalene sulfonates

Figure 5.1: Hydrolysis reaction of phenol acetate

Figure 5.2: Hydrolysis reaction of 2-ethylbutyryl-2-napthol-6-sulfonate

Figure 5.3: Linear relationship of the acid constant $\mathrm{pK}_{\mathrm{a}}$ of the phenolic reaction product versus hydrolysis constant $k$ at $25^{\circ} \mathrm{C}$

Figure 5.4: $\quad \mathrm{pK}_{\mathrm{a}}$ of the phenolic reaction product versus half-life of 44 phenol acetate esters at $80^{\circ} \mathrm{C}$ calculated from Arrhenius parameters

Figure 5.5: Half-life versus temperature for the acetates of 2.6-dimethylphenol, naphthol, pentachlorophenol, and 2-phenylphenol

Figure 5.6: Activation energy Ea versus pre-exponential factor $A$ for the acetates of chlorophenols and alkylphenols

Figure 5.7: Half-life of the 2-ethylbutyryl-2-naphthol-6-sulfonate ester at $80^{\circ} \mathrm{C}$ versus $\mathrm{pH}$

Figure 5.8: Pseudo first-order reaction kinetics of 2-ethylbutyryl-2-naphthol-6-sulfonate ester at different $\mathrm{OH}^{-}$concentrations for 80 and $95^{\circ} \mathrm{C}$

Figure 5.9: Arrhenius plot for alkaline catalyzed second order rate constants of the 2-ethylbutyryl-2-naphthol-6-sulfonate ester

Figure A.1: $\quad$ H-NMR-Spectrum of Ester C 
Figure A.2: $\quad$ C13-NMR Spectrum of Ester C

Figure A.3: $\quad$ NMR-Spectrum of Ester C

Figure A.4: m-TOF chromatogram of Ester C (positive, m/z 100-1050)

Figure A.5: m-TOF chromatogram of Ester C (negative, m/z 180-720)

Figure A.6: m-TOF chromatogram of Ester C (negative, m/z 319.6-326) 


\section{List of Tables}

Table 3.1: $\quad$ Recovery of NS on different solid phase sorbents

Table 3.2: $\quad$ Recoveries of NS in highly saline brines with concentrations between 0 and $175 \mathrm{~g} / \mathrm{L} \mathrm{NaCl}$

Table 3.3: Composition of brine, taken from the deep geothermal test site Bruchsal, Germany

Table 3.4: Calibration parameters of the overall method, including SPE and HPLCdetection

Table 3.5: $\quad$ Mean recovery and RSD of NS on SPE by using different sample volumes in $10 \mathrm{~g} / \mathrm{L} \mathrm{NaCl}$

Table 4.1: Hydrolysis constants and half-lives at ambient temperature and estimated half-lives for $120^{\circ} \mathrm{C}$ for 43 phenols and naphthol

Table 4.2: Compounds analyzed for thermal decay with the chemical structure compound name, and excitation and emission maximum

Table 5.1: Fluorescence intensity for six naphthol sulfonates and two naphthol disulfonates

Table 5.2: $\quad$ Arrhenius parameters and calculated half-life for $30^{\circ} \mathrm{C}$ and $110^{\circ} \mathrm{C}$ for 42 phenolic esters

Table 5.3: $\quad$ Arrhenius parameters and half-lives at $100^{\circ} \mathrm{C}$ for $\mathrm{pH} 6,7$, and 8 of different phenol acetates

Table 5.4: Arrhenius parameters and half-life of the 2-ethylbutyryl-2-naphthol6-sulfonate ester at different $\mathrm{pH}$

Table A.1: Ion-chromatographic measurements of the 2-ethylbutyryl-2-naphthol6-sulfonic ester 


\section{Chapter 1}

\section{Introduction}

\subsection{Background and motivation}

The utilization of geothermal heat is gaining significance worldwide. In the face of decreasing fossil energy resources and greenhouse gas emissions, renewable energy sources such as photovoltaic, biogas, hydropower, wind energy, and geothermal heat and -power production are in focus.

Today, by the more advanced drilling technology and the reduced drilling costs, deep geothermal resources becomes more and more profitable. This makes geothermal energy production cost-effective also in comparatively low-enthalpy regions like northern Europe and others. Depending on the available natural resources at the respective location and the way of the heat will be utilized, there are several possibilities to extract the thermal energy from the ground. It may be used for electricity generation or district heating, and deep hot water aquifers can be used as well as hot dry rock systems.

The hydrogeology of geothermal systems is complex. Simultaneously, it is crucial to characterize the circulating fluid properties and -flow paths to predict the long-term behavior of the system. In this regard, tracer tests are an essential reservoir engineering tool (Horne 1985). For example, in most geothermal systems the extracted heat exceeds the natural inflow into the system, resulting in a cool-down of the reservoir (O'Sullivan et al. 2010). Also, the chemical composition of the circulating fluid may change and mineral dissolution and precipitation can occur, leading to a change in permeability's. Today, mostly conservative tracer techniques are used to characterize geothermal systems. Additionally, great efforts are being done in the application of tracers that react in a specific way relative to boundary conditions of the reservoir, such as temperatures or mineral surfaces. Reacting tracers can enhance the information gained from a tracer test significantly. For example, up to now there is no monitoring tool available to measure the thermal regime in geothermal reservoirs. Its cool-down during operation can therefore only be predicted by modeling techniques. 


\subsection{Objectives and approaches}

This thesis aims to investigate the stability of organic molecules that may be used as geothermal tracers. It deals with the investigation of substances that can be applied as conservative tracers and with the extension of these tracers with thermosensitive properties. Also, an analytical method for the detection of geothermal tracers in brines is shown. Due to the non-commercial availability of the investigated reactive tracers, a method for the synthesis of hydroxynaphthalene sulfonic esters is presented. Also, methods are shown to vary reaction kinetics by changes in the molecule structure.

For deep geothermal applications, naphthalene sulfonates are widely used as conservative tracers. These are proposed to be stable under the physicochemical conditions of most geothermal reservoirs and not to underlie sorption processes on rock surfaces (Rose et al. 2001). Further, they are easy to detect in water by fluorescence spectroscopy. Due to these benefits, these substances are studied in detail and the most important boundary conditions that affect their stability are examined. Also, naphthalene sulfonates were chosen to be the reaction products of the thermosensitive tracers that are investigated in this work. To extend naphthalene sulfonates with thermosensitive properties, an ester group is added to the molecule that is able to undergo a thermosensitive reaction by hydrolysis. One advantage of this reaction is that the reaction kinetics can be influenced in several ways. In this context, the leaving ester group can be varied in its molecular properties. Also, various substituents can be added to the molecule that have an influence on reaction rates. Beside this, the hydrolysis reaction may be affected by reservoir fluid properties. In this work, these effects are studied in detail to examine if the reaction is suitable for geothermal applications. Also, suggestions are given for the target design of thermal reacting tracers with respect to the thermal regime of the respective reservoir.

The predicted thermal regime of a typical geothermal reservoir at two different time steps after operation is given in Figure 1.1 (A). By applying a tracer test using thermal reactive tracers, different temperature profiles would result in different breakthrough curves (Figure 1.1, C). By using multiple tracers, that have different reaction rates with temperature (Figure 1.1, B), the breakthrough curves may be able to map temperature profiles along the flow path. 


\section{Reservoir at the beginnung Cooled reservoir during operation of production}

A)
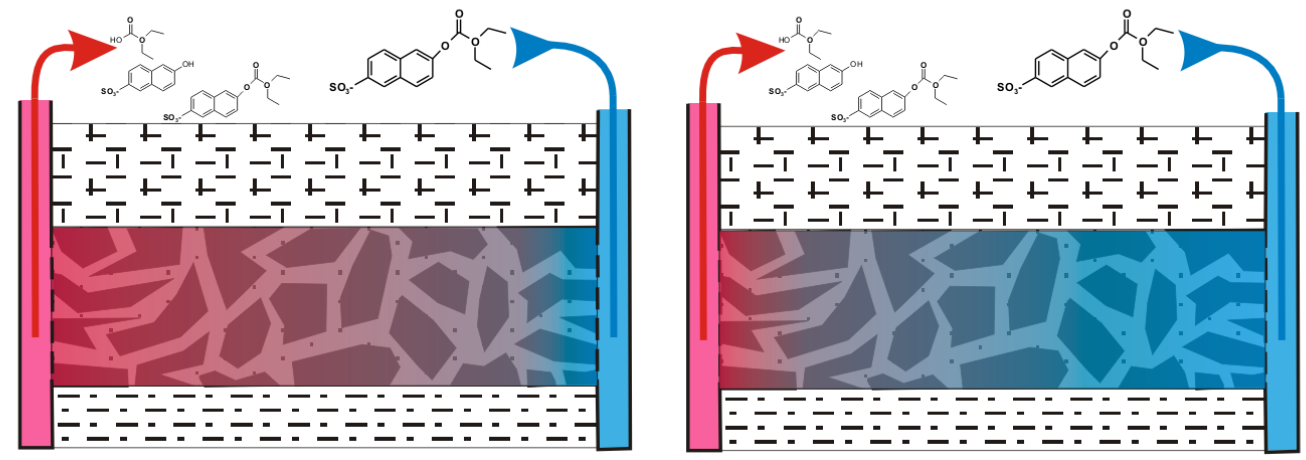

B)
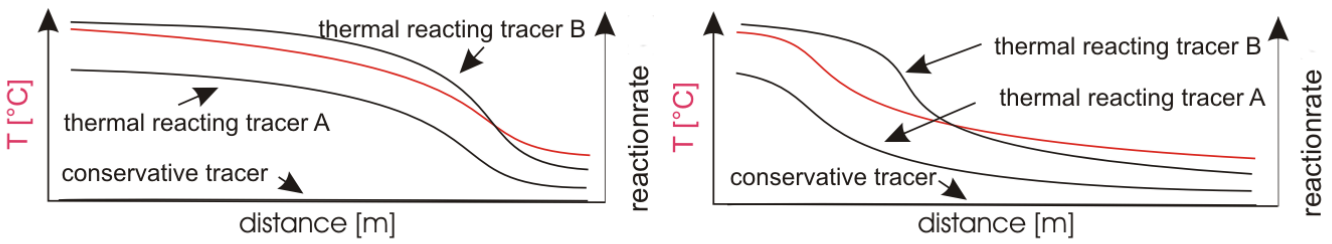

C)
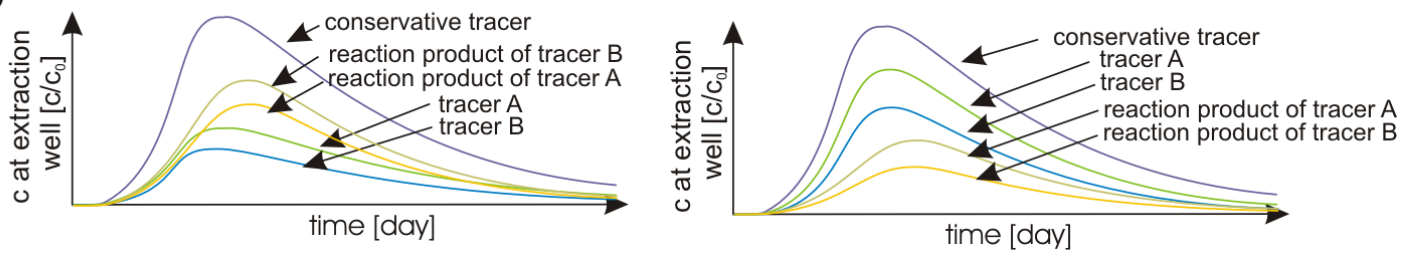

Fig. 1.1: Thermal regime in a typical geothermal reservoir at the beginning of production and after several years of production (A). The reaction rates of two thermosensitive tracers with different reaction kinetics are given in $B$. The predicted breakthrough curves of a conservative tracer and two thermal reacting tracers are given in $\mathrm{C}$.

\subsection{Format of the thesis}

An introduction into geothermal applications is given in Chapter 2. This introduction includes a general overview of the geothermal progress worldwide and applications that are used to utilize heat extraction from the subsurface. Also, the characteristics of existing geothermal tracers and methods for geothermal reservoir characterization using tracers are presented. Further, the basics of chemical reaction mechanisms and kinetics are demonstrated, as long as they are useful for the application in the development of reactive geothermal tracers. At the end of this chapter, a method for the large-scale synthesis of the investigated reacting tracers is shown. Also, an overview about analytical methods for the detection of tracers in brines is given. 
The main research work is presented in the Chapters 3, 4, and 5, which are written as manuscripts for presentation in journal and proceeding papers.

In Chapter 3, an analytical method for the detection of geothermal tracers in highly saline brines is presented.

Chapter 4 deals with the investigation of the stability of routinely used tracers with respect to different boundary conditions. Also, the first investigations in the development of thermal reactive tracers are presented.

Chapter 5 describes the development of thermal reactive tracers for the use in geothermal systems.

Chapter 6 gives a general conclusion over the results demonstrated in this thesis and gives recommendations for further research.

Please note that as a result of the cumulative nature of this thesis, a reference list is provided at the end of every chapter.

\subsection{References}

Horne, R. N. (1985): Reservoir aspects of reinjection. Geothermics 14, 449-457

O'Sullivan, M., Yeh, A., Mannington, W. (2010): Renewability of geothermal resources. Geothermics 39, 314-320

Rose, P. E., Benoit, W. R., Kilbourna, P. M. (2001): The application of the polyaromatic sulfonates as tracers in geothermal reservoirs. Geothermics 30, 617-640 


\section{Chapter 2}

\section{Geothermal energy usage - a general overview}

In the face of decreasing fossil energy resources and the increasing interest in emission free energy, renewable energy is gaining importance worldwide. In 2008, approximately $78 \%$ of the total energy and $69 \%$ of the total electricity consumption was supplied by fossil energy (REN21 2010). Concurrently, the increasing global population from approximately 7 billion in 2009 to an estimated 10 billion in 2050 (UN 2009) and the increasing energy consumption of the single individual, leads to an expected increasing energy consumption by approximately $50 \%$ from 2008 to 2035 (EIA 2011). Depending on the prospective, there are different estimations on how long the fossil energy reserves (the fossil energy sources that can now be gained cost-effective) will last. However, assuming a steady consumption, the oil and natural gas resources will last approximately 50 years and the coal resources 170 years (BMWi 2006). Considering global warming trends, greenhouse emissions have gained an increased attention over the past several years. For the US, over $90 \%$ of the greenhouse gas emissions of 2007 were produced by the energy sector (DoS 2010). Other energy resources basing on natural resources like nuclear energy are discussed controversial as well. Having less greenhouse gas emissions, uranium and plutonium resources are limited as fossil fuel resources, and the problem of nuclear waste disposal is not solved. Considering these facts, great efforts have been done over the past several years to find new ways for renewable energy utilization and to optimize existing technologies.

In 2008, renewable energy supplied approximately $19 \%$ of the total energy consumption worldwide (REN21 2010). The majority came from large hydropower installations but the use of this technology is more or less constant, regarding high land use and damages to natural resources. The greatest expansion of specific renewable energy technology has been in the solar and wind power sector with a 60\% respectively 27\% annual expansion between 2004 and 2009 (REN21 2010). These technologies show a high potential for having a significant role in the energy supply in the future, but the drawback is that these technologies do not produce energy continuously. Therefore, the produced energy has to be stored, leading to a decreased efficiency and additional problems. Biomass and biofuels are also important components in the renewable energy production but they are considered critically because of the competition with food production. 
Depending on the local accessibility of natural resources, geothermal energy has only a small but strongly increasing part in the production of renewable energy in most countries. Iceland, for example, obtains approximately $25 \%$ of its electrical energy from geothermics with an increase of $210 \%$ from 2005 to 2010 . The proportion of geothermal energy from the total energy consumption, including district heating, is approximately 60\% (Bertani 2010). Most other countries, which have comparatively low geothermal resources like the US, receive only less than $1 \%$ of their electricity from geothermal sources. However, the installed capacity in the US of $>3000 \mathrm{MW}$ in 2010 (Bertani 2010) was the greatest worldwide. But also in these countries, technical progress can help to implement geothermics. A study from MIT (Tester et al. 2006) stated that large amounts of the energy use in the US could be supplied by geothermal in 2050 using EGS (enhanced geothermal systems). In Germany, it is planned to increase the amount of renewables of the total electrical energy production to 30\% until 2020 (Deutscher Bundestag 2008). As in the US, most amounts of geothermal energy production could be gained by EGS (Jung et al. 2002). However, the installed geothermal electricity production in Germany has significantly increased from 2005 to 2010 but the total amount of 6 MW in 2010 (Bertani 2010) is still insignificant.

In the past, geothermal energy has been mainly gained from reservoirs where the desired temperatures are easily to access like regions having a high geothermal gradient. With the rapid improvement in drilling technology and the increasing costs of electricity, geothermal energy production becomes profitable also in low-enthalpy regions. The study from MIT (Tester et al. 2006) states that large amounts of geothermal electricity generation can be installed cost-effective in the US by using EGS. For the near future, an increase from $10,700 \mathrm{MW}$ in 2010 to $18,500 \mathrm{MW}$ in 2015 is predicted worldwide (Holm et al. 2010). Beyond that further growth, also in Germany, can be assumed.

\subsection{Geothermal reservoir types and applications for its exploitation}

Geothermal resources vary widely with respect to depth, physical and chemical properties of the host rock, and the abundance of water. The requests on the utilization of the reservoirs vary as well. This results in a manifold of different techniques to extract the heat most efficiently.

A distinction of geothermal resources can be made between shallow and deep reservoirs. Shallow reservoirs are usally up to a few $100 \mathrm{~m}$ in depth. The main 
focus in these applications is to reach moderate temperatures that are not influenced by surface temperatures. Shallow reservoirs are used primarily for direct use or heat pumps can be utilized to increase the temperatures of the fluid. Also, applications to discharge or to store heat in the ground are possible.

Deep geothermal reservoirs achieve significantly higher temperatures. The temperature of earth increases with depth. This geothermal gradient is 25$30^{\circ} \mathrm{C} / \mathrm{km}$ in average but it varies highly according to the geological properties of the respective location (Ledru and Frottier 2010). For electric energy production, usally temperatures higher than $140^{\circ} \mathrm{C}$ have to be obtained for being cost-effective by using steam and turbines (Afgan et al. 1998). At lower temperatures, a binary cycle has to be involved where a fluid, having a lower boiling point than water, is vaporized and operates a turbine (organic rankine cycle and kalina cycle). In regions with normal geothermal gradients (like most regions of northern Europe), efficient temperatures can be achieved at approximately 4000-5000 m depth. Deep geothermal reservoirs can also be effectively used for district heating. In the region in and nearby Munich, Germany, for example, several wells have been installed to produce heat from the Malm aquifer at 3000-5000 m depth. At higher temperatures and depths, this aquifer is also planned to be used for electricity production, or for a combination of electricity production and district heating (Stober et al. 2010).

Depending on the deep reservoir conditions, a distinction between different types of reservoirs can be drawn. There are hydrothermal systems where the naturally existing fluids are used as a heat energy carrier. These reservoirs are often used in the low- to middle temperature range. Petrothermal systems normally reach higher depths and temperatures. These are called hot dry rock, hot wet rock, or hot fractured rock. Both systems can be stimulated by chemical and physical methods, resulting in increased flow rates. In some cases, there are no natural pathways to circulate the fluid and the reservoir has to be generated by fracturing techniques. This enhanced geothermal systems are applicable under several geological conditions and they can be used much more comprehensive than hydrothermal systems.

\subsection{Exploration and characterization methods of geothermal reservoirs}

Because the drilling costs are the largest part in the overall costs of a geothermal plant in most cases, accurate geological explorations are important to lower the prospecting risks. The main factors affecting the efficiency of a reservoir are the 
temperature of the extracted fluid, its output quantity, and the reservoir sustainability. Geological models can be generated to predict these properties and help to find geological layers with appropriate specifications. They are based on the information gained from seismic measurements, geophysical well logs, drilling core samples, fluid chemistry composition analysis, pumping tests, and others. Once a geothermal well is constructed, the reservoir can be characterized in more detail at the specific location of the test site. Most of the characterization techniques like well logs or core sampling give only point information at the location of well. But some methods are able to give integrated three-dimensional information of the reservoir. By conducting pumping tests, for example, permeability's and storage coefficients can be estimated. Fluid chemistry analysis can give hints about the age of the fluid, its origin and the reservoir rock composition. Also, tracer tests can be performed to estimate flow paths, fluid residence times, and well interactions.

Characterization and monitoring methods that gives integrated spatial information about the reservoir are most important for geothermal systems in which the natural conditions are heavily modified by its application. Especially in EGS, techniques are needed not only to evaluate fracturing results, but else to give information about flow paths, conductivities, and well interactions. In this regard, tracers are the most important tool in reservoir engineering (Horne 1985).

In these days, geological models and numerical simulations have become a widely used characterization tool. They are able to combine the information gained from different exploration methods, as well as to make predictions of the reservoir formation while its utilization. However, there are big differences in the implementation of features like hydro-mechanical processes and chemical reactions, as well as dual-porosity or fracture modeling. There is modeling software used that was originally developed for surface and groundwater-flow and -transport models like FEFLOW, for example. For geothermal applications, many of these codes have to be extended by hydromechanics, as well as by heat and multiphase flow. There is also multi-physical software available like COMSOL that combines solute transport with multiphase flow. Also, boundary conditions can be selfdefined. Therefore, it is applicable for geothermal investigations. More adapted to geothermal utilization, and one of the most common codes is TOUGH2, which has been extended by chemical reactions in TOUGHREACT (Xu et al. 2006). TOUGHREACT is currently being evaluated for its use to simulate injection/withdrawal tests of thermal reacting tracers (Pruess and Doughty 2010). For tracer breakthrough curve interpretation, different codes and user interfaces have been developed. In these days, most hydrogeological modeling software 
products support solute transport, and are therefore more or less applicable to interpret tracer breakthrough curves.

\subsection{Sustainability of geothermal systems}

To dispose the extracted fluid and to obtain the natural hydraulic conditions in the reservoir, in most deep geothermal systems a multi-well system of at least two wells is installed, consisting of injection and extraction wells. The natural heat flow from the subsurface ranges from $57 \mathrm{~mW} / \mathrm{m}^{2}$ in granite continental crust to $99 \mathrm{~mW} / \mathrm{m}^{2}$ through the basaltic oceanic crust and is $82 \mathrm{~mW} / \mathrm{m}^{2}$ in the average (Uyeda 1988). This quantity is much less than the extracted heat from the subsurface in most geothermal systems. Therefore, the temperature of the reservoir decreases over time (O'Sullivan et al. 2010).

The cool-down rate of a geothermal reservoir depends on several parameters. These are composed by the operating conditions of the geothermal plant, such as flow rates and the temperature of the reinjected fluid, as well as the geological conditions. The main geological parameters that affect the cool-down rate and therefore the long-term efficiency are the natural heat flow from the subsurface, the heat exchange surface area, and the reservoir size. At this moment, there is no monitoring tool available to measure the cool-down of the reservoir in between the wells. Therefore, the characteristics of the thermal gradient and its changes over time are mostly unknown. In homogenous media, a sharp temperature transition from farfield temperature to injection temperature is expected (Shook 2001). Therefore, it can be assumed that the temperature drawdown at the extraction well is also comparatively fast after several years of extraction with a constant temperature. To predict the characteristics of the thermal front, modeling approaches have been investigated (e.g. Shook 2001), but not validated yet by field data. For a correct prediction of the thermal breakthrough by modeling techniques, heat exchange surfaces may be quantified (Ghergut et al. 2009). There are approaches doing this by the use of sorbing tracers. Also, multiple substances which have different diffusion coefficients can be simultaneously used in push-pull experiments, leading to varying breakthrough curves (Ghergut, 2009, Pruess and Doughthy 2010). But until now, especially methods using sorbing tracers are not fully developed, also because of the unavailability of suitable tracers. 


\subsection{Tracer techniques in geothermal applications}

In these days, tracer techniques are frequently applied for the characterization of geothermal reservoirs. Depending on the test design, such as single-well push-pull or inter-well circulation, and the tracer that is used (conservative or reactive, single phase or partitioning), there are numerous applications suitable to gain information about the reservoir properties:

- For flow path tracking (interactions between wells, interactions between layers, interactions between reservoirs)

- To estimate fluid residence times and -velocities

- To measure the proportions of the injected to the extracted fluid and to estimate reservoir volumes

- To quantify fluid-rock contact surfaces

- To help to understand thermal, hydraulic, mechanic, and chemical changes as coupled processes

In these days, preferably conservative tracers are used. Conservative in the meaning of geothermal applications indicates that their transport- and distribution behavior in the reservoir is the same as for the circulating fluid. Also, they should not underlie physical or chemical reactions such as degradation, transformation, or sorption. Because of the different diffusive behavior into the matrix of chemical substances that have a different molecular weight, there is no ideal conservative tracer compound. Therefore, a conservative behavior is always an approximation. This may be considered with respect to the tracer test design, the information that should be gained from the test, and the way of modeling the data.

A comparatively new approach is to use tracers that react in a specific way with the different physicochemical and geological conditions of the reservoir to gain more information. Being used in other hydrological fields of research (e.g. Haggerty et al. 2008, Zimmermann et al. 2002), reactive tracers are not often applied in geothermal applications yet. This is also because the kinetics of most chemical reactions are not limited to one single boundary condition and it is therefore hard to find suitable tracers, as well as to interpret the data. Thermal reactive tracers in geothermal applications are proposed to measure thermal drawdowns by undergoing a thermosensitive reaction since a long time (Robinson et al. 1984, Tester et al. 1986, Batchelor 1986). In this experimental setup, a substance is 
injected into the reservoir, undergoing a first-order reaction that is kinetically controlled by temperature. At the extraction well, the reaction product of the injected tracer is measured. Repeating the test over time, differences in breakthrough curves may give qualitative information of the cool-down of the reservoir. Also, thermal reacting tracers could act as an early warning system for thermal breakthrough. By using two thermosensitive substances simultaneously, or by measuring the reaction product and the tracer itself, the thermal regime may be measured quantitatively (Robinson 1980, Chemburkar et al. 1990). But until now, this technique has not been often used, also due to the unavailability of suitable tracers.

The use of sorbing tracers has been proposed to quantify heat transfer areas and in consequence, for the prediction of a thermal drawdown (Brown 1997, Pruess et al. 2005). Sorption is an expression of multiple processes such as physisorption, chemisorption, and ion exchange. Also, these processes are influenced by $\mathrm{pH}$, temperature, pressure, ion strength of the fluid, the character of mineral surfaces, and the chemical properties of the tracer. However, due to these difficulties, there are only limited modeling approaches, and "tracers do not exist that can reliably measure, and/or monitor the surface area responsible for rock-fluid heat and mass exchange" (DOE 2009). The sorption behavior of different dyes under geothermal boundary conditions is currently investigated by Rose et al. (2011), using a flow reactor.

There are numerous tracers that have been evaluated and tested for their use in geothermal applications. Every tracer has it advantages and disadvantages, and therefore the "optimal" tracer selection depends strongly on the physicochemical characteristics of the reservoir, the tracer test type, and the information intended to be gained from the test. Also, it must be guaranteed that no distortion from previous tracer tests will occur. In this regard it is recommended to have several different tracers available.

To give useful and evaluable information, the tracer has to fulfill several requirements. Because of the in most cases high dilution in the reservoir, they should have a low detection limit in geothermal brines, preferably with a simple and robust detection method to reduce costs and to give reliable data. In some cases, online measurements are essential. To measure changes in concentration, the background signal of the brine has to be low. Background signals can be caused by a natural background, by previous tracer tests, or from additives given to the reservoir (e.g. drilling fluids or stimulation agents), and others. Tracers must also have a significant solubility in brines. On one hand, it increases the probability that 
the tracer is transported in the mobile phase, and does not sorb on rock because of its polarity. On the other hand, it is ensured that the tracer is injected completely diluted. Ionic compounds can undergo ionic exchange, but this effect decreases at elevated temperatures because of the exothermal character of the reaction. Further, the tracer has to be stable under the physicochemical conditions of a geothermal reservoir. In this case not only the temperature, but also the $\mathrm{pH}$ and the redox potential have to be considered. Especially in push-pull test in porous media, where diffusion cannot be neglected to dispersion, the differences in diffusion with molecular weight of the tracer have to be considered. However, this can be also a "feature" to enhance information, for example to give information about the fluid-rock interface area (Ghergut et al. 2007).

Additionally to the requests of a conservative tracer, reactive tracers have to fulfill further requirements. Reactive tracers should have well defined reaction parameters, undergoing a first-order reaction that is sensitive to the boundary condition that has to be evaluated. If the tracer undergoes a second order reaction, evaluation should indicate whether the reaction is assumed to be a "pseudo-first" order reaction. In this case, the second parameter that controls the reaction kinetics is constant or can be neglected. Assuming a constant second parameter, the kinetic constants have to be evaluated under the same (chemical-) conditions that are present within the reservoir. In some cases, the second parameter can be entered in the chemical reaction equations (Robinson and Tester 1990).

An overview of artificial tracers that had been used for geothermal applications is given below.

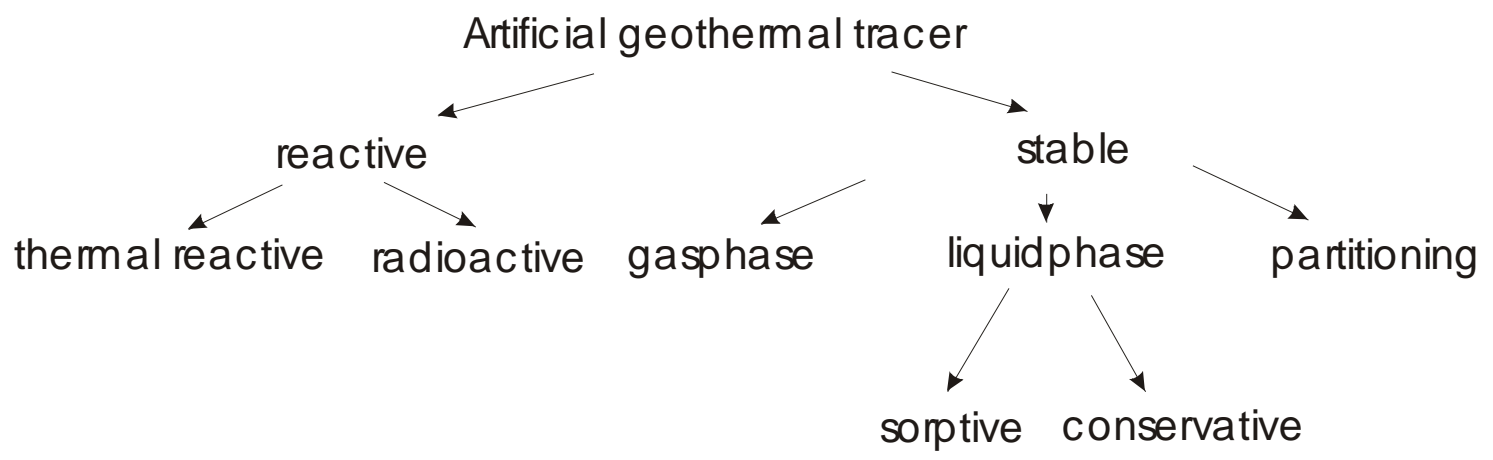

Figure 2.1: Classification of artificial tracers in geothermal applications

Artificial tracers can be divided in two functions: Their stability in the reservoir and their partitioning behavior into phases (Figure 2.1). As described, thermal reactive tracers are not often used thus far, because of the difficulties in controlling the reaction kinetics (Robinson and Birdsell 1987, Batchelor 1986). Radionuclides as 
radioactive geothermal tracers have a lot of advantages. They are easy to analyze with small interferences due to their emitted beta or gamma radiation. However, due to the safety hazard their use is limited in geothermal applications. In some cases, this problem can be solved by using activable tracers (Chrysikopolus 1986). For analysis, these are transferred to radionucildes by neutron irrigation. ${ }^{3} \mathrm{H}$ in the form of tritiated water is the most often used radioactive tracer, because its has low detection limits and a very similar behavior to water according to its diffusion coefficient and phase change (e.g. Ghergut et al. 2007). One drawback of tritium is that it interferes with natural tritium studies. Most important for deep reservoir studies are stable tracers. For liquid phase applications, organic substances or inorganic salts can be used. However, because of the high natural background for many ions in deep geothermal reservoirs, the use of inorganic salts is limited (Chrysikopolus 1993). Therefore, organic dyes or substituted aromatic acids are preferred for many applications. Organic dyes are well established tracers in near to surface hydrological applications. Some these tracers like Uranin, Rhodamine WT, and others also have been tested for geothermal applications (e.g. Ghergut et al. 2007, Rose and Adams 1994). Depending on the physicochemical conditions of the reservoir and the favored transport behavior, not all of these substances are applicable. Rhodamine WT, for example, may be sorbed on silica and precipitates (Hirts et al. 2001). Also, naphthalene sulfonates have been widely used in field applications (Rose et al. 2002; Sanjuan et al. 2006; Ghergut et al., 2007). The thermal stability of these substances have been investigated in the laboratory, showing a temperature stability of $>250{ }^{\circ} \mathrm{C}$ under reducing conditions (Rose et al. 2001). A variety of substituted benzoic acids have been tested for their thermal stability as well (Adams et al. 1992), and sodium benzoate has been proven as being stable for field application (Hirtz et al. 2001).

High enthalpy reservoirs can reach temperatures of over $250^{\circ} \mathrm{C}$ (Holm et al. 2010). In these reservoirs, the operating fluid is transported mainly as steam. To characterize these systems, gas-phase and partitioning tracers are needed. The requirements for vapor and partitioning tracers are the same as for liquid phase tracers: They must have a low detection limit, along with a low natural background. Also, they must be stable under reservoir conditions and should be conservatively transported. Within this context, several substances have been investigated in the laboratory and in the field. Alcohol tracers such as methanol, ethanol, propanol, and butan-2-ol have been investigated for their thermal stability by Adams (1995) and Adams et al. (2001) in the laboratory. Field applications have been conducted by Fukuda et al. (2005), Lovelock (2001), and Hirtz et al. (2001). Some of these substances showed insufficient stability in high temperature reservoirs. Also, the 
detection limits are poor (Adams 1995). To eliminate these inadequacies, fluorinated alcohols are under investigation (Adams and Nash 2004). The vaporliquid partitioning coefficients of fluorinated alcohols have a range from approximately 6 to 40 at $150^{\circ} \mathrm{C}$, making them suitable as partitioning tracers (Adams et al. 2004). Halogenated hydrocarbons have also been investigated as vapor tracers: Hydrofluorocarbons have been tested for their thermal stability by Adams (2001), and chlorofluorocompounds and other halogenated alkanes have been tested for their application as geothermal tracers by Adams et al. (1991). The drawback of most of these substances is that they are not commercially available due to ozone depletion issues. Perfluorocompounds have been used by Hirtz et al. (2010) and Reimus (2011). For example, $\mathrm{SF}_{6}$ is used routinely due to its high temperature stability along with a low detection limit.

A comparatively new approach is the target design of substances in the lab that implements the requested properties. Beside organic molecules (Nottebohm 2010), particle tracers and nanosensors are under investigation. Alaskar et al. (2010) investigated the flow of silica particle transport in porous media, and examined capabilities to modify these with different reservoir sensitive properties. They also investigated the melting behavior of tin-bismuth alloyed silica particles and the temperature characteristics of dye-attached silica particles (Alaskar et al. 2011). Rose et al. (2010) used small semiconductors that fluoresce at different, adjustable wavelengths. Also, they proposed to provide these substances with different diffusive and soprtive characteristics. Redden et al. (2010) developed encapsulation techniques using different polymer coatings to form colloids, which have thermosensitive properties. However, none of these substances have been applied in the field.

As well as solute and particle tracers, also heat can be used to estimate reservoir surfaces by conducting push-pull experiments (Ghergut 2007, Pruess and Doughthy 2010). Because the diffusion coefficient of heat is about three magnitudes higher compared to solute tracers, heat is extremely valuable if it is used in combination with an artificial solute tracer. In this context, heat is more able to reflect the largescale features of the reservoir, while solute tracers are more attached to the smallscale characteristics (Ghergut 2007).

Beside artificial tracers, the natural fluid chemistry can be used to characterize various parameters of the geothermal system. These so called "natural tracers" can give information about the geological settings and rock composition, as well as the residence time of the fluid in the system, the mixing processes, and the thermal regime of the reservoir. To examine reservoir temperatures, different element 
ratios such as Na/Li (Sanjuan 2010), Na/K/Ca (Fournier and Truesdell 1973), and others can be used as "geothermometers." However, geothermometers are only suitable for initial temperature measurements of the reservoir, because the reaction kinetics of most reactions are too slow to achieve a chemical equilibrium if the reservoir is affected by geothermal heat extraction.

As described in section 2.2, there are several codes available to interpret tracer data. Robinson (1980) and Tester et al. (1986) first modeled breakthrough curves of thermal reacting tracers. Today, several authors model synthetic tracer data to give suggestions for the kinetic properties of a tracer that is able to reflect the thermal regime of a geothermal reservoir with a sufficient sensitivity (Reimus et al. 2011, Plummer et al. 2011, Behrens et al. 2009, Williams 2010).

\subsection{Reactivity and stability of organic molecules and options for using chemical reactions for thermal investigations}

Depending on the physicochemical properties of the solvent and the molecular characteristics of the tracer, organic molecules can undergo manifold reactions. For the use as a thermal reactive tracer, there are several requests on the tracer substance:

- specific reaction kinetics with respect to the boundary condition that has to be evaluated. Other influences should be negligible or constant

- completely known reaction path and reaction kinetics of all reaction steps. In the most simple and reliable case, there is only one single reaction step that controls the overall reaction kinetics

- useful reaction rates of the tracer in a range that is able to reflect the temperatures in the reservoir and the timescale of the planned experiment

- at least one stable final reaction product

- robust and sensitive detection method of the final reaction product

- conservative behavior of the tracer itself and the reaction products in the reservoir. Otherwise a reference tracer with similar transport behavior has to be injected simultaneously

With respect to these requirements, the useful types of reaction can be identified: If a participant beside the tracer is involved in the reaction, it must be present in a 
sufficient amount. Therefore, water is a good participant and hydrolysis reactions are suitable for the use as a thermosensitive reaction. Also, this reaction is known to be temperature sensitive. In most cases, hydrolysis reactions are catalyzed by hydroxide or hydronium ions (Schwarzenbach 2003). Therefore, the reaction kinetics depends on the $\mathrm{pH}$ of the solution. This effect has to be considered in the selection of the tracer.

Beside the selection of the thermosensitive reaction, the stability of the final reaction product has to be assured. Many aromatic organic ring structures are persistent in natural aquatic systems. This may be a first indicator for its stability also in geothermal applications.

\subsection{Analytical methods for the detection of highly polar organic molecules from geothermal brines}

In the last decades, analytical techniques have been in serious progress. This includes the proof identification of substances in different aqueous matrices, as well as improved detection limits. Depending on the chemical characteristics of the analytes, its concentrations, and the matrices, different chromatographic and spectroscopic techniques are applied. Chromatographic methods are used for the separation of the sample components, and spectroscopic methods for the identification of the analytes. Chromatographic methods are based on the different interaction intensities of sample components in a mobile phase versus a stationary phase. To achieve separation, both phases can be changed according to the sample and the analyte characteristics. If the analytes are vaporizable at moderate temperatures, they may be analyzed by gas chromatographic (GC) methods. Otherwise, for example liquid chromatographic techniques (LC) have to be used. For purification and preconcentration of the sample, phase extraction methods can be utilized.

Geothermal tracers are selected with respect to their detectability in brines. A simple and sensitive spectroscopic method is fluorescence detection. Therefore, fluorescent dyes and compounds that fluoresces below the visible spectrum are often used as tracers in geothermal applications. Beside direct measurements, more complex analytical techniques can be applied to improve detection limits, and to separate the analytes from sample contaminants. For polar and ionic organic molecules like naphthalene sulfonates that are not able to vaporize, liquid chromatographic applications have been developed. These include different highperformance liquid chromatographic methods, and also several spectroscopic 
methods like mass-spectroscopy and fluorescence detection. Due to the high polar character of naphthalene sulfonates, they are not retained on stationary phases in standard reversed phase applications. Therefore, an ion-pairing agent is added to the mobile phase to achieve retention.

For highly saline waters like many geothermal brines, the inorganic matrix salts have to be separated from the analytes before analysis. There are methods for example by dialysis. Also, methods have been developed to preconcetrate analytes by solid phase extraction (SPE) methods. However, SPE in combination with highly saline brines has not been investigated yet.

\subsection{Synthesis and purification of naphthalesulfonic esters for the use as thermosensitive substances}

In tracer tests for deep geothermal applications, normally several $100 \mathrm{~g}$ to a few $\mathrm{kg}$ of the tracer substance are used, depending on the predicted dilution in the reservoir and the limit of detection of the reaction product. Because the substances that are used in the investigations of the present thesis are not commercially available, a technique was developed to synthesize hydroxynaphthalene sulfonic esters fast and effectively. The method bases on the Schotten-Baumann technique (Einhorn variation) for the synthesis of esters.

For ester synthesis, $50 \mathrm{~g}$ of the corresponding alcohol (in this case 2-Naphthol-6sulfonic acid potassium salt) were given into a completely dried and evacuated distilling flask. Then, the substance was dissolved into $200 \mathrm{~mL}$ of dimethylformamide and $155 \mathrm{~mL}$ of pyridine was added. Finally, a 1.5 mole equivalent excess to the alcohol of the corresponding acid chloride was added (in this case $39.1 \mathrm{~mL}$ 2-ethylbutyryl chloride). To achieve a complete reaction, the solution was heated for 12 hours at $80{ }^{\circ} \mathrm{C}$ under argon atmosphere, resulting in a changed color of the liquid from yellow to brown.

In the next step, the liquid was evaporated by a vacuum rotary evaporator, resulting in a brownish and highly viscous substance. Into this substance, $28.5 \mathrm{~g}$ of potassium hydrogen carbonate, dissolved in approximately $400 \mathrm{~mL}$ of water, was added. Within this step, a high degree of gas and loam generation was noted. This solution was evaporated by a rotary evaporator until completely dry. Then, approximately $400 \mathrm{~mL}$ of hexane was added to the resulting substance and it was agitated until all the solid substance had been transformed to a brownish solution and a yellow flocculation. Finally, the flakes were filtered and the residual was dried 
in a vacuum desiccator. After the drying, the synthesized product had an amount of approximately 65 to $70 \mathrm{~g}$, indicating a complete turnover of the reagents to the potassium salt of the corresponding ester.

The purity of the resulting substance was specified by micrOTOF, H-NMR, and C13-NMR for the organic substances and ion-chromatography for the inorganic substances. Corresponding spectra are given in the appendix. The investigations of the organic substances prove a purity of $>99 \%$ for the ester, and the ionchromatographic measurements showed only impurities of chloride and potassium (Tab A.1). If the pure potassium salt of the substance is favored, the ester can be purified by recrystallization. This results in a substance including negligible amounts of chloride and a potassium concentration that corresponds to the potassium salt of the ester (Tab A.1). However, recrystallization techniques of substances that have very similar solubility behavior (in this case the naphthalene sulfonic ester and the inorganic salts) always goe along with a significant loss in substance. Therefore, it is recommended to disclaim this step and to make exact ion-chromatographic measurements of the inorganic salts to quantify the mass of the produced ester.

\subsection{References}

Adams, M. C., Beall, J. J., Enedy, S. L., Hirtz, P. (1991): The application of halogenated alkanes as vapor-phase tracers: A field test in the Southeast Geysers. Transactions, Geothermal Resources Council 15, 457-463

Adams, M. C., Moore, J. N., Fabry, L. G. Fabry, Ahn, J.-H. (1992): Thermal stabilities of aromatic acids as geothermal tracers. Geothermics 21, 323-339

Adams, M. C. (1995): Vapor, liquid and two-phase tracers for geothermal systems. Proceedings, World Geothermal Congress 1995, Florence, 1875-1880

Adams, M. C., Beall, J. J., Enedyc, S. L., Hirtz, P. N., Kilbourn, P., Koenige, B. A., Kunzmand, R., Smith, J. L. B. (2001): Hydrofluorocarbons as geothermal vapor-phase tracers. Geothermics 30, 747-775

Adams, M. C., Nash, G. (2004): Tracing geothermal Fluids. Final Report. DOE Grant No. DEFG07-00ID13893. http://www.osti.gov/bridge/servlets/purl/822403-vd1r8Y/native/ 822403.pdf (last accessed: 15.02.2012)

Adams, M. C., Yamada, Y., Yagi, M., Kasteler, C., Kilbourn, P., Dahdah, N. (2004): Alcohols as two-phase tracers. Proceedings, $29^{\text {th }}$ Workshop on Geothermal Reservoir Engineering, Stanford University, Stanford, California, January 26-28, SGP-TR-175

Afgan, N., Gobaisi, D. A., Carvalho, M. G., Cumo, M. (1998): Sustainable Energy Development. Renewable and Sustainable Energy Reviews 2, 235-286 
Alaskar, M., Ames, M., Horne, M., Li, K., Connor, S., Cui, Y. (2010): In-situ multifunction nanosensors for fractured reservoir characterization. Proceedings, $35^{\text {th }}$ Workshop on Geothermal Reservoir Engineering, Stanford University, Stanford, California, February 13, SGP-TR-188

Alaskar, M., Ames, M., Liu, C., Horne, R., Li, K., Cui, Y. (2011): Smart Nanotracers for InSitu Temperature Measurement in Fractured Geothermal Reservoirs. Proceedings, $36^{\text {th }}$ Workshop on Geothermal Reservoir Engineering, Stanford, SGP-TR-191

Batchelor, A. S. (1986): Reservoir behavior in a stimulated hot dry rock system. Proceedings, $11^{\text {th }}$ Workshop on Geothermal Reservoir Engineering, Stanford University, Stanford, California, January 21-23, SCP-TR-93

Behrens, H., Ghergut, I., Sauter, M., Licha, T. (2009): Tracer properties and spiking results from geothermal reservoirs. Proceedings, $31^{\text {th }}$ Workshop of Geothermal Reservoir Engineering, Stanford University, Stanford, California, February 9-11, SGP-TR-187

Bertani, R. (2010): Geothermal power generation in the World 2005-2010 Update Report. Proceedings, World Geothermal Congress, Bali, Indonesia, 25-29 April

BMWi (Bundesministerium für Wirtschaft und Technologie) -Arbeitsgruppe Energierohstoffe (2006): Kurzbericht: Verfügbarkeit und Versorgung mit Energierohstoffen. http://www.bmwi.de/BMWi/Redaktion/PDF/E/energierohstoffbericht (last accessed: 15.02.2012)

Brown, D. (1997): Review of Fenton Hill HDR test results. Proceedings, New Energy and Industrial Technology Development Organization (NEDO) geothermal and HRD conference, Sendai (Japan), 10-17 Mar

Chemburkar, R. M., Brown, L. F., Travis, B. J., Robinson, B. A. (1990): Numerical determination of temperature profiles in flowing systems from conversions of chemically reacting tracers. Chemical engineering science 46, 1349-1360

Chrysikopolus, C., Kruger, P. (1986): Thermal stability of chelated indium activable tracers. Proceedings, $11^{\text {th }}$ Workshop on Geothermal Reservoir Engineering Stanford University, Stanford, California, January 21-23, SGP-TR-93

Chrysikopolus, C. V. (1993): Artificial tracers for geothermal reservoir studies. Environmental Geology 22, 60-70

Deutscher Bundestag (2008): Erneuerbare-Energien-Gesetz vom 25. Oktober 2008 (BGBI. I S. 2074), das durch Artikel 1 des Gesetzes vom 28. Juli 2011 (BGBI. I S. 1634) geändert worden ist. Bundesdrucksache. Berlin 2011

DOE (United States Department of Energy) (2008): An evaluation of enhanced geothermal systems technology. Geothermal technologies program. Washington, DC, USA. http://www1.eere.energy.gov/geothermal/pdfs/evaluation_egs_tech_2008.pdf (last accessed: 15.02 .2012 )

DoS (United States Department of State) (2010): U.S. Climate Action Report 2010. Washington: Global Publishing Services 
EIA (Energy Information Administration) (2011): International Energy Outlook 2011. Office of Integrated Analysis and Forecasting, U.S. Department of Energy, http://205.254.135.24/forecasts/ieo/pdf/0484(2011).pdf (last accessed 15.02.2012)

Fournier, R. O., Truesdell, A. H. (1973): An empirical Na-K-Ca geothermometer for natural waters. Geochimica et Coemochimica Acta 37, 1255-1275

Fukuda, D., Asanuma, M., Hishi, Y., Kotanaka, K. (2005): Alcohol tracer testing at the Matsukawa vapor-dominated field, northeast Japan. Proceedings, $30^{\text {th }}$ Workshop on Geothermal Reservoir Engineering, Stanford University, Stanford, California, January 31February 2, SGP-TR-176

Ghergut, I. Sauter, M., Behrens, H., Licha, T., McDermott, C. I., Herfort, M., Rose, P., Zimmermann, G., Orzol, J., Jung, R., Huenges, E., Kolditz, O., Lodemann, M., Fischer, S., Wittig, U., Güthoff, F., Kühn, M. (2007): Tracer tests evaluating hydraulic stimulation at deep geothermal reservoirs in Germany. Proceedings, $31^{\text {th }}$ Workshop on Geothermal Reservoir Engineering Stanford University, Stanford, California, January 22-24, SGP-TR183

Ghergut, I., Sauter, M., Behrens, H., Licha, T., Tischner, T., Jung, R. (2009): Single-well dual tracer spikings during EGS creation. Proceedings, $34^{\text {th }}$ Workshop on Geothermal Reservoir Engineering Stanford University, Stanford, California, February 9-11, SGP-TR187

Haggerty, R., Argerich, A., Marti, E. (2008): Development of a smart tracer for the assessment of microbiological activity and sediment-water interaction in natural waters: The resazurin-resorufin system. Water Resources Research 44, 1-10

Hirtz, P. N., Kunzman, R. J., Broaddus, M. L., Barbitta, J. A. (2001): Developments in tracer flow testing for geothermal production engineering. Geothermics 30, 727-745

Hirtz, P. N., Kunzman, R. J., Adams, M. C., Roberts, J. W., Sugandhi, A., Martiady, K., Mahagyo, P., Suvian Iman, A. (2010): First multi well vapor and two-phase tracer test in a geothermal reservoir using perfluorocarbons and alcohols. Proceedings, World Geothermal Congress, Bali, Indonesia, 25-29 April 2010

Holm, A., Blodgett, L., Jennejohn, D., Gawell, K. (2010): Geothermal Energy: International Market Update. http://www.geo-energy.org/pdf/reports/ GEA_International_Market_Report_Final_May_2010.pdf (last accessed: 15.02.2012)

Horne, R.N. (1985): Reservoir aspects of reinjection. Geothermics 14, 449-457

Jung, R., Röhling, S., Ochmann, N., Rogge, S., Schellschmidt, R., Schulz, R., Thielemann, T. (2002): Abschätzung des technischen Potenzials der geothermischen Stromerzeugung und der geothermischen Kraft-Wärmekopplung (KWK) in Deutschland. - Bericht für das Büro für Tech-nikfolgenabschätzung beim Deutschen Bundestag; BGR/GGA, Archiv-Nr. 122 458; Hannover.

Ledru, P., Frottier, L. G. (2010): Reservoir Definition. In: Geothermal Energy Systems : Exploration, Development and Utilization, Huenges, E. (Ed.), Wiley-VCH 
Lovelock, B. G. (2001): Steam flow measurement using alcohol tracers. Geothermics 30, 641-654

Nottebohm, M., Licha, T., Sauter, M. (2010): Thermal Decay of Selected Organic Substances as "Smart Tracers" in Geothermal Reservoirs. Proceedings, 35 ${ }^{\text {th }}$ Workshop on Geothermal Reservoir Engineering, Stanford University, Stanford, California, February 1-3, SGP-TR188

O'Sullivan, M., Yeh, A, Mannington, W. (2010): Renewability of geothermal resources. Geothermics 39, 314-320

Plummer, M. A., Palmer, C. D., Hull, L. C, Mattson, E. D. (2010): Sensitivity of a reactivetracer based estimate of thermal breakthrough in an EGS to the properties of the reservoir and tracer. Proceedings, $35^{\text {th }}$ Workshop on Geothermal Reservoir Engineering, Stanford University, Stanford, California, February 1-3, SGP-TR-188

Pruess, K., van Heel, T., Shan, C. (2005): Tracer testing for estimating heat transfer area in fractured reservoirs. Proceedings, World Geothermal Congress 2005, Antalya, Turkey, 24-29 April

Pruess, K., Doughty, C. (2010): Thermal single well injection-withdrawal tracer tests for determining fracture-matrix heat transfer area. Proceedings, $35^{\text {th }}$ Workshop on Geothermal Reservoir Engineering Stanford University, Stanford, California, February 13, SGP-TR-188

Redden, G., Stone, M., Wright, K. E., Mattson, E., Palmer, C. D., Rollins, H., Harrup, M., Hull, L. C., (2010): Tracers for characterizing enhances geothermal systems. Proceedings, $35^{\text {th }}$ Workshop on Geothermal Reservoir Engineering Stanford University, Stanford, California, February 1-3, SGP-TR-188

Reimus, P. W., Watson, T., Vermeul, V., Newell, D., Williams, M. (2011): Laboratory testing and modelling to evaluate perfluorocarbon compounds as tracers in geothermal systems. Proceedings, 36 ${ }^{\text {th }}$ Workshop on Geothermal Reservoir Engineering Stanford University, Stanford, California, January 31 - February 2, SGP-TR-191

REN21 (Renewable Energy Policy Network for the $21^{\text {st }}$ Century) (2010): Renewables - Global Status Report 2010. http://www.ren21.net/ (last accessed: 15.02.2012)

Robinson, B. A. (1980): Non-reactive and chemically reactive tracers: Theory and applications. PhD dissertation, Massachusetts Institute of Technology, Cambridge, MA

Robinson, B. A., Tester, J. W., Brown, L. F. (1984): Using chemically reactive tracers to determine temperature characteristics of geothermal reservoirs. Proceedings, Geothermal Resources Council Ann. Meeting, Nov. 26-29 Aug., Reno, Nevada

Robinson, B. A., Birdsell, S. A. (1987): Tracking thermal fronts with temperaturesensitive, chemically reactive tracers. Proceedings, $5^{\text {th }}$ Geothermal Program Review, Washington, DC, 14-15 April 
Robinson, B. A., Tester, J. W. (1990): Kinetics of alkaline hydrolysis of organic esters and amides in neutrally-buffered solution. International Journal of Chemical Kinetics 22, 431448

Rose, P.E., Adams, M.C. (1994): The application of rhodamine WT as a geothermal tracer. Geothermal Resource Council Transactions 18, 237-240

Rose, P. E., Benoit, W. R., Kilbourna, P. M. (2001): The application of the polyaromatic sulfonates as tracers in geothermal reservoirs. Geothermics 30, 617-640

Rose, P., Johnson, D. S., Kilbourn, P., Kastelen, C. (2002): Tracer testing at Dixie Valley, Nevada using 1-naphthalene sulfonate and 2,6-naphthalene-disulfonate. Proceedings, $27^{\text {th }}$ Workshop on Geothermal Reservoir Engineering, Stanford University, Stanford, Calfornia, January 28-30, SGP-TR-171

Rose, P., Riasetto, D., Siy, J., Bart, M., Reimus, P., Mella, M., Leecaster, K., Petty, S. (2011): Quantum dots as tracers in geothermal and EGS reservoirs. $36^{\text {th }}$ Workshop on Geothermal Reservoir Engineering Stanford University, Stanford, California, January 31 February 2, SGP-TR-191

Rose, P., Leecaster, K., Bartl, M. (2011): Tracing injection fluids in engineered geothermal systems. Proceedings, AAPG/SPE/SEG HEDBERG Conference "Enhanced Geothermal Systems", 14-18 March, - NAPA, California

Sanjuan, B., Pinault, J.-L., Rose, P., Gérard, A., Brach, M., Braibant, G., Couzet, C., Foucher, J.-C., Gautier, A., Touzelet, S. (2006): Tracer testing of the geothermal heat exchanger at Soultz-sous-Forêts (France) between 2000 and 2005. Geothermics 35, 622-653.

Sanjuan, B., Millot, R., Brach, M., Asmundsson, R., Giroud, N. (2010): Use of a new Sodium/Lithium ( $\mathrm{Na} / \mathrm{Li})$ geothermometric relationship for high temperature dilute geothermal fluids from Iceland. Proceedings, World Geothermal Congress, Bali, Indonesia, 25-29 April

Schwarzenbach, R. P., Gschwend, P. M., Imboden, D. M. (2003). Environmental Organic Chemistry, second edition, Wiley-Interscience Publishers

Shook, G. M. (2001): Predicting thermal breakthrough in heterogeneous media from tracer tests. Geothermics 30, 573-589

Stober, I., Fritzer, T., Obst, K., Schulz, R. (2010). Tiefe Geothermie, Nutzungsmöglichkeiten in Deutschland. Bundesministerium für Umwelt, Naturschutz und Reaktorsicherheit (BMU) http://www.bmu.de/files/pdfs/allgemein/application/pdf/ broschuere_geothermie_tief_bf.pdf (last accessed: 15.02.2012)

Tester, J. W., Robinson, B. A., Ferguson, J. H. (1986): Inert and reacting tracers for reservoir sizing in fractured, hot dry rock systems. Proceedings, $11^{\text {th }}$ Workshop on Geothermal Reservoir Engineering, Stanford University, Stanford, California, January 2123, SGP-TR-93

Tester, J. W., Anderson, B., Batchelor, A., Blackwell, D., DiPippo, R., Drake, E., Garnish, J., Livesay, B., Moore, M. C., Nichols, K., Petty, S., Toksoz, N., Veatch, R., Augustine, C., 
Baria, R., Murphy, E., Negraru, P., Richards, M. (2006): The future of geothermal energy: Impact of enhanced geothermal systems (EGS) on the United States in the $21^{\text {st }}$ century. Massachusetts Inst. Technology, DOE ContractDE-AC07-05ID 14517 Final Rept., http://geothermal.inel.gov/publications/future_of_geothermal_energy.pdf

(last accessed: 15.02 .2012 )

UN (United Nations, Department of Economic and Social Affairs, Population Division) (2009): World Population Prospects, The 2008 Revision, Highlights. Working Paper No. ESA/P/WP. 210

Uyeda S. (1988): Geodynamics. In: Haenel R, Rybach L, Stegena L (Eds.). Handbook of terrestrial heat-flow density determination. Dordrecht Germany: Kluwer Academic Publishers

Williams, M. D., Vermeul, V. R., Reimus, P. W., Newell, D., Watson, T., (2010): Development of Models to Simulate Tracer Behavior in Enhanced Geothermal Systems. Status Report. Pacific Northwest National Laboratory, Prepared for the U.S. Department of Energy under Contract DE-AC05-76RL01830, http://www.pnl.gov/main/publications/external/ technical_reports/PNNL-19523.pdf (last accessed 15.02.2012)

Xu, T., Sonnenthal, E., Spycher, N., Pruess, K. (2006): TOUGHREACT V1.2 User's Guide: A Simulation Program for Nonisothermal Multiphase Reactive Geochemical Transport in Variably Saturated Geologic Media. LBNL-55460, Lawrence Berkeley Laboratory, Berkeley, California.

Zimmerman, M. D., Bennett, P. C., Sharp Jr., Wan-Joo Choi, W.-J. (2002): Experimental determination of sorption in fractured flowsystems. Journal of Contaminant Hydrology 58, 51-77 


\section{Chapter 3}

Detection of Naphthalene sulfonates from highly saline brines with high-performance liquid chromatography in conjunction with fluorescence detection and solid-phase extraction

M. Nottebohm ${ }^{a, b}$, T. Licha ${ }^{a}$

Citiation: Nottebohm, M., Licha, T. Detection of Naphthalene sulfonates from highly saline brines with high-performance liquid chromatography in conjunction with fluorescence detection and solid-phase extraction. Submitted and accepted after minor revisions by Journal of chromatographic science

a) Applied Geology, Geosciences Center, University of Göttingen, Goldschmidtstr. 3, 37077 Göttingen, Germany

b) Corresponding author - phone: (49) +551/3919332; martin.nottebohm@geo.uni-goettingen.de 


\section{Abstract}

A procedure is developed for the simultaneous determination of 1-naphthalene sulfonate, 2-naphthalene sulfonate, 1,5-naphthalene disulfonate, 1,6-naphthalene disulfonate, 2,6-naphthalene disulfonate, and 2,7-naphthalene disulfonate from highly saline geothermal brines using ion-pair high-performance liquid chromatography with fluorescence detection after solid-phase extraction. The substances are baseline separated within 33 minutes and the recoveries in brines with salinities of up to $175 \mathrm{~g} / \mathrm{L} \mathrm{NaCl}$ are $100( \pm 10) \%$ by solid phase extraction. For the overall method, the method quantification limits of the analytes are between 0.05 and $0.4 \mu \mathrm{g} / \mathrm{L}$. Also, the method is shown to be feasible for matrices encountered in deep geothermal reservoirs.

\subsection{Introduction}

Naphthalene sulfonates (NS) are highly water-soluble compounds that have a $\mathrm{pK}_{\mathrm{ow}}$ of $<2$. This indicates a high mobility in aquatic systems (Greim et al. 1994). Furthermore, NS show fluorescence and are therefore easily detected at low concentrations. Due to these qualities, along with temperature stability up to at least $250^{\circ} \mathrm{C}$ under reducing conditions (Rose et al. 2002, Nottebohm et at. 2010), NS are established tracers for water spiking in deep geothermal reservoirs (Rose et al. 2002, Nottebohm et al. 2010, Sanjuan et al. 2006, Ghergut et al. 2007). NS are also important substances in the chemical industry, being included in the "list of high production volume chemicals" of the Organisation for Economic Cooperation and Development (OECD) (2004). They are mainly used as tanning agents as well as intermediates in the production of azo-dyes and pharmaceuticals. Some NS have a low biodegradability and are therefore not removed in wastewater treatment plants and only little is known about their toxicity (Alonso et al. 2005). Therefore, detection and investigation of these substances has been occurring for many years.

Most of the analytical techniques for the detection of these substances are based on high-performance liquid chromatography (HPLC) that uses an ion-pairing agent to achieve a sufficient retardation and separation of the analytes on the column (Storm et al. 1999, Altenbach and Gieger, 1995, Bastian et al. 1994, Gimeno et al. 2001, Zerbinati et al. 1993, Alonso et al. 1999). References for optimisation of ionpair chromatography were given by Rudzinski et al. (1983). Anion-exchange chromatography methods have been developed as well (Kim et al. 1991). Capillary electrophoresis methods have also been investigated, showing a sufficient 
separation by using different additives to neutralise the analytes (Kok et al. 1996). Unfortunately, the detection limits of capillary electrophoresis were only in the low to sub $\mathrm{mg} / \mathrm{L}$ range combined with preseparation enrichment (Kok et al. 1997). Gas chromatographic methods have also been developed but are not often used because of the difficulties encountered in the derivatisation of the NS compounds (Liu and Ding 2001).

For matrix separation and preconcentration of NS, solid-phase extraction methods (SPE) are common. Most researchers used conventional reversed phase solid phases in combination with ion-pairing agents (Bastian et al. 1994, Zerbinati et al. 1993). Also, anion-exchange, polymeric, and organic carbon solid phases have been investigated (Altenbach and Giger 1995, Bastian et al. 1994, Gimeno 2001). A summary of the analytical methods for NS that were published before 1995 has been given by Reemtsma (1996). However, existing analytical methods for the simultaneous analysis of NS isomers are limited to river, coastal, and bank filtrate waters (Lange et al. 1995, Gimeno et al. 2001, Zerbinati et al. 1993), or industrial wastewaters (Storm et al. 1999, Altenbach et al. 1995, Bastian et al. 1994).

Depending on the application, the analyte, and the matrix, most authors were able to achieve detection limits in the low to sub $\mu \mathrm{g} / \mathrm{L}$ range (Lange et al. 1995, Rose et al. 2002, Storm et al. 1999, Altenbach and Giger 1995, Bastian et al. 1994, Gimeno et al. 2001, Zerbinati et al. 1993, Alonso et al. 1999). However, the trace-level detection using SPE of NS in geothermal brines that have salinities up to $150 \mathrm{~g} / \mathrm{L}$ total dissolved solids (TDS) and potentially high amounts of organic compounds has not yet been described.

\subsection{Experimental}

\subsubsection{Reagents}

Naphthalene-1-sulfonic acid sodium salt (>95\%, 1-NS), Naphthalene-2-sulfonic acid sodium salt (>98\%, 2-NS), 1,5-Naphthalene disulfonic acid disodium salt (1,5-NDS), 1,6-Naphthalene disulfonic acid disodium salt (>98\%, 1,6-NDS), 2,6-Naphthalene disulfonic acid disodium salt (>95\%, 2,6-NDS), 2,7-Naphthalene disulfonic acid disodium salt (2,7-NDS), and the internal standard 2-Naphthol-3,6disulfonic acid sodium salt (>70\%, 2-OH-3,6-NDS) were obtained from TCI Europe (Zwijndrecht, Belgium). Tetrabutyl ammonium bromide (HPLC grade, TBAB), Cetyltrimethyl ammonium bromide (99+, CTMAB), methanol (HPLC fluorescence grade), disodium sulphate ( $\mathrm{pA})$, disodium hydrogen phosphate (analytical reagent 
grade), potassium dihydrogen phosphate (analytical reagent grade), sodium chloride (99.5\%), and hydrochloric acid (37\%, Suprapur) were received from Fischer Scientific GmbH (Schwerte, Germany). Ultrapure water was obtained from a combined water purification system consisting of Elix 5 (Progard 1 silver cartridge) and Milli-Q Gradient A10 (Quantum Ex Ultrapure Organex + Q-Gard 1 cartridge), both from Millipore (Schwalbach, Germany).

\subsubsection{Apparatus and procedure}

The chromatographic experiments were performed with a Varian (Palo Alto, CA, USA) Prostar HPLC system. The system included a Prostar 363 fluorescence detector, a Prostar 325 UV-visible detector, two Prostar 210 high pressure pumps, a Prostar 410 autosampler with a column thermostat, and a vacuum solvent degassing unit. As the separation column, an ODS-AQ from YMC Europe (Dinslaken, Germany) with guard-column, a Luna $\mathrm{C}_{18}$ (2) from Phenomenex Inc. (Torrence, CA, USA), a Luna PFP (2) from Phenomenex, and a Varian Pursuit XR-s $\mathrm{C}_{18}$ column all with $150 \times 2 \mathrm{~mm}$ I.D. and $3 \mu \mathrm{m}$ particle diameter were used. The columns were set with the aid of a thermostat at $35^{\circ} \mathrm{C}$ and sample volumes of $25 \mu \mathrm{L}$ were injected. The flowrate was $0.25 \mathrm{~mL} / \mathrm{min}$. The final chromatographic conditions were as follows: eluent $A$ was $100 \%$ water and eluent $B$ was water-methanol (50:50, v/v). Both were added with $5 \mathrm{mM}$ TBAB, $4 \mathrm{~g} / \mathrm{L}$ disodium sulphate, and $40 \mu \mathrm{L} / \mathrm{L} 37 \%$ hydrochloric acid. The starting conditions were: $45 \%$ eluent $B$ up to $3 \mathrm{~min}$. Then, a linear gradient to $55 \%$ eluent $B$ at 14 min was performed to elute the disulfonates. Afterwards, eluent B was increased to $75 \%$ at $18 \mathrm{~min}$. Then, eluent B was kept constant up to $27 \mathrm{~min}$ to elute the monosulfonates. To equilibrate the system, eluent B was reduced to $55 \%$ within $30 \mathrm{sec}$. and then kept constant up to $33 \mathrm{~min}$.

To achieve the lowest detection limit possible, the fluorescence maxima of the NS were determined using a fluorescence spectrometer Cary Eclipse 50 from Varian.

For SPE, two different kinds of polymer based solid-phase materials and one $\mathrm{C}_{18^{-}}$ packing were investigated. Respectively, these were: Strata X-RP from Phenomenex, Bond Elut Plexa from Varian, and Bakerbond Octadecyl Silica from Mallinckrodt Baker (Phillipsburgh, USA). All columns had a $500 \mathrm{mg}$ sorbent material and a reservoir for $6 \mathrm{~mL}$ of sample volume. The extracting procedure was as follows: Conditioning the sorbent with $10 \mathrm{~mL}$ of methanol, conditioning the sorbent with $10 \mathrm{~mL}$ of pure water, and afterwards conditioning the sorbent with $10 \mathrm{~mL}$ of conditioning solution. The conditioning solution consists of $2.5 \mathrm{~mL}$ of $100 \mathrm{mM}$ TBAB, $2.5 \mathrm{~mL}$ of $100 \mathrm{mM}$ potassium dihydrogen phosphate solution, and $2.5 \mathrm{~mL}$ of $65 \mathrm{mM}$ disodium hydrogen phosphate solution added to $50 \mathrm{~mL}$ pure water, resulting in a 
$\mathrm{pH}$ of 6.1 . The same amounts of buffer and ion-pair solutions were added to $50 \mathrm{~mL}$ of sample before the extraction of the analytes. After the extraction, the sorbent was washed with $10 \mathrm{~mL}$ of conditioning solution, the cartridges were dried and later the analytes were eluted using $4 \mathrm{~mL}$ methanol. During the extraction, washing, and eluting procedures, the maximum flowrates were kept below $2 \mathrm{~mL} / \mathrm{min}$, and during the conditioning below $5 \mathrm{~mL} / \mathrm{min}$. After the elution, the methanol was evaporated from the extract in a nitrogen steam at $60^{\circ} \mathrm{C}$ until completely dry. Afterwards, the samples were dissolved in $4 \mathrm{~mL}$ of pure water.

The major anion analyses of the data given in Table 3.3 were conducted on a DIONEX 500, using electrochemically suppressed conductivity detection. For separation, an AS11-HC column was used with potassium hydroxide as the eluent. Cations were analysed on a DIONEX 320, using electrochemically suppressed conductivity detection. The separation was conducted on a CS16 column, using methane sulfonic acid as the eluent.

\subsubsection{Calibration and validation}

The linear range of the method was estimated using a ten-point calibration curve with an analyte-concentration ranging from 0.025 to $2.5 \mu \mathrm{g} / \mathrm{L}$. The uppermost concentration was stated as the standard with the highest concentration within the $95 \%$ confidence interval of the calibration curve. For all analytes, the upper limit in the linear range was restricted by the measurement limit of the fluorescence detector, resulting in peak area cut off. Using these concentrations, at least 7 points were in the $95 \%$ confidence interval for every analyte.

The calculation of the method quantification limits (MQL) and method detection limits (MDL) for the overall method were calculated with the MS-Excel Macro ValiData Version 3.02 (Roher-Wegscheider-Neuböck, Leoben, Austria), according to the standard DIN 32645. An eleven-point linear regression line ranging from 0.025 to $0.5 \mu \mathrm{g} / \mathrm{L}$ with a confidence interval of $95 \%$ was used. The uppermost and lowermost concentrations were extracted threefold and the concentration levels in between were extracted twice. All samples were injected and measured once.

\subsection{Results and discussion}

All NS shows a strong fluorescence at a very similar wavelength with the exception of the internal standard 2-OH-3,6 NDS (Figure 3.1). The measured values are nearly the same found by Rose et al. (2002). Therefore, a mean wavelength 
maximum of 225 in excitation and 338 in emission was chosen to detect all analytes. To further improve detection limits for selected analytes, the wavelengths can be adjusted for each analyte according to the data provided in Figure 3.1. The difference in emission wavelength of the internal standard and the analytes are $>100 \mathrm{~nm}$. Therefore, no spectral cross interference was found between analytes and the internal standard.

Compound
Excitation /
max. [nm]

Figure 3.1: Structures and fluorescence maxima for 1-NMS, 2-NMS, 1,5-NDS, 1,6NDS, 2,6-NDS, 2,7-NDS, and 2-OH-3,6-NDS

With the method described above, all analytes can be sufficiently separated. With the exception of 1,6-NDS and 2,7-NDS, the resolution factor (Rs) always exceeds 1.5, indicating a baseline separation. The Rs of 1,6 -NDS and 2,7-NDS is 1.32. A chromatogram is given in Figure 3.2. Furthermore, one may observe that the separation is strongly effected by the salinity of the injected sample. By increasing the salinity of the sample to $10 \mathrm{~g} / \mathrm{L} \mathrm{NaCl}$, the peak broadening of the naphthalene 
disulfonates becomes significant and separation efficiency decreases. At a salinity of $100 \mathrm{~g} / \mathrm{L} \mathrm{NaCl}$, significant concentrations of the disulfonates show no retention on the column. For the naphthalene monosulfonates, no correlation between change in retention time and high salinity in the sample can be found (Figure 3.2). Maybe this phenomenon can be attributed to the possibility of the monosulfonates to undergo additional hydrophobic interactions with the stationary phase.

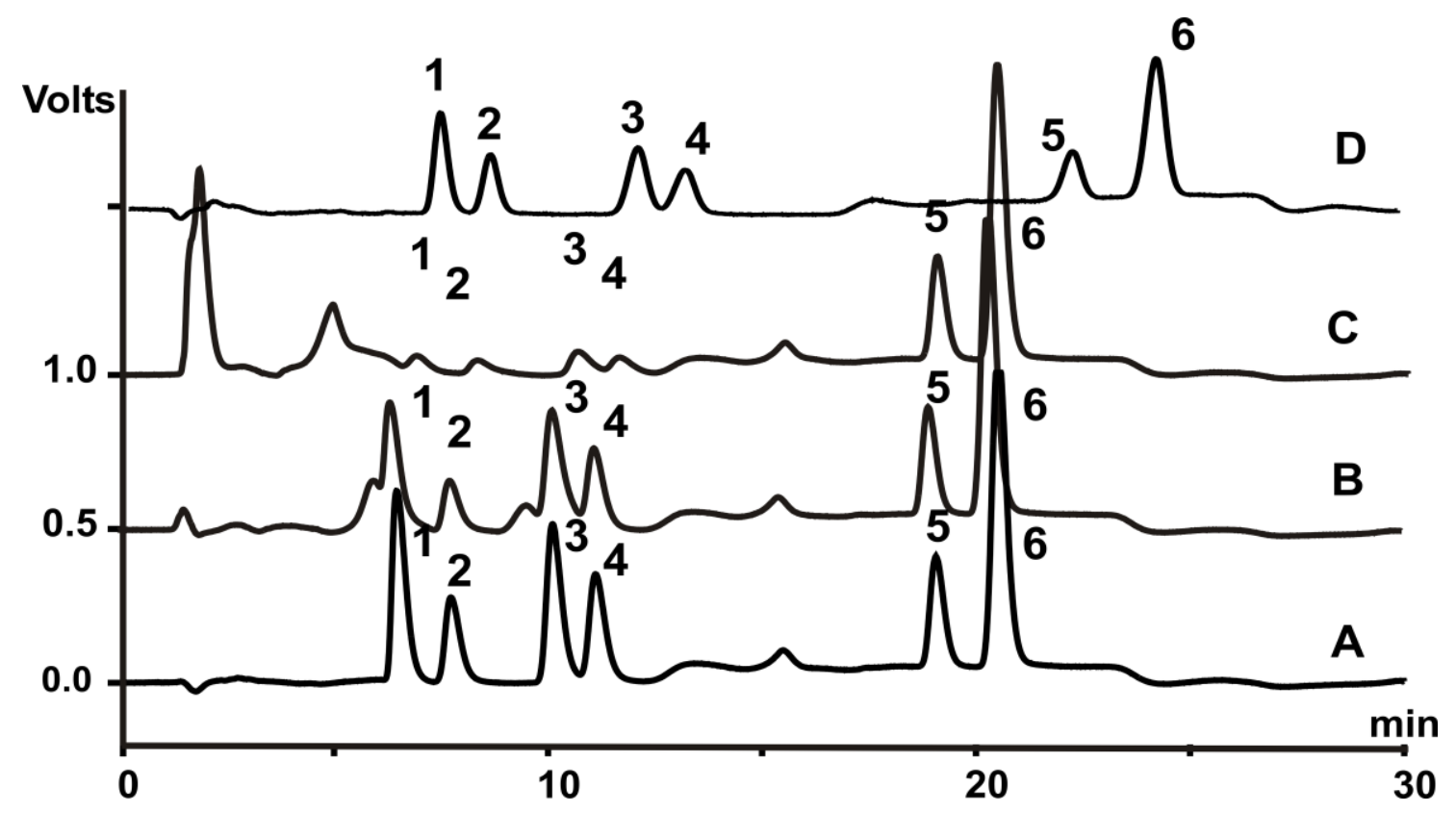

Figure 3.2: Chromatogram of a $10 \mu \mathrm{g} / \mathrm{L}$ mix-standard consisting of 2,6-NDS (1), 1,5-NDS (2), 2,7-NDS (3), 1,6-NDS (4), 1-NMS (5), and 2-NMS (6) in pure water (A), $10 \mathrm{~g} / \mathrm{L} \mathrm{NaCl}(\mathrm{B})$, and $100 \mathrm{~g} / \mathrm{L} \mathrm{NaCl}(\mathrm{C})$, using a Phenomenex Luna C18 (2) column. And a chromatogram of a $0.4 \mu \mathrm{\mu g} / \mathrm{L}$ mix-standard, consisting of the same analytes after SPE in $100 \mathrm{~g} / \mathrm{L} \mathrm{NaCl}$, using a YMC ODS-AQ column (D).

Previous experiments using a phosphate buffer and tetrabutyl ammonium bromide or-hydroxide, as used by other authors (Lange et al. 1995, Rose et al. 2002, Storm et al. 1999, Altenbach and Giger 1995, Bastian et al. 1994, Gimeno et al. 2001, Zerbinati et al. 1993), has also provided a successful baseline separation of all analytes. But in this case an increasing backpressure of the HPLC column within approximately 50 hours resulted, indicating a plugging of the column with precipitating phosphate salts. The same issue has been reported by Rose et al. (2002). Experiments without phosphate or any additives apart from the ion-pairing agent and acid to avoid a plugging of the column, resulted in broader peaks and thus to a not sufficient separation. It seems that the use of phosphate buffer in the eluent always carries the risk of the formation of phosphate precipitates. To avoid this problem, the herein suggested method is based on using sulphate as a counter 
ion, thus increasing the overall robustness of the method. The use of sulphate showed no change in backpressure for at least $500 \mathrm{~h}$ under standard operating conditions.

Changing the stationary phase of the HPLC column had no significant effects on the separation of NS isomers, as long as the dimensions of the column and the particle size are identical. Most experiments were conducted with an ODS-AQ from YMC Europe, but baseline separation was also possible on a Phenomenex Luna $\mathrm{C}_{18}$ (2), a Varian XRs- $\mathrm{C}_{18}$, and a Phenomenex Luna PFP (2), as long as the schedule of the eluent composition was a little adjusted.

Experiments with ion-pairing agents other than TBAB have been conducted as well. In the case of using ion-pairing agents of lower polarity, lower amounts of the agent are required to achieve a sufficient retardation and separation on the column. In the case of CTMAB, for example, the amounts could be reduced to at least $0.05 \mathrm{mM}$. This however has its limitations. It was found that significant amounts of CTMAB are still present in the eluent after $20 \mathrm{~h}$ of flushing the column with methanol and water (50:50, v/v). By installing the flushed column into a LC-MS, significant amounts of СTMAB were detected semi-quantitatively. In this experimental setup, a scan in positive mode was performed ranging from 150 to $400 \mathrm{~m} / \mathrm{z}$. Details of the experimental setup, the analytical system, and the eluents used are given by Nödler et al. (2010). This indicates that CTMAB sorbs onto the stationary phase and equilibrium of the ion-pairing agent between the column and the eluent cannot be achieved within a reasonable timespan. Therefore, a robust method development with CTMAB would be hindered immediately by this physical difficulty. In this method, TBAB was therefore used as the recommended ionpairing agent.

Table 3.1: Recovery of NS on different solid phase sorbents in \% $(0.5 \mu \mathrm{g} / \mathrm{L}$ of each analyte added to $50 \mathrm{~mL}$ samples)

\begin{tabular}{ccccccc}
\hline \multirow{2}{*}{ Solid phase sorbent, matrix } & \multicolumn{7}{c}{ Compound } \\
& 1-NMS & 2-NMS & 1,5-NDS & 1,6-NDS & 2,6-NDS & 2,7-NDS \\
\hline Strata X-RP, $\mathrm{H}_{2} \mathrm{O}$ & 93 & 96 & 94 & 92 & 93 & 91 \\
Strata X-RP, $10 \mathrm{~g} / \mathrm{L} \mathrm{NaCl}$ & 93 & 104 & 93 & 93 & 92 & 92 \\
Strata X-RP, $100 \mathrm{~g} / \mathrm{L} \mathrm{NaCl}$ & 98 & 106 & 94 & 94 & 93 & 93 \\
Bakerbond, $\mathrm{H}_{2} \mathrm{O}$ & 93 & 95 & 94 & 91 & 90 & 89 \\
Bakerbond, $100 \mathrm{~g} / \mathrm{L} \mathrm{NaCl}$ & 94 & 97 & 30 & 58 & 28 & 53 \\
Bondelut Plexa, $\mathrm{H}_{2} \mathrm{O}$ & 96 & 100 & 91 & 93 & 107 & 92 \\
Bondelut Plexa, $10 \mathrm{~g} / \mathrm{L} \mathrm{NaCl}$ & 94 & 96 & 91 & 90 & 105 & 90 \\
Bondelut Plexa, $100 \mathrm{~g} / \mathrm{L} \mathrm{NaCl}$ & 93 & 95 & 8 & 17 & 19 & 19 \\
\hline
\end{tabular}


The recovery of the respective tested solid-phase materials in the SPE is excellent, approaching nearly $100 \%$ in samples without $\mathrm{NaCl}$. By adding $100 \mathrm{~g} / \mathrm{L} \mathrm{NaCl}$ to the samples, recoveries of the naphthalene disulfonates on the Bond Elute Plexa and the Bakerbond Octadecyl sorbent significantly decrease, indicating a breakthrough of these substances. Only the Strata X-RP solid-phase material shows no dependency on $\mathrm{NaCl}$ concentration within the sample (Table 3.1). This could be possibly attributed to the additional interaction mechanisms of the Strata X-RP phase such as pi-pi and dipole interactions, as well as additional hydrophobic interactions. Therefore, this sorbent was used in the method development. To study the effects of $\mathrm{NaCl}$ on recoveries of NS onto Strata-X-RP sorbents in detail, a test with increasing salinities of up to $175 \mathrm{~g} / \mathrm{L}$ was performed. $50 \mathrm{~mL}$ of brine with increasing salinities of $25 \mathrm{~g} / \mathrm{L} \mathrm{NaCl}$ were spiked with $0.5 \mu \mathrm{g} / \mathrm{L}$ of each analyte. Within this test, no influences of salinity on the recovery rates can be observed (Table 3.2). The mean recoveries of each analyte including all salinities are between 91 and $96 \%$. Also, the use of $20 \mathrm{~g} / \mathrm{L} \mathrm{MgCl}_{2}$ did not affect the recoveries. The use of SPE has no influence on the chromatograms obtained by HPLC. The chromatograms of spiked samples, including the analyte and inorganic salts after SPE, are nearly the same as chromatograms of standards directly injected to HPLC (Figure 3.2, chromatogram D). Changes in retention times in this chromatogram are only caused by changing the column from a Phenomenex Luna C18 (2) to a YMC ODS-AQ and a simultaneous variation of the timeschedule of the eluent composition.

Table 3.2: Recoveries of NS in highly saline brines with concentrations between 0 and $175 \mathrm{~g} / \mathrm{L} \mathrm{NaCl}(25 \mathrm{~g} / \mathrm{L}$ steps, $\mathrm{n}=8,0.5 \mathrm{\mu g} / \mathrm{L}$ of each analyte added to $50 \mathrm{~mL}$ samples) and in reservoir matrix. Mean, RSD, and recoveries are given for all salinities.

\begin{tabular}{ccccc}
\hline Compound & $\begin{array}{c}\text { Mean } \\
\text { [ } \mathbf{\mu g} / \mathbf{L}]\end{array}$ & RSD [\%] & Recovery [\%] & $\begin{array}{c}\text { Recovery in reservoir } \\
\text { matrix [\%] }\end{array}$ \\
\hline 1-NMS & 0.53 & 1.54 & 95 & 102.9 \\
2-NMS & 0.44 & 9.0 & 91 & 101.4 \\
1,5-NDS & 0.46 & 5.48 & 92 & 110.9 \\
1,6-NDS & 0.43 & 4.55 & 96 & 112.7 \\
2,6-NDS & 0.49 & 1.49 & 96 & 100.1 \\
2,7-NDS & 0.48 & 2.28 & 92 & 110.8 \\
\hline
\end{tabular}

Finally, the method was tested in an original matrix of a deep geothermal system located in Bruchsal, Germany. Ion-chromatographic measurements show a salinity of over $120 \mathrm{~g} / \mathrm{L}$, dominated by $\mathrm{Na}$ and $\mathrm{Cl}$ (Table 3.3). For this test, $50 \mathrm{~mL}$ of sample were spiked with $0.1 \mu \mathrm{g} / \mathrm{L}$ of all analytes and the internal standard. In the analysis, 
the recoveries of NS are in the range of 100 to $113 \%$ (Table 3.2 ). This shows that the method is feasible for matrices encountered in deep geothermal brines.

Table 3.3: Composition of brine, taken from the deep geothermal test site Bruchsal, Germany. Measurements were conducted by IC.

\begin{tabular}{cccccc}
\hline \multicolumn{2}{c}{ Anions } & & & \multicolumn{2}{c}{ Cations } \\
Compound & conc. [g/L] & & Compound & conc. $[\mathrm{g} / \mathrm{L}]$ \\
\cline { 1 - 2 } \cline { 5 - 6 } $\mathrm{Cl}^{-}$ & 73.7 & & $\mathrm{Na}^{+}$ & 39.1 \\
$\mathrm{SO}_{4}^{2-}$ & 0.6 & & $\mathrm{~K}^{+}$ & 3.3 \\
$\mathrm{Br}^{-}$ & 0.3 & & $\mathrm{Mg}^{2+}$ & 0.4 \\
& & & $\mathrm{Ca}^{2+}$ & 8.0 \\
& & & $\mathrm{Li}^{+}$ & 0.2 \\
\hline
\end{tabular}

Table 3.4: Calibration parameters of the overall method, including SPE and HPLCdetection. Method quantification limit and linear range are valid for $50 \mathrm{~mL}$ sample extraction, $4 \mathrm{~mL}$ redissolution, and a $25 \mu \mathrm{L}$ injection of the extract. Details to the calculations are given in the text.

\begin{tabular}{cccc}
\hline Compound & $\begin{array}{c}\text { Linear range } \\
{[\boldsymbol{\mu g} / \mathbf{L}]}\end{array}$ & $\begin{array}{c}\text { Method quantification limit } \\
(\mathbf{M Q L})[\boldsymbol{\mu g} / \mathbf{L}]\end{array}$ & $\begin{array}{c}\text { Method detection limit, } \\
\text { absolute (MDL) [pg] }\end{array}$ \\
\hline 1-NMS & $0.025-1.75$ & 0.05 & 0.7 \\
2-NMS & $0.007-0.75$ & 0.16 & 2.8 \\
1,5-NDS & $0.025-2.00$ & 0.08 & 4.8 \\
1,6-NDS & $0.025-2.00$ & 0.40 & 10 \\
2,6-NDS & $0.025-1.50$ & 0.08 & 1.2 \\
2,7-NDS & $0.025-1.75$ & 0.19 & 3.9 \\
\hline
\end{tabular}

The calibration parameters of the overall method including SPE and HPLC-detection are given in Table 3.4. For most analytes the linear range covers a concentration range of nearly 2 orders of magnitude and is therefore sufficient for standard applications. Also, the MQL of $0.4 \mu \mathrm{g} / \mathrm{L}$ or lower are adequate for most applications. If the detection limit of the method is not sufficient for analysis, the extracting volumes may be increased. This however has its limitations. At an extraction volume of $500 \mathrm{~mL}$, the disulfonates shows a significant breakthrough on the extraction. The monosulfonates are not at all affected in their recoveries of up to $500 \mathrm{~mL}$ (Table 3.5). 
Table 3.5: Mean recovery and relative standard deviation (RSD) of naphthalene sulfonates on SPE by using different sample volumes in $100 \mathrm{~g} / \mathrm{L} \mathrm{NaCl}$. The samples were spiked with $25 \mathrm{pg}$ absolute of each analyte $(n=6)$.

\begin{tabular}{|c|c|c|c|c|c|c|c|c|}
\hline \multirow{3}{*}{ Compound } & \multicolumn{8}{|c|}{ Sample volume $[\mathrm{mL}]$} \\
\hline & \multicolumn{2}{|c|}{50} & \multicolumn{2}{|c|}{100} & \multicolumn{2}{|c|}{250} & \multicolumn{2}{|c|}{500} \\
\hline & $\begin{array}{c}\text { recovery } \\
{[\%]}\end{array}$ & $\begin{array}{l}\text { RSD } \\
\text { [\%] }\end{array}$ & $\begin{array}{c}\text { recovery } \\
{[\%]}\end{array}$ & $\begin{array}{l}\text { RSD } \\
\text { [\%] }\end{array}$ & $\begin{array}{c}\text { recovery } \\
{[\%]}\end{array}$ & $\begin{array}{l}\text { RSD } \\
{[\%]}\end{array}$ & $\begin{array}{c}\text { recovery } \\
{[\%]}\end{array}$ & $\begin{array}{l}\text { RSD } \\
\text { [\%] }\end{array}$ \\
\hline $1-\mathrm{NMS}$ & 102 & 3.9 & 95 & 3.3 & 105 & 7.9 & 101 & 5.2 \\
\hline 2-NMS & 94 & 7.9 & 102 & 5.7 & 101 & 2.4 & 102 & 2.6 \\
\hline $1,5-N D S$ & 106 & 3.7 & 101 & 2.5 & 101 & 2.4 & 52 & 13.0 \\
\hline 1,6 -NDS & 106 & 6.5 & 100 & 2.1 & 93 & 21.1 & 46 & 20.9 \\
\hline 2,6-NDS & 104 & 4.5 & 97 & 0.9 & 107 & 5.5 & 71 & 8.5 \\
\hline 2,7-NDS & 107 & 3.3 & 100 & 3.5 & 104 & 8.1 & 59 & 8.1 \\
\hline
\end{tabular}

\subsection{Conclusions}

A robust method for the simultaneous determination of six NS from highly saline brines was developed. Salinities up to $175 \mathrm{~g} / \mathrm{L} \mathrm{NaCl}$ showed no influence on the recoveries of SPE and the subsequent chromatographic detection. The method was demonstrated to be successfully applicable for the matrices encountered in deep geothermal brines in Northern Europe. By the use of the SPE method, it is possible to separate the inorganic matrix successfully from the organic ionic analytes. Simultaneously, a preconcentration of the analytes is possible thus reducing detection limits significantly.

\section{Acknowledgments}

The authors gratefully acknowledge the financial support of this work by the German Federal Ministry of Environment (BMU, 0327579).

\subsection{References}

Alonso, M. C., Castillo, M. and Barcelo, D. (1999). Solid-phase extraction procedure of polar benzene- and naphthalenesulfonates in industrial effluents followed by unequivocal determination with ion-pair chromatography/electrospray-mass spectrometry. Anal. Chem. 71: 2586-2593 
Alonso, M.C., Tirapu, L., Ginebreda, A. and Barcelo, D. (2005). Monitoring and toxicity of sulfonated derivatives of benzene and naphthalene in municipal sewage treatment plants. Environ. Pollut. 137: 253-262

Altenbach, B. and Giger, W. (1995). Determination of Benzene- and Naphthalenesulfonates in wastewater by solid phase extraction with graphitized carbon black and ion pair liquid chromatographie with UV detection. Anal. Chem. 67: 2325-2333

Bastian, B., Knepper, T.P., Hoffmann, P. and Ortner, H.M. (1994). Determination of aromatic sulfonic acids in industrial wastewater by ion-pair chromatographie. Fresen. J. Anal. Chem. 348: 674-679

Ghergut, I., Sauter, M., Behrens, H., Licha, T., McDermott, C.I., Herfort, M., Rose, P., Zimmermann, G., Orzol, J., Jung, R., Huenges, E., Kolditz, O., Lodemann, M., Fischer, S., Wittig, U., Güthoff, F. and Kühn, M. (2007). Tracer tests evaluating hydraulic stimulation at deep geothermal reservoirs in Germany. Proceedings of the 31 st Workshop on Geothermal Reservoir Engineering, Stanford University, Stanford, CA. SGPTR-183

Gimeno, R.A., Marc, R.M. and Borrull, E. (2001). Determination of aromatic sulfonates in coastal water by on-line ion-pair solid-phase extraction/ion-pair liquid chromatography with uv detection. Chromatographia 53: 22-26

Greim, H., Ahlers, J., Bias, R., Broecker, B., Hollander, H., Gelbke, H.-P. Klimisch, H.-J, Mangelsdorf, I., Paetz, A., Schöne, N., Stropp, G., Vogel, R., Weber, C., ZieglerSkylakakis, K. and Bayer, E. (1994). Toxicity and ecotoxicity of sulfonic acids: strctureactivity relationship. Chemosphere 28: 2203-2236

Kim, I. S., Sasinos, F. I., Rishi, D. K., Stephens, R. D. and Brown, M. A. (1991). Determination of aromatic sulfonic acids in aqueous environmental samples by anionexchange chromatography coupled to particle beam mass spectrometry and uv spectrophotometry. J. Chromatogr. 589: 177-183

Kok, S. J., Koster, E. H. M., Gooijer, C., Velthorst, N. H., Brinkman, U. A. Th. and Zerbinati, O. (1996). Separation of twenty-one naphthalene sulfonates by means of capillary electrophoresis. J. High Resol. Chromatogr. 19: 99-104

Kok, S. J., Kristenson, E. M., Gooijer, C., Velthorst, N. H. and Brinkman, U. A. Th. (1997). Wavelength-resolved laser-induced fluorescence detection in capillary electrophoresis: naphthalenesulphonates in river water. J. Chromatogr. A 771: 331-341

Lange, F. T., Wenz, M. and Brauch, H.-J. (1995). Trace-level determination of aromatic sulfonates in water by on-line ion-pair extraction on-pair chromatography and their behavior in the aquatic environment. J. High Resol. Chromatogr. 18: 243-252

Liu, C.-H. and Ding W.-H. (2001). Determination of naphthalenesulfonic acid isomers by large-volume ion-line derivatization and gas chromatography-mass spectrometry. J. Chromatogr. A 926: 341-346 
Nottebohm, M., Licha, T., Ghergut, I., Nödler, K. and Sauter, M. (2010). Development of thermosensitive tracers for push-pull experiments in geothermal reservoir characterization. Proceedings of the World Geothermal Congress 2010 Bali, Indonesia

Nödler, K., Licha, T., Bester, K. and Sauter, M. (2010). Development of a multi-residue analytical method, based on liquid chromatography-tandem mass spectrometry, for the simultaneous determination of 46 micro-contaminants in aqueous samples. $J$. Chromtogr. A 1217: 6511-6521

OECD Secretariat. The 2004 OECD list of high production volume chemicals, Paris: Organisation for Economic Co-operation and Development (2004). http://www.oecd.org/dataoecd/55/38/33883530.pdf (last accessed 15.01.2011)

Reemtsma, T. (1996). Methods of analysis of polar aromatic sulfonates from aquatic environments. J. Chromatogr. A 733: 473-489

Rose, P. E., Johnson, S. D., Kilbourn, P. and Kasteler, C. (2002). Tracer testing at the Dixie Valley, Nevada using 1-Naphthalene sulfonate and 2.6-Naphthalenedisulfonate. Proceedings of the 27th Workshop on Geothermal Reservoir Engineering, Stanford University, Stanford, CA . SGP-TR-171

Rudzinski, W. E., Bennett, D., Garcia, V. and Seymour, M. (1983). Influence of mobile phase and role of added electrolyte in retention of ionized solutes in hplc. J. Chromatogr. Sci. 21: $57-61$

Sanjuan, B.,.Pinault, J.-L, Rose, P., Gérard, A., Brach, M., Braibant, G., Couzet, C., Foucher, J.-C., Gautier, A. and Touzelet, S. (2006). Tracer testing of the geothermal heat exchanger at Soultz-sous-Forêts (France) between 2000 and 2005. Geothermics 35: $622-653$

Storm, T., Reemtsma, T. and Jekel, M. (1999). Use of volatile amines as ionpairingagents for the high-performance liquid chromatographic-tandem mass spectrometric determination of aromatic sulfonates in industrial wastewater. J. Chromatogr. A 854: 175-185

Zerbinati, O., Ostacoli, G., Gastaldi, D. and Zelano, V. (1993). Determination and identification by high-performance liquid chromatography and spectrofluorimetry of twenty-three aromatic sulphonates in natural waters. J. Chromatogr. 640: 231-240 


\section{Chapter 4}

\section{Development of Thermosensitive Tracers for Push- Pull Experiments in Geothermal Reservoir Characterization}

Martin Nottebohm ${ }^{a, b}$, Tobias Licha ${ }^{a}$, Iulia Ghergut ${ }^{a}$, Karsten Nödler ${ }^{a}$ and Martin Sauter $^{\mathrm{a}}$

Citiation: Nottebohm, M., Licha, T., Ghergut, I., Nödler, K., Sauter, M. (2010): Development of Thermosensitive Tracers for Push-Pull Experiments in Geothermal Reservoir Characterization, Proceedings World Geothermal Congress 2010 Bali, Indonesia, 25-29 April 2010

a) Applied Geology, Geosciences Center, University of Göttingen, Goldschmidtstr. 3, 37077 Göttingen, Germany

b) Corresponding author - phone: (49) +551/3919332; martin.nottebohm@geo.uni-goettingen.de 


\section{Abstract}

The aim of the laboratory experiments presented here is to identify molecular structures for thermosensitive tracers, which are adequate for the assessment of reservoir temperatures from short-term, single-well, push-pull tracer testing techniques under the typical low temperature conditions of geothermal reservoirs in Northern Europe.

Considering the widespread experience in the application of naphthalene sulfonates as tracers in geothermal reservoirs, this substance class provides well studied base molecules that can be modified into thermally sensitive tracers. It is planned to use the hydrolysis reaction from various esters of naphthol sulfonates. In order to find esters with adequate reaction kinetics, the mechanism of hydrolysis is studied on 44 phenol acetates and transferred to naphthol sulfonates.

\subsection{Introduction}

In addition to geophysical and seismic experiments, tracertests with virtually chemical inert tracers have been established as a useful tool for the characterization of geothermal reservoirs (Rose et al. 2001, Sanjuan et al. 2006, Ghergut et al. 2007). These tracers are used for flow path tracking and for the investigation of fluid residence times. Several organic compounds have successfully been used for such tests, e.g. naphthalene sufonates, fluoresceine, and fluorinated benzoic acids. In the future, short-term push-pull experiments on different test sites in Northern Europe using chemically inert tracers will be extended to simultaneous investigations on the thermal development of the reservoir, together with its heat exchange capacities and properties.

Thermosensitive tracers have a high potential to increase the information in the characterization of geothermal reservoirs (DuTeaux and Callahan 1996). They have been suggested for tracking thermal fronts and for calculating thermal drawdowns (Tester et al. 1986, Robinson and Birdsell 1987). Herefore, the hydrolysis reaction was demonstrated to be suitable in addressing the encountered temperature ranges in geothermal reservoirs and the timescales of the experiments. Thus, this reaction type seems to have the potential of extending its use to the typical features of a push-pull experiment. The features include, a) low temperature ranges, b) the confined duration of the experiments, and c) the likely presence of oxygen.

The thermosensitive tracers to be developed will have to address the specific characteristics of Northern European reservoirs and the specific demands of the 
experimental setup of push-pull experiments. Therefore, these tracers should show a comparatively rapid thermal degradation (days) under mild temperatures (approx. $120-140^{\circ} \mathrm{C}$ ). Their reactivity with oxygen, even under oxygen limiting conditions, need to be investigated since the presence of oxygen cannot be ruled out due to the experimental design of push-pull experiments. Furthermore, the tracers must be readily soluble in water and brine.

Different homologues of naphthalene sulfonate isomeres have been successfully used as ionic, highly mobile, highly fluorescing, and chemically inert tracers at several geothermal sites (e.g. Ghergut et al. 2007). This gives the opportunity to measure breakthrough curves by direct and onsite fluorescence measurements. The possibility to detect different isomers of these compounds in the laboratory allows the design of tracers that have different reaction kinetics and which can be therefore employed simultaneously in one tracer test to increase information. Our aim is to develop thermosensitive tracers based on naphthalene sulfonates by introducing hydroxyl groups into these molecules which are likely to form esters. The hydrolysis reaction of these esters will then be the thermosensitive extension. To predict the most successful modifications to the molecular structures of naphthalene sulfonates, the hydrolysis reaction of acetates from several phenol isomers is investigated exemplarily as a study object.

Furthermore, the presented paper describes for the first time the stability of naphthalene sulfonates and naphthol sulfonates at elevated temperatures in the presence of oxygen traces.

\subsection{Hydrolysis constants of phenolic esters measured by HS- SPME-GC-MS}

Esterification has been established as a powerful derivatization technique for the analysis of phenols in water by GC-MS. This derivatization reaction is especially attractive as it is compatible with solid phase microextraction (SPME) and thus the complete analysis can be fully automated (Buchholz 1994). Considering the large number of analytes, which are possible to detect simultaneously in one sample by this approach under controlled and identical conditions, this method is most suitable to investigate the influence of structural differences in phenolic acetates on their hydrolysis kinetics. Data quality and comparability in the reaction constants between the investigated compounds has been shown to be very accurate for example by Bierwagen and Keller (2000). With this experimental design, the sterical inhibiting influences of substituted groups can be investigated, together 
with inductive and mesomeric effects of different substituents on the molecule with high precision.

Due to their highly ionic character naphthalene sulfonates cannot be detected by gas chromatography. Therefore, phenolic esters are analyzed in lieu in order to transfer the findings of structural effects influencing the kinetics of hydrolysis to naphthalene sulfonates.

\subsubsection{Experimental Method}

The hydrolysis constants for 44 phenolic esters including naphthol at ambient temperature were identified using a HP 6890 GC system with a HP 5972A mass selective detector from Hewlett Packard and a solid phase micro extracting (SPME) system from CTC Analytics.

For the sample preparation, $150 \mathrm{mg} \mathrm{NaHCO}_{3}$ were added to $1 \mathrm{~mL}$ of a $12.5 \mu \mathrm{g} / \mathrm{L}$ standard mix, which included all analytes. Then, the phenols were esterified by adding $50 \mu \mathrm{L}$ of acetic anhydride. A set of samples was prepared initially and then every 12 hours one sample was measured. With this schedule, at least 4 data points, having a significant decrease in concentration, were obtained within 168 hours of preparation for every compound in the consecutive determination of the hydrolysis constant $\mathrm{k}$.

The investigated character of ester hydrolysis is given by:

$\mathrm{RCOCOCH} 3+\mathrm{H} 2 \mathrm{O} \rightarrow \mathrm{RCOH}+\mathrm{HOCOCH} 3$

The first-order rate constant $\mathrm{k}$ was calculated by:

$\ln \left(\frac{c}{c_{0}}\right)=-k \cdot t$

Therefore, $k$ is linear for plotting $c[\mathrm{~mol} / \mathrm{L}]$ on the $y$-axis and $1 / t[\mathrm{~min}]$ on the $\mathrm{x}$ axis. Then $k$ can be calculated from the slope of the linear regression line. An example for the data fit and calculation of $k$ for 4 -chloro-3-cresol is given in Figure 4.1. 


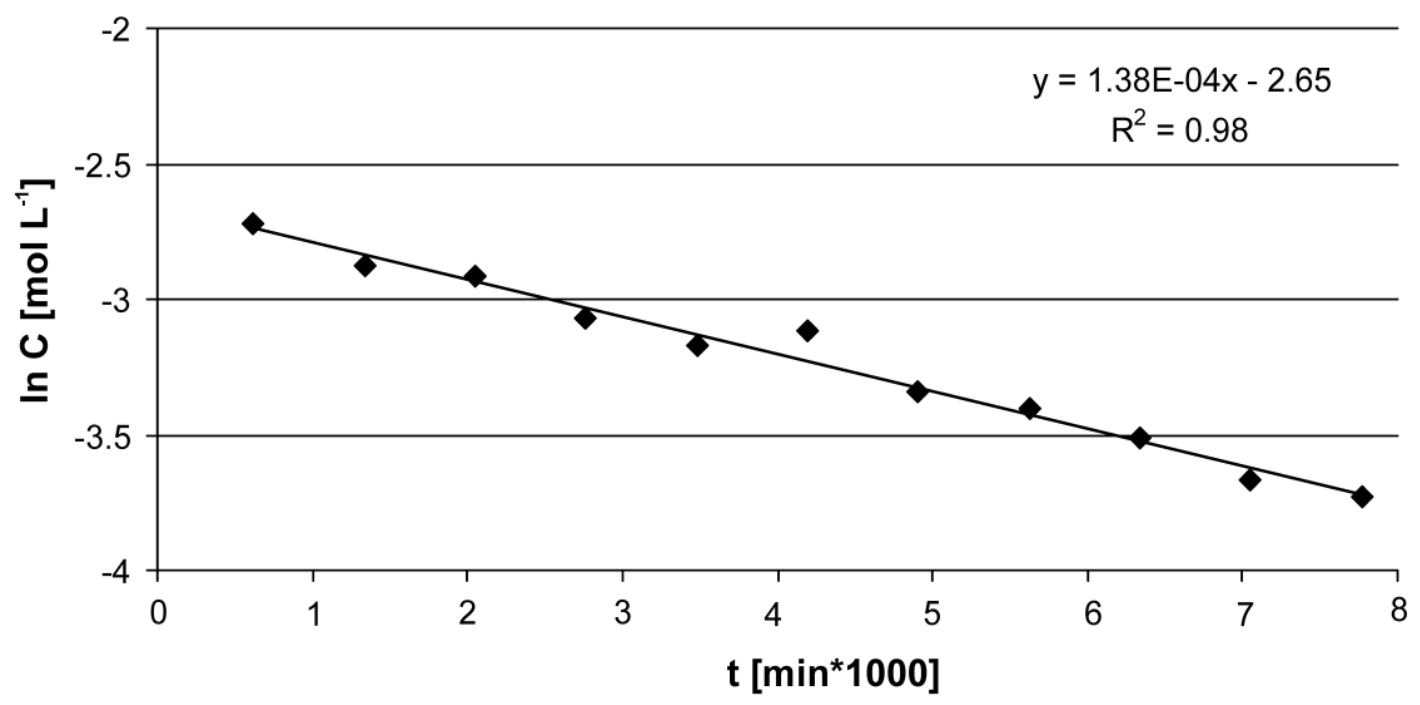

Figure 4.1: Calculation of the first-order rate constant $k$ for 4 -chloro-3-cresol

The half-life in first-order kinetics can be calculated from:

$\mathrm{t}_{1 / 2}=\frac{\ln 2}{\mathrm{k}}$

\subsubsection{Results}

By plotting the rate constants $\mathrm{k}$ for the hydrolysis reactions versus the $\mathrm{pK}_{\mathrm{a}}$ of the non-esterified substances, it can easily be demonstrated that the reaction rate increases by up to 4 orders of magnitude with increasing the acid constant $\mathrm{pK}_{\mathrm{a}}$ by 3 orders of magnitude (Figure 4.2). Furthermore, this correlation is linear for at least 3 groups of substances. This implies that Hammet's law is valid for this type of reaction as well as for this substance class and thus transferable to other compounds. The classification into three groups agrees with the molecular structure of the compounds as each involves substances that have several similarities concerning their chemical structure. In one group a chlorine atom is located next to the hydroxyl group and in the second group two chlorine atoms are located next to the hydroxyl group. As a result the ester is better protected from hydrolysis attack by water molecules and the reaction rate decreases. 


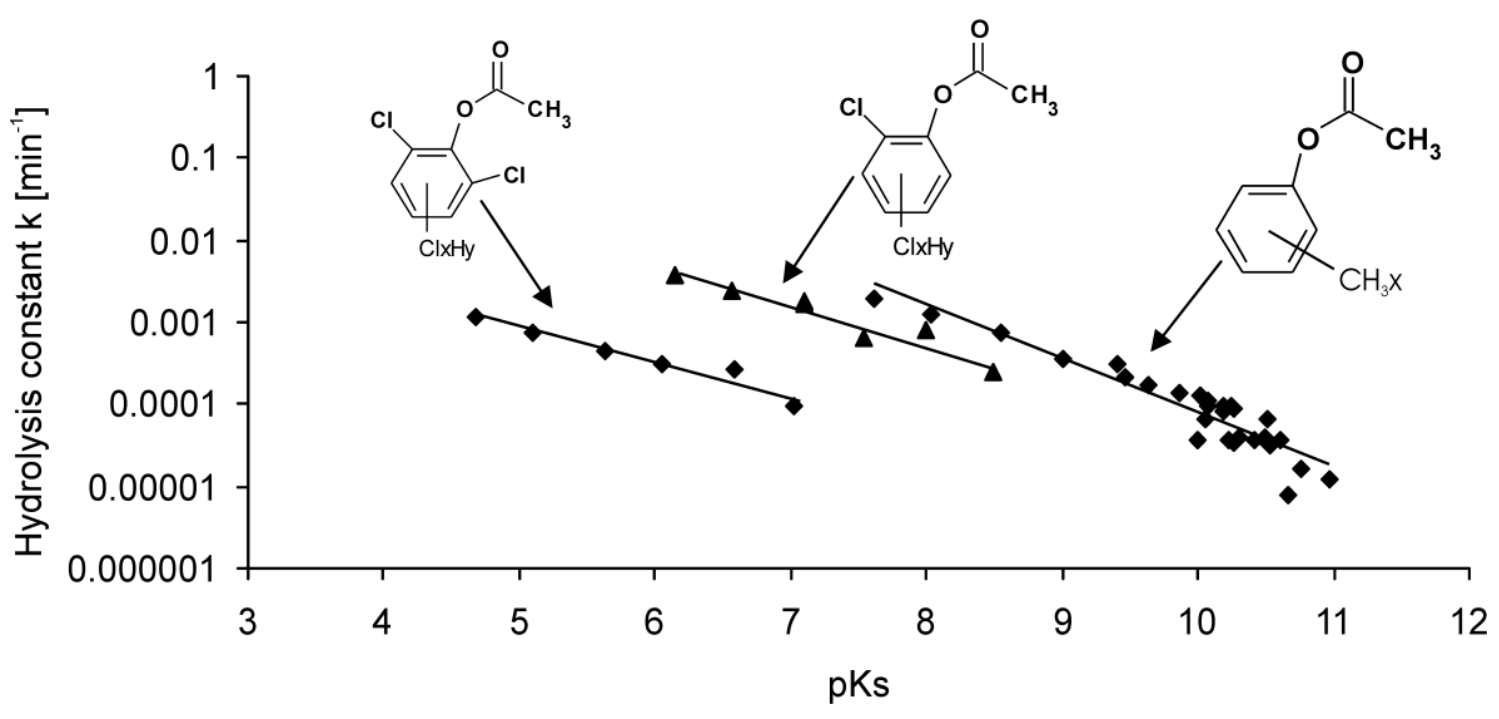

Figure 4.2: Hydrolysis constant $k$ at ambient temperature versus $\mathrm{pK}_{\mathrm{a}}$

Also, mesomeric (M) and inductive (I) effects from different substituents affects the hydrolysis reaction rate. If the substituents are not adjacent to the hydroxyl group, their sterical hinderance effect can be neglected and the effect on hydrolysis kinetics is solely assigned to the substituents electron density influence on the aromatic ring(s). This effect can best be studied by comparing the reaction rates of respective phenol acetates (i.e 3,5 DMP vs. 3,5 DCP) in table 4.1. Functional groups, which posses a positive inductive effect $(+\mathrm{I})$ lead to a decreased reaction rate (e.g. alkyl groups) and functional groups with a negative inductive effect (-I) increase reaction rates (e.g. $\mathrm{Cl}$ ). By increasing the number of substituents, this effect is intensified. Following this context, most of the trimethyl phenols are significantly more stable than cresols and the chloro phenols having a single chlorine group are more stable than their higher chlorinated analogues.

Table 4.1: Hydrolysis constants and half-lives at ambient temperature and estimated half-lives for $120^{\circ} \mathrm{C}$ for 43 phenol acetates and naphthol acetate. Abbreviations: DMP: Dimethyl phenol, TMP: Trimethyl phenol, EP: Ethyl phenol, PP: Propyl phenol, Kre: Cresol, CP: Chloro phenol, DCP: Dichloro phenol, TrCP: Trichloro phenol, TeCP: Tetrachloro phenol, PCP: Pentachlor phenol (all as acetates), RT: ambient temperature. $\mathrm{pK}_{\mathrm{a}}$ values were calculated using SciFinder Scholar ${ }^{\mathrm{TM}}$

\begin{tabular}{ccccc} 
Compound & $\mathbf{p K}_{\mathbf{a}}$ & $\mathbf{t}_{\mathbf{1 / 2}}$ at RT [h] & $\mathbf{K}$ at RT $\left[\mathbf{m i n}^{-\mathbf{1}} \mathbf{]}\right.$ & $\mathbf{t}_{\mathbf{1 / 2}}$ at $\mathbf{1 2 0}{ }^{\circ} \mathbf{C}[\mathbf{h}]$ \\
\hline 2,6-DMP & 10.66 & 1426.2 & $8.10 \mathrm{E}-06$ & 71.3 \\
2,4,6-TMP & 10.97 & 931.6 & $1.24 \mathrm{E}-05$ & 46.6 \\
2,3,6-TMP & 10.77 & 683.6 & $1.69 \mathrm{E}-05$ & 34.2 \\
2,3,5-TMP & 10.53 & 373.9 & $3.09 \mathrm{E}-05$ & 18.7
\end{tabular}




\begin{tabular}{|c|c|c|c|c|}
\hline 2-EP & 10.27 & 334.9 & $3.45 \mathrm{E}-05$ & 16.7 \\
\hline 2-PhenyIP & 9.99 & 317.4 & $3.64 \mathrm{E}-05$ & 15.9 \\
\hline 2-nPP & 10.49 & 316.5 & $3.65 \mathrm{E}-05$ & 15.8 \\
\hline 3,4-DMP & 10.23 & 313.1 & $3.69 \mathrm{E}-05$ & 15.7 \\
\hline 2,4-DMP & 10.61 & 312.2 & $3.70 \mathrm{E}-05$ & 15.6 \\
\hline 2,5-DMP & 10.42 & 308.9 & $3.74 \mathrm{E}-05$ & 15.4 \\
\hline o-Kre & 10.31 & 299.3 & $3.86 \mathrm{E}-05$ & 15.0 \\
\hline 2-iPP & 10.49 & 283.8 & 4.07E-05 & 14.2 \\
\hline 3,4,5-TMP & 10.51 & 176.1 & $6.56 \mathrm{E}-05$ & 8.8 \\
\hline 3-EP & 10.06 & 171.1 & $6.75 \mathrm{E}-05$ & 8.6 \\
\hline 3,5-DMP & 10.18 & 136.4 & $8.47 \mathrm{E}-05$ & 6.8 \\
\hline p-Kre & 10.26 & 129.7 & 8.91E-05 & 6.5 \\
\hline 3-nPP & 10.07 & 122.2 & $9.45 \mathrm{E}-05$ & 6.1 \\
\hline $2,6-\mathrm{DCP}$ & 7.02 & 122.0 & $9.47 \mathrm{E}-05$ & 6.1 \\
\hline 4-iPP & 10.19 & 117.5 & $9.83 E-05$ & 5.9 \\
\hline 4-EP & 10.25 & 117.2 & $9.86 \mathrm{E}-05$ & 5.9 \\
\hline m-Kre & 10.07 & 108.2 & $1.07 \mathrm{E}-04$ & 5.4 \\
\hline 3-iPP & 10.02 & 88.5 & $1.31 \mathrm{E}-04$ & 4.4 \\
\hline $4 \mathrm{Cl}-3-\mathrm{Kre}$ & 9.63 & 83.7 & $1.77 \mathrm{E}-04$ & 4.2 \\
\hline Phenol & 9.86 & 82.9 & $1.39 \mathrm{E}-04$ & 4.1 \\
\hline $4-C P$ & 9.47 & 54.6 & $2.12 \mathrm{E}-04$ & 2.7 \\
\hline $2-C P$ & 8.50 & 47.5 & $2.43 \mathrm{E}-04$ & 2.4 \\
\hline $2,4,6-\operatorname{TrCP}$ & 6.59 & 42.1 & $2.74 \mathrm{E}-04$ & 2.1 \\
\hline Naphthol & 9.40 & 38.8 & $2.98 \mathrm{E}-04$ & 1.9 \\
\hline $2,3,6-\operatorname{TrCP}$ & 6.06 & 38.7 & $2.99 \mathrm{E}-04$ & 1.9 \\
\hline $3-C P$ & 9.00 & 31.8 & $3.64 \mathrm{E}-04$ & 1.6 \\
\hline $2,3,4,6-\mathrm{TeCP}$ & 5.63 & 25.0 & $4.62 E-04$ & 1.3 \\
\hline $2,3-D C P$ & 7.53 & 18.3 & $6.30 \mathrm{E}-04$ & 0.9 \\
\hline $2,3,5,6-\mathrm{TeCP}$ & 5.09 & 15.9 & $7.26 \mathrm{E}-04$ & 0.8 \\
\hline 3,4-DCP & 8.55 & 15.7 & $7.38 \mathrm{E}-04$ & 0.8 \\
\hline $2,4 / 2,5-\mathrm{DCP}$ & 8.00 & 14.3 & 8.06E-04 & 0.7 \\
\hline $\mathrm{PCP}$ & 4.68 & 9.8 & $1.18 \mathrm{E}-03$ & 0.5 \\
\hline $3,5-D C P$ & 8.04 & 9.1 & $1.27 \mathrm{E}-03$ & 0.5 \\
\hline $2,3,4-\operatorname{TrCP}$ & 7.10 & 7.1 & $1.63 \mathrm{E}-03$ & 0.4 \\
\hline $2,4,5-\operatorname{TrCP}$ & 7.10 & 6.4 & $1.80 \mathrm{E}-03$ & 0.3 \\
\hline $3,4,5-\operatorname{TrCP}$ & 7.61 & 5.8 & $2.00 \mathrm{E}-03$ & 0.3 \\
\hline $2,3,5-\operatorname{TrCP}$ & 6.57 & 5.0 & $2.33 \mathrm{E}-03$ & 0.2 \\
\hline $2,3,4,5-\mathrm{TeCP}$ & 6.15 & 3.1 & $3.74 \mathrm{E}-03$ & 0,2 \\
\hline
\end{tabular}

It must be concluded that for substituents having a negative inductive effect (-I), the steric hinderance effect as a counter effect on the hydrolysis reaction rate is significant. For substituents having a positive inductive $(+\mathrm{I})$ effect on the aromatic ring system the addition of steric hinderance can be neglected, as long as the alkyl groups are small (up to C3). 
Following QSAR strategies (Hansch et al. 1995), the mechanisms that controls the hydrolysis kinetics may be transferred to more complex phenolic compounds. This can be seen on naphthol and 2-hydroxy biphenyl, which plot on the same regression line as phenol (Figure 4.2). As such, it can be predicted how the acetate esters of naphthol sulfonates would behave. First of all, the sulfonic group with its pronounced negative inductive effect $(-\mathrm{I})$, combined with its negative mesomeric effect $(-M)$, will decrease the electron density in the aromatic system and thus make the hydroxyl group more acidic and the respective esters less stable. This higher acidity of the hydroxyl group compared to naphthol is supported by the experimental data from Zollinger and Büchler (1950), who present lower $\mathrm{pK}_{\mathrm{a}}$ values for sulfonated naphthols compared to naphthol. As a consequence, the hydroxyl group and the sulfonic group must not be on the same aromatic ring in order to keep the accelerating effect of the sulfonic group on the hydrolysis as low as possible. Furthermore, the number of sulfonic groups should be as low as possible. However, at least one sulfonic group should be last on the molecule, since the overall aqueous solubility is controlled by this group.

Based on the results from the phenolic acetates, considerations for an appropriate thermally reacting tracer set with adequate reaction times are justified. In the experiments of Robinson and Tester (1990), it was found that the reaction rates of hydrolysis reactions increases by a factor of approximately 20 , if the temperature increases by $100^{\circ} \mathrm{C}$. In Figure 4.2 , it can be seen that the half-lifes $\left(t_{1 / 2}\right)$ for most of the substances are not yet sufficient for the favored timescales of even shortterm tracer tests. Furthermore, it has to be considered that the addition of sulfonic groups will lead to a lower $\mathrm{pK}_{\mathrm{a}}$ of the hydroxyl group and thus accelerate the hydrolysis reaction compared to the data from naphthol. There are now two possibilities for molecule modifications, leading to a decrease in the reaction rate of hydrolysis. First option is the addition of functional groups, having a positive inductive effect $(+\mathrm{I})$ to the molecule. The second option is the esterification with other acids than acetic acid. It is known that acids with longer or branched alkyl chains can result in a sterical hinderance to the ester group thus leading to slower reaction rates (Organikum, 2004).

\subsection{Thermal stability of naphthalene sulfonates in the presence of oxygen traces}

In order to use the hydrolysis of the earlier described esters based on naphthalene sulfonates in push-pull experiments quantitatively as tracers, the thermal stability of the emerging naphthol sulfonates must be known. Additionally, the earlier as 
thermally stable described naphthalene sulfonates are also investigated as reference substances. The thermal stability of 1,5-naphthalene disulfonate and 1,3,6-naphthalene trisulfonate has been described by Rose et al. (2001). He found that these compounds are stable up to $300^{\circ} \mathrm{C}$ in an anoxic environment. Own push-pull experiments, however, show a lower recovery of this compound class relative to ${ }^{3} \mathrm{H}_{2} \mathrm{O}$, which is maybe addressed to the presence of oxygen traces originating from the experimental design of these field experiments.

\subsubsection{Thermal batch experiments with individual compounds}

For the thermal stability tests, 2-naphthol-6-sulfonate and five naphthalene sulfonates were investigated in individual heated batch experiments. The naphthalene sulfonates included: 1-naphthalene monosulfonate (1NMS), 1,5-naphthalene disulfonate (1,5NDS), 1,6-naphthalene disulfonate (1,6NDS), 2,6-naphthalene disulfonate (2,6NDS), and 2,7-naphthalene disulfonate (2,7NDS). The reagents were selected based on their commercial availability. Naphthalene trisulfonates were not tested since only a composite of different isomers was available. All chemicals were received from TCI-Europe in their highest available purity. The determination of the excitation and emission maxima and the determination of the respective concentrations in the batch experiments were performed using a Cary-Eclipse fluorimeter from Varian. A list of the test substances with their structural formula, together with their respective fluorescence properties, is given in Table 4.2.

Table 4.2: Compounds analyzed for thermal decay with the chemical structure, compound name, and excitation and emission maximum

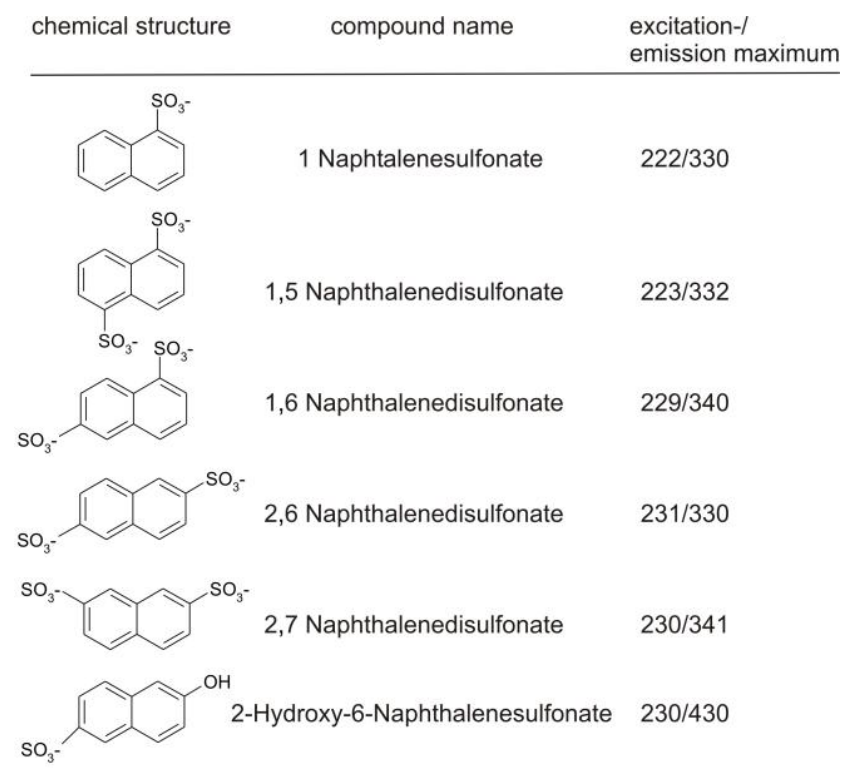


For the heated batch experiments, the substances were dissolved in ultrapure water (18 $\mathrm{mohm}$ ) and then diluted to $5 \mathrm{mg} / \mathrm{L}$. Ultrapure water was received from a Mili-Q Gradient A10 system from Millipore. No buffers were added to avoid problems in the identification of degradation products by ESI-LC-MS. Earlier tests with identical setup and the addition of buffers (carbonate, phosphate) showed no significant differences in the results. Individual reference solutions were kept in order to be able to quantify the fluorescence loss later on.

All experiments were conducted with 4 replicates individually for each test substance, each with a total volume of $20 \mathrm{~mL}$ of the respective solution in $40 \mathrm{~mL}$ Hostaflon $^{\circledR}$ TFM vessels from CEM. No attempts were made to reduce the oxygen in the vessels. The vessels were put into a GC-oven from Chrompack, heated up within $60 \mathrm{~min}$ to the target temperature, and kept at this temperature for significant timesteps (days).

At the end of the heating batch experiment the oven was cooled down within $30 \mathrm{~min}$ to room temperature. The samples were immediately taken from the vessels and diluted according to the linear working range of the fluorimeter with ultrapure water. The loss due to heat treatment by the batch experiments was quantified relative to the fluorescence intensities of reference solutions.

It was found that the semi-quantitative loss in fluorescence intensity at $150{ }^{\circ} \mathrm{C}$ for a 24 hour heat treatment is as follows: naphthol sulfonates > naphthalene sulfonates $>$ naphthalene disulfonates. This effect increases significantly for temperatures above $130^{\circ} \mathrm{C}$. It could be confirmed by batch experiments that naphthalene disulfonates are more stable than their monosulfonated analogues, which diminished to $95 \%$ within $165 \mathrm{~h}$. However, naphthalene sulfonates also showed a significant loss in concentration from $35 \%(2,6$ NDS) to $58 \%$ (1,6 NDS). The results are shown in Figure 4.3. 


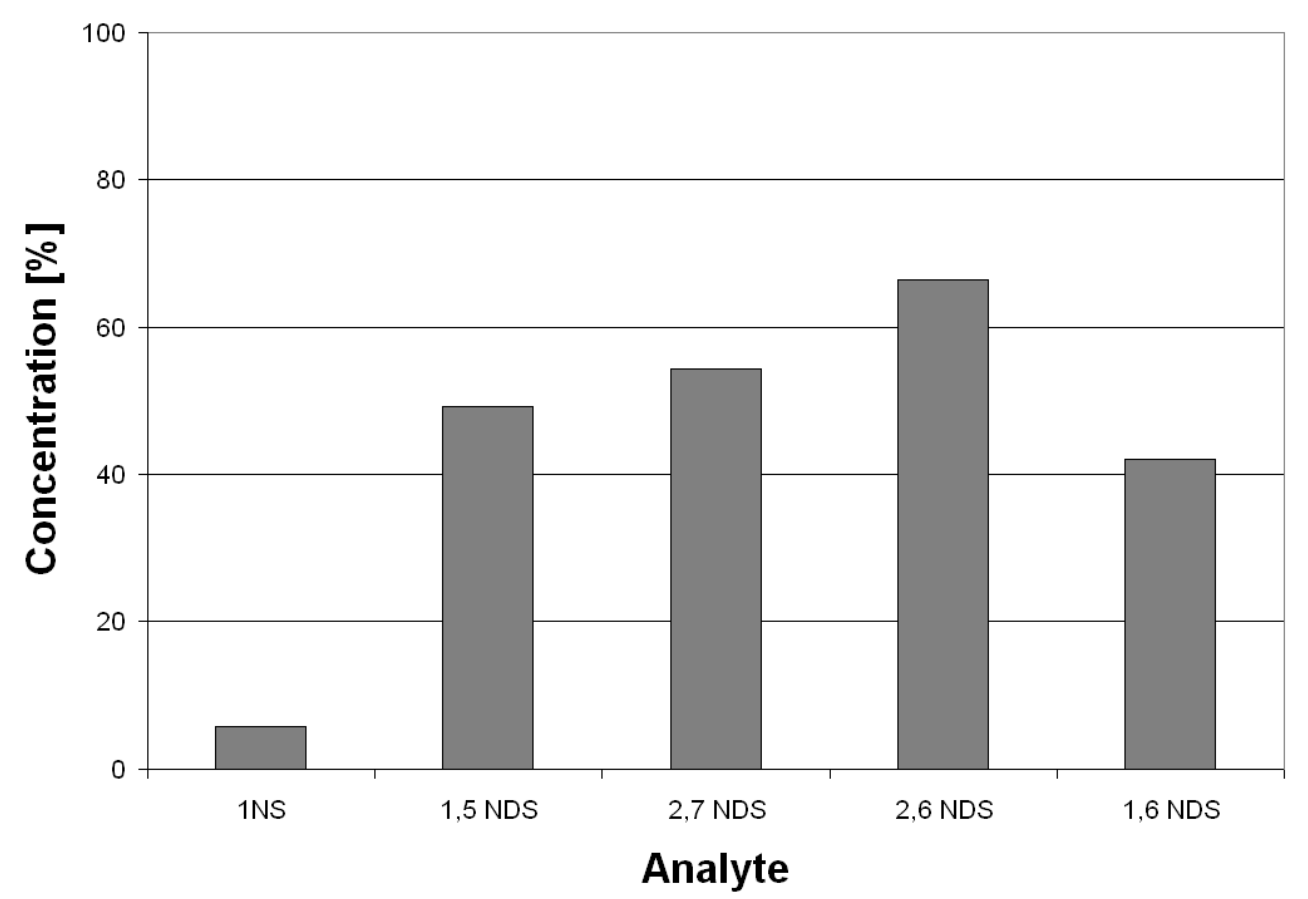

Figure 4.3: Decrease in fluorescence of naphthalene sulfonates after $165 \mathrm{~h}$ at $150^{\circ} \mathrm{C}$

Because of the strong discrepance between these results and the fact that some of these compounds have been stable in geothermal reservoirs over months (e.g. Sanjuan et al. 2006), the samples were analyzed by LC-MS techniques to identify the type of relevant reaction and to exclude possible quenching effects in the fluorescence measurements. Since breakdown products of naphthalene (di)sulfonates have earlier been investigated with different intensions and are therefore known (Gosetti et al. 2005), initially more attention was drawn to the investigation of the processes leading to the fluorescence decay of the naphthalene sulfonates.

\subsubsection{Investigation of the reaction products by LC-MS}

LC-MS methods are a powerful tool a) for the identification of known substances in unknown matrices and $b$ ) to indicate the possible structure of unknown substances by the investigation of the specific masses and product-ions. Therefore, this technique can be used to investigate whether a decrease in fluorescence of the sample is caused by quenching effects of the matrix, or if it can be assigned to the decay of the substance. Furthermore, it is possible to identify potential reaction products. If only one stable reaction product is formed, it can be used instead of the sulfonates to quantify the hydrolysis reaction. If more than one reaction product is identified, this will give more information on the character of the decay reaction. This is especially helpful if, for example, additives need to be identified 
which effect the reaction in the field during push-pull experiments. It may also help to reconsider the experimental design of push-pull tests if the cause of the decay is known.

The reaction products were analyzed using a Varian ProStar System with a 1200 Quadrupole MS. The mobile phase consists of: eluent A: $1 \mathrm{mM}$ acetic acid, $1 \mathrm{mM}$ tributylamine as ionpairing agent with $5 \%$ methanol $(\mathrm{pH} \mathrm{4.5)}$ and eluent $\mathrm{B}$ of $100 \%$ methanol. In order to elute all the analytes from the column (Phenomenex C18(2), $150 \times 3 \mathrm{~mm}, 3 \mu \mathrm{m}$ particle size) within an acceptable runtime a gradient was applied from 30 to $70 \%$ B in $25 \mathrm{~min}$. For the identification of the specific $\mathrm{m} / \mathrm{z}$ ratio of the reaction products, the samples were scanned from 90 to 400 amu using negative electrospray ionisation (ESI) as ionization technique. Additionally neutral loss experiments were performed to support the functional group specific identification. To determine the relative distribution pattern of breakdown products for the individual sulfonates with time, the samples were analyzed by ESI-LC-MS with the earlier identified masses (m/z: 245, 229, 213, 255, 351, 335, 217, 216, 143 and $137 \mathrm{amu}$ ) in selected ion monitoring (SIM) mode.

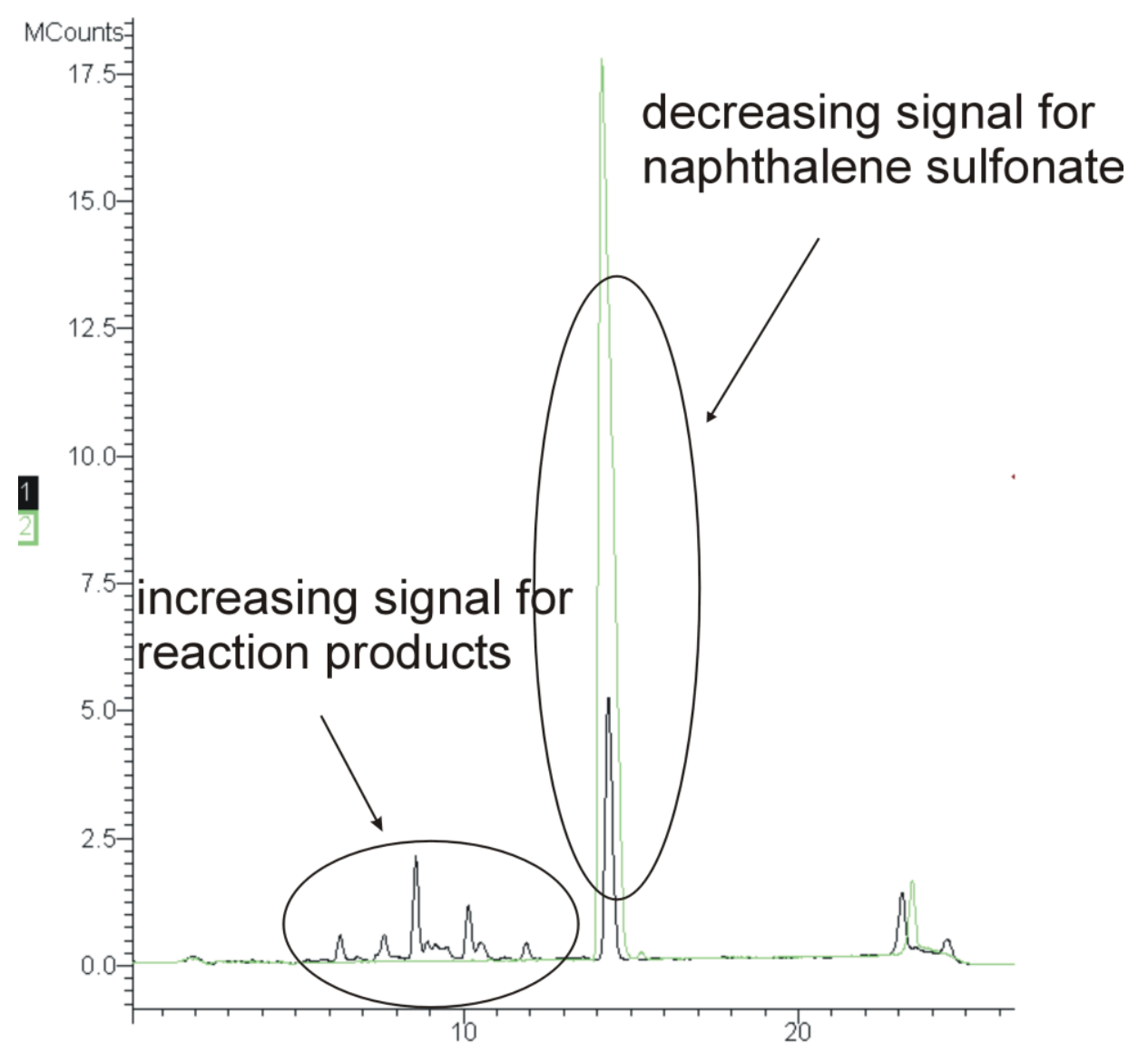

Figure 4.4: TIC-Spectrum of 1-NMS before (green line) and after the stability test (black line) 
A total ion chromatogram (TIC) for 1-NMS before and after a stability test with $66 \mathrm{~h}$ runtime is given in Figure 4.4. It is shown clearly that the decrease in the fluorescence signal is not caused by quenching effects since the results from LC-MS measurements are in good agreement with results obtained by direct fluorescence. Furthermore, it shows different reaction products, instead of a single stable one. A list of the investigated reaction products is given in Figure 4.5.

\section{Reaction products of naphthalene sulfonates at $150 \mathrm{C}$}

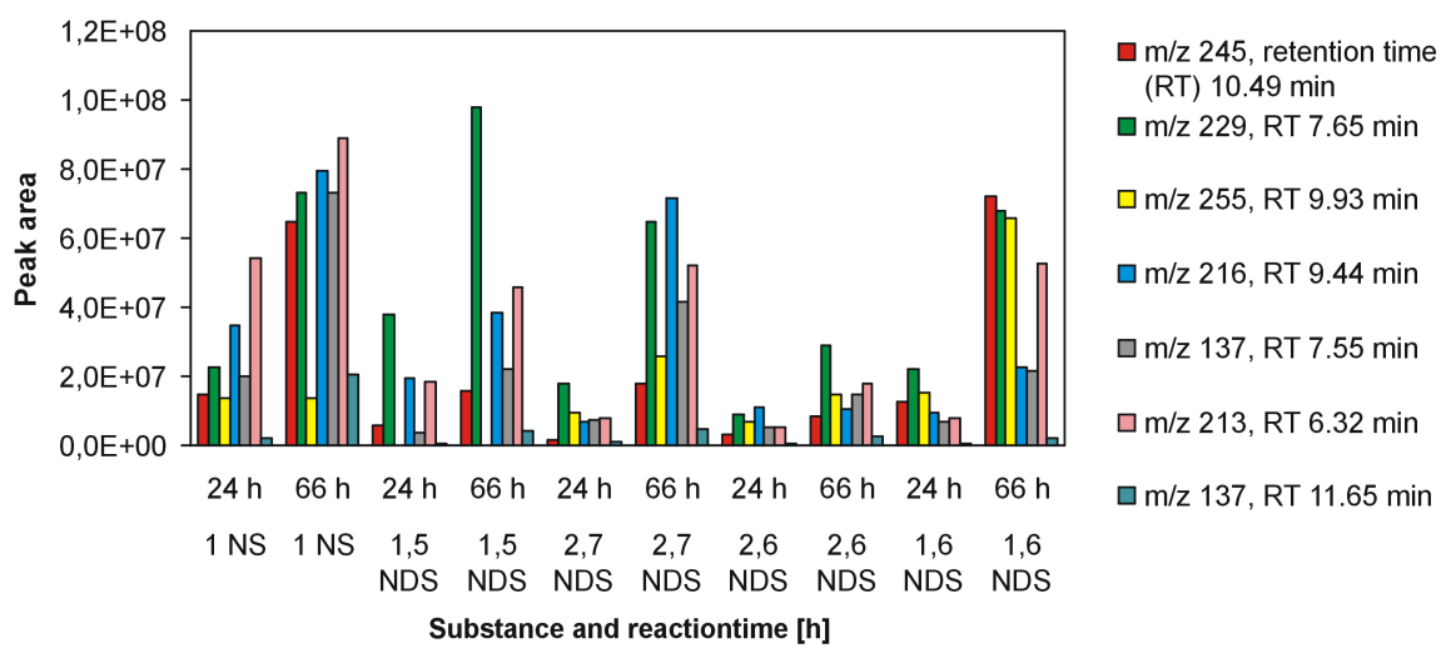

Figure 4.5: Investigated reaction products of different naphthalene sulfonates after $24 \mathrm{~h}$ and $66 \mathrm{~h}$ at $150{ }^{\circ} \mathrm{C}$

Nearly all reaction products show an increasing concentration within reaction time. The differences of the peak areas in between the different isomers correlate with the results in the decrease of fluorescence. Additionally, the good correlation of the obtained concentration of the sulfonates by LC-MS with fluorescence measurements allows the conclusion that the obtained breakdown products cannot be analyzed by fluorescence spectroscopy, and thus they do not falsify fluorescence data.

It was found that many compounds identified in the heated batch experiments have the same $\mathrm{m} / \mathrm{z}$ ratio and similar retention times as detected by Storm (2002). He investigated the reaction products of the oxidative destruction of 1,5-NDS (masses 245, 229, 255 and 213) by ozonization at ambient temperature. Salicylic acid ( $m / z$ 137) could be identified using the pure substance as a reference standard. For the compound with the $\mathrm{m} / \mathrm{z}$ ratio 216 , no possible reaction product structure can yet be suggested from SIM. A list of the suggested structures in agreement to Storm (2002) is given in Figure 4.6. 
<smiles>O=C(O)c1ccccc1OS(=O)(=O)O[Na]</smiles>

Figure 4.6: Proposed and identified reaction products of the thermal degeneration of naphthalene sulfonates

The structures of the reaction products imply that the reaction is initiated by the presence of oxygen at elevated temperatures. However, to estimate the exact mechanism of the reaction, more efforts in the precise structural analysis may be conducted and it has to made clear, which products are compound specific, i.e. final products and which ones are intermediates of this reaction.

\subsection{Conclusions}

The hydrolysis of organic esters can offer an appropriate reaction, sensitive to the thermal variability in geothermal reservoirs. The strong influence of the reaction product acidity on the reaction kinetics makes it possible to cover a broad range of different temperatures in the reservoir and different tracer test times. The linear relation in this context allows the prediction of reaction rates, if the hydrolysis constants of similar substances are known. Furthermore, it is possible to control the kinetics of this reaction by the influence of the substituent's steric, inductive, and mesomeric effects.

Considering this, in the next step the hydrolysis kinetics of selected naphthol sulfonic esters, having varying $\mathrm{pK}_{\mathrm{a}}$ of the hydroxyl group and different chain length of the ester group will be investigated.

It has been found that naphthalene sulfonates are sensitive to oxygen at typical geothermal reservoir temperatures. Therefore, it has to be decided if this can be a relevant process within push-pull experiments. Samples from these experiments will be scanned in future for the identified typical breakdown products of the naphthalene sulfonates by LC-MS to compare the field data and laboratory experiments. 
Considering the presented experiments and the positive experience from several tracer tests in the past, different isomers of naphthol sulfonate esters promise to be practical thermosensitive tracers in the characterization of deep geothermal reservoirs in Northern Europe by short-term push-pull experiments.

\section{Acknowledgments}

The authors gratefully acknowledge the financial support of this work by the German Federal Ministry of Environment (BMU, 0327579).

\subsection{References}

Bierwagen, B., Keller, A. A. (2001): Measurement of Henry's Law Constant for Methyl TertButhyl Ether Using Solid-Phase Microextraction, Environmental Toxicology and Chemistry, 20, nr. 8, 1625-1629

Buchholz, K., Pawliszyn, J. (1994): Optimization of Solid Phase Microextraction (SPME) in Water and Air for Phenol Analysis, Analysis Anal. Chem., 66, 160-167

DuTeaux, R., Callahan, T.J. (1996): Comparing reactive and non reactive tracers to measure changes in liquid dominated, fractured geothermal reservoirs: Geothermal Resources Transactions, 20, 447-451

Ghergut, I., Sauter, M., Behrens, H., Licha, T., McDermott, C.I., Herfort, M., Rose, P., Zimmermann, G., Orzol, J., Jung, R., Huenges, E., Kolditz, O., Lodemann, M., Fischer, S., Wittig, U., Güthoff, F., Kühn, M. (2007): Tracer Tests Evaluating Hydraulic Stimulation at Deep Geothermal Reservoirs in Germany, Proceedings, $31^{\text {th }}$ Workshop on Geothermal Reservoir Engineering, Stanford University, Stanford, CA (2007).

Gosetti, F., Gianotti, V. Ravera, M., Genarro, M.C. (2005): HPLC-MS to Investigate the Oxidative Destruction Pathway of Aromatic Sulfonate Wastes, Journal of Environmental Quality, 34, 2328-2333

Hansch, C., Leo, A., and Hoekman, D. (1995): Exploring QSAR - Hydrophobic, Electronic, and Steric Constants. American Chemical Society, Washington, D.C.

Organicum, 22th ed., Wiley-VCH, (2004)

Robinson, B. A., Tester, J. W. (1990): Kinetics of Alkaline Hydrolysis of Organic Esters and Amides in Neutrally-Buffered Solution, International Journal of Kintics, 22, 431-448

Robinson, B. A., Birdsell, S. A. (1987): Tracking Thermal Fronts with Temperaturesensitive, Chemically Reactive Tracers, Fifth Geothermal Program Review, Washington, DC

Rose, P., Benoit, W. R., Kilbourn, P. M. (2001): The application of polyaromatc sulfonates as tracers in geothermal reservoirs, Geothermics, 30, 617-640. 
Sanjuan, B., Pinault, J.-L., Rose, P., Gérard, A., Brach, M., Braibant, G., Couzet, C., Foucher, J.-C., Gautier, A., Touzelet, S. (2006): Tracer Testing of the Geothermal Heat Exchanger at Soultz-sous-Forêts (France) between 2000 and 2005, Geothermics, 35, 622-653.

Storm, T. (2002): Aromatische Sulfonate: Untersuchungen zum Stoffverhalten in Industrieabwasser und aquatischer Umwelt mit HPLC-MS, Dr. Thesis, TU Berlin

Tester, J. W., Robinson, B. A., Ferguson, J. H (1986): Inert and Reacting Tracers for Reservoir Sizing in Fractured, Hot Dry Rock Systems, Proceedings, $11^{\text {th }}$ Workshop on Geothermal Reservoir Engineering, Stanford University, Stanford, CA.

Zollinger, H. and Büchler, W. (1950): Einfluss der Sulfongruppen auf den Dissoziationsgrad der Hydroxyle in Naphtholsulfonsäuren, Helv. Chim. Acta, 33, 2002-2010 


\section{Chapter 5}

\section{Tracer design for tracking thermal fronts in geothermal reservoirs}

Martin Nottebohm ${ }^{\mathrm{a}}$, Tobias Licha ${ }^{\mathrm{a}}$ and Martin Sauter ${ }^{\mathrm{a}}$

Citiation: Nottebohm, M., Licha, T., Sauter, M.: Tracer design for tracking thermal fronts in geothermal reservoirs. Submitted and accepted pending minor revisions by Geothermics

a) Applied Geology, Geosciences Center, University of Göttingen, Goldschmidtstr. 3, 37077 Göttingen, Germany

b) Corresponding author - phone: (49) +551/3919332; martin.nottebohm@geo.uni-goettingen.de 


\section{Abstract}

This paper describes the first steps in the design of new custom-made tracers for the investigation of thermal characteristics in deep geothermal reservoirs. Based on ester hydrolysis, the influences of different substituents on the reaction kinetics are studied in detail using the analogue phenol acetates under the influence of varying $\mathrm{pH}$ and temperatures. Furthermore, a 2-ethylbutyl-2-naphthol-6-sulfonic ester is tested in laboratory experiments for its applicability as a practical thermo-sensitive tracer, considering also the influences of brine and rock matrix. The reaction is shown to be strongly thermo-sensitive while the reaction kinetics can be varied by two orders of magnitude by altering the sterical hindrance groups. These changes in the reaction kinetics are found to be predictable by using the results of this work. It has been found that the half-life can be decreased by the factor of three, if the reacting group is sterically hindered from one side and by the factor of ten, if the reacting group is hindered from both sides. Also, mesomeric and inductive effects of substituents on the aromatic ring have significant effects on reaction rates. The $\mathrm{pH}$-dependency on the reaction speed could be quantified and it is shown that the reaction complete alkaline catalyzed. Therefore, this reaction fulfills the many considerations of a tracer-test, such as varying absolute temperature, test durations, and temperature gradients.

Keywords: tracer, smart tracer, thermal breakdown, phenol acetates, hydrolysis

\subsection{Introduction}

In nearly every geothermal system, the extracted energy exceeds the natural thermal heat flow (O'Sullivan, 2010). As a result, the reservoir cools down over time, resulting in a thermal breakthrough at the production well. Currently there are no monitoring tools available to measure the actual temperature of the region between the production and injection wells in a deep geothermal reservoir. Due to this technical inadequacy, an estimation of the time when the cooling front reaches the production well is almost impossible. Experimental modeling has been applied as a tool in geothermal power plant operation to find the optimum balance between extracted heat and long-term sustainability since a couple of years (e.g., Shook, 2001). However, the robustness of these techniques has not been validated yet by field experiments. Over the past years, modeling has gained more and more significance in the field of geothermal-energy research and progress continues at a rapid pace. Model calibration may be greatly enhanced by studies on in-situ measurement techniques, such as tracer tracking with themo-sensitive tracers. 
Applications using isotope or chemical geothermometry for estimating an average reservoir temperature have been developed as well (e.g., Sanjuan 2010). These methods are adequate in a thermally unaffected reservoir but are not practical for evaluating temperature changes during power plant operation. This is because of the inability to assess influences of mixing processes and the comparatively slow equilibration of chemical composition.

The use of tracers has been established over past years as a powerful tool for characterizing geothermal reservoirs. They are mainly used for flow path tracking and to estimate fluid residence times (Rose et al., 2001; Sanjuan et al., 2006; Ghergut et al., 2007). For these applications, conservative tracers are preferred. Conservative tracers must be stable under geothermal conditions and do not interact with the reservoir rocks. Furthermore, they should be detectable at low concentrations, and it must be ensured they are non-toxic for people or the environment.

Using tracers, which react in a predictable way under known physicochemical geothermal conditions, is a relatively new and very innovative concept. By knowing how a tracer reacts under deep geothermal reservoir conditions, new insights about the reservoir characteristics may be gained. The first experiments using "smart" tracers in geothermal applications have been conducted to quantify the solid-liquid phase interface using tracers with different Peclet numbers and matrix diffusion coefficients (Ghergut et al., 2007). Redden (2010) later investigated temperaturetime sensitive colloid tracers for geothermal applications.

Research on the use of thermo-sensitive tracers for tracking thermal fronts and calculating thermal drawdown of geothermal reservoirs started several years ago (Tester et al., 1986; Robinson and Birdsell, 1987; Plummer, 2010). However, field tests using ethyl acetate and ethyl alcohol did not produce useful results (Kwakwa, 1988). Also, Behrens et al. (2009) suggested the differences in the breakthroughcurves of a thermo-sensitive tracer "seeing" different temperatures in the reservoir might be difficult to detect. Plummer (2010) stated that the information of a tracer test could significantly be increased if the Arrhenius parameters of the tracers can be optimally adjusted or specifically changed. Adams (1991) suggested using two different tracers with different reaction kinetics.

Due to the manifold requests of thermosensitive tracers, the suggestion of these compounds requires a thorough understanding how chemical structures of a molecule will change its thermosensitive properties as well as the detection limit, the transport behavior in the reservoir and the thermal stability of the reaction 
product. A promising molecular class is based on the naphthalene sulfonates, into which thermo-sensitive groups can be incorporated. Naphthalene sulfonates have several chemical attributes that make them desirable as geothermal tracers. They are highly water-soluble compounds, having a $\log D$ of -2.87 for 2-naphthalenesulfonate and -6.6 for 1.5-naphthalene disulfonate at neutral $\mathrm{pH}$ (calculated using SciFinder Scholar ${ }^{\mathrm{TM}}$ ). This indicates a high mobility in acquous systems. Also, naphthalene sulfonates as base-molecules, with preferred reaction products from the thermal decay of the thermo-sensitive tracers, are stable at temperatures of up to $250^{\circ} \mathrm{C}$ and higher (Rose et al., 2001), as long as no oxygen is present (Nottebohm et al., 2010). A low detection limit in geothermal brines can be achieved by high pressure liquid chromatography with fluorescence detection (Rose et al., 2002). Furthermore, naphthalene sulfonates are non-toxic (Greim et al., 1994) and their use in groundwater studies is not restricted. Therefore, naphthalene sulfonates are approved as practical tracers for geothermal applications.

The most promising thermo-sensitive groups to be incorporated in the basemolecules are chemical structures that can undergo hydrolysis. Hydrolysis is known to be highly temperature sensitive and was therefore investigated earlier for geothermal applications (Robinson and Birdsell, 1987). Also, the reaction kinetics for this reaction type can be easily controlled. Therefore, based on the promising experiences from studies done on naphthalene sulfonates as conservative tracers (Rose et al., 2001; Sanjuan et al., 2006; Ghergut et al., 2007) and from the study on hydrolysis reactions for thermo-sensitive tracers (Robinson and Birdsell, 1987), naphthalene sulfonic esters were tested in this present study to combine this benefits. The thermal reaction kinetics were determined using several phenolic esters as analogues, and structural suggestions for practical thermo-sensitive tracers can be calculated from the Arrhenius parameters given in this study with respect to the varying requirements of different test sites and test durations.

\subsection{Theoretical background}

\subsubsection{Hydrolysis as a thermosensitive reaction}

The generalized carboxylic ester hydrolysis reaction is given by:

$$
\mathrm{R}_{1} \mathrm{COOR}_{2} \stackrel{\left[\mathrm{H}_{2} \mathrm{O}\right]}{\longrightarrow} \mathrm{R}_{1} \mathrm{COOH}+\mathrm{HOR}_{2}
$$


where $\mathrm{R}_{1} \mathrm{CO}$ is the carboxylic component and $\mathrm{OR}_{2}$ is the alcoholic component of the ester. These esters are unstable in water and react irreversibly with water in a predictable way by releasing a carboxylic acid and an alcohol. As water is normally used as working fluid and therefore available in unlimited amounts in a geothermal reservoir, the reaction speed only depends on temperature and ester concentration. This makes hydrolysis a predictable thermo-sensitive reaction. However, these esters can undergo hydrolysis through alkaline and acidic catalysis resulting in a reaction speed, which additionally becomes $\mathrm{pH}$-dependent. Also, geothermal brines are naturally buffered and $\mathrm{pH}$ gradients are not expected within a single reservoir. This means, if the $\mathrm{pH}$ of the brine is constant, the reaction speed only depends on reservoir temperature. Many catalysed reactions in natural systems, especially hydrolysis, have been found to be alkali catalyzed (Schwarzenbach, 2003). The principles of the alkali catalyzed hydrolysis of esters are given in Fig. 5.1.

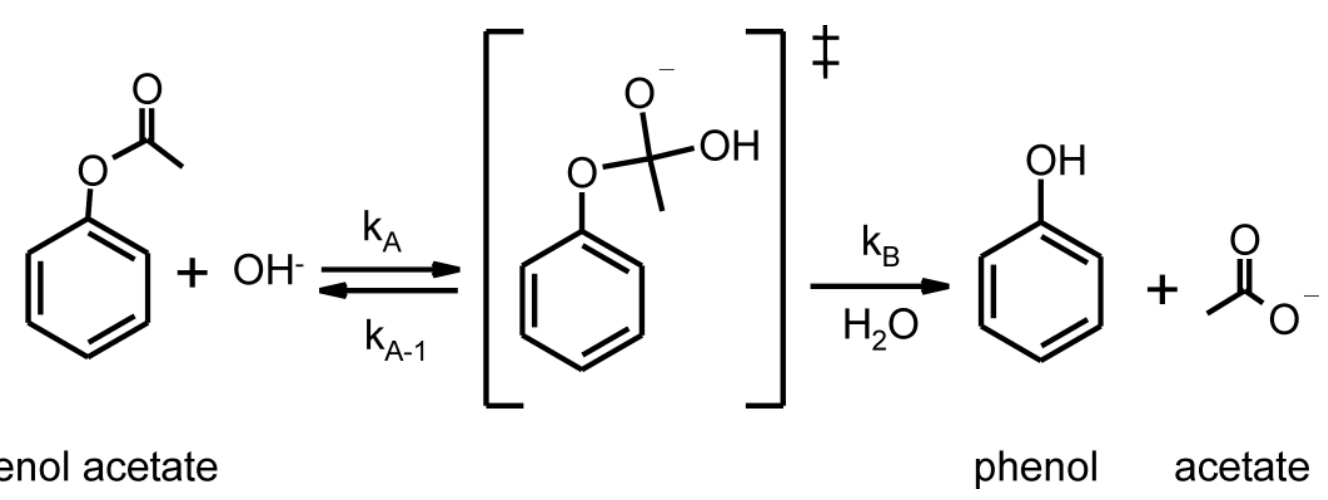

Figure 5.1: Hydrolysis reaction of phenol acetate

Beside its drawback of being $\mathrm{pH}$-dependent, this reaction mechanism forced through a transition state, commonly referred to as $\mathrm{S}_{\mathrm{N}} 2$ mechanism (Schwarzenbach, 2003), offers great potential in the molecular design of new thermo-sensitive tracers. This is because the rate determining step in the transition state is the reaction with the nucleophile $\left(\mathrm{OH}^{-}\right)$. Therefore, the molecular structure of the neighbouring groups to the ester group greatly influences the overall reaction rate of hydrolysis by sterical effects. Further, reaction rates increase with the concentration of the nucleophile in a constant and truly predictable way.

\subsubsection{Reaction kinetics}

As the formation of the transition complex is the rate-limiting step, the net reaction speed is controlled by a second order type reaction. The time law of second order reaction types can be described by the differential equation: 
The time law of second order reaction types is:

$\frac{-d[\text { Ester }]}{d t}=k_{2} \cdot[$ Ester $] \cdot[$ Catalyst $]$

where $t$ stands for the time [h] and $k_{2}$ is the second order rate constant $\left[\mathrm{L} \mathrm{mol}^{-1} \mathrm{~h}^{-1}\right]$ for the thermal decay of the ester at a given catalyst concentration.

If the concentration of the catalyst is constant or in excess of the concentration of the ester, the reaction may be described by (pseudo-) first order reaction kinetics:

$$
k_{2} \cdot[\text { Catalyst }]=k_{h}
$$

where $k_{h}\left[\mathrm{~h}^{-1}\right]$ is the observed overall hydrolysis rate constant at constant catalyst concentration.

According to Eq. (3), $k_{h}$ linearly increases with the concentration of the catalyst. Therefore, assuming only one active catalysing mechanism (alkaline catalysis by $\left.\mathrm{OH}^{-}\right), k_{h}$ should correlate linearly with $\mathrm{pH}$.

If the concentration change of the catalyst can be neglected as described in Eq. (3), the integration of Eq. (2) gives:

$\ln \left(\frac{[\text { Ester }]}{[\text { Ester }]_{0}}\right)=-k_{h} \cdot t$

The half-life in pseudo first-order reactions can be calculated from:

$t_{1 / 2}=\frac{\ln 2}{k_{h}}$

while for second order reactions, it can be calculated using $k_{h}$ from Eq. (3) in Eq. (5).

\subsubsection{Temperature dependency of reaction kinetics}

The Arrhenius law describes the temperature dependency of the reaction rate constant $k$ and is independent of the reaction order.

$k=A \cdot E^{-E a /(R \cdot T)}$ 
where $A$ is the pre-exponential factor $\left[\mathrm{h}^{-1}\right], E a$ is the activation energy $\left[\mathrm{kJ} \mathrm{mol}^{-1}\right], R$ is the universal gas constant $\left[\mathrm{kJ} \mathrm{mol}^{-1} \mathrm{~K}^{-1}\right], k$ is the reaction rate constant and $T$ is the absolute temperature $[\mathrm{K}]$. Therefore, by knowing $E a$ and $A, k$ can be predicted for all temperatures encountered in geothermal reservoirs.

\subsection{Experimental methods}

The investigations of structural influences affecting hydrolysis kinetics were conducted on the base-molecule phenol, as this compound class offers a wide variety of compounds and structural elements that can be investigated simultaneously. The effect of structural elements on the hydrolysis constants $k_{h}$ was investigated using more than 40 different molecules of phenol acetate esters. The results of structure-kinetic relationships from phenolic esters were later transferred to hydroxynaphthalene sulfonate esters.

As an example of its use as a practical thermo-sensitive tracer, a 2-ethylbutyl2-naphthol-6-sulfonate ester was synthesized and its hydrolysis constants $k_{h}$ were determined for seven different $\mathrm{pH}$ values ranging from five to eight, in contact with rock powder, and for high salinity conditions.

\subsubsection{Hydrolysis of phenolic esters}

The hydrolysis constants, $k_{h}$, of the phenol acetate esters were identified using gas chromatographic techniques utilizing a HP 6890 GC system with a HP 5972A mass selective detector from Hewlett Packard, and a solid phase micro extracting (SPME) system from CTC Analytics. Gas chromatographic techniques have many advantages compared to other analytical techniques, such as having a high precision, high selectivity, and a high reproducibility of the results. Also, it is possible to detect many analytes simultaneously. Furthermore, this technique is able to separate and detect very similar analytes such as (position-) isomers. Due to these benefits, it is possible to qualify small changes in reaction kinetics and the influence of different functional groups and positions of additional groups. These experiments are vital steps for suggesting suitable thermo-sensitive substances with respect to the special thermal conditions of different geothermal reservoirs. Also, the influence of $\mathrm{pH}$ and different leaving carboxyl groups on reaction kinetics was studied on the example of five different phenolic esters. The investigated character of phenolic ester hydrolysis is given in Fig. 5.1. 
For sample preparation, $150 \mathrm{mg} \mathrm{NaHCO}$ was added to $1 \mathrm{ml}$ of a $12.5 \mu \mathrm{g} / \mathrm{L}$ standard mix that included all analytes. Then, the phenols were esterified by adding $50 \mu$ of acetic anhydride. The final $\mathrm{pH}$ in this solution was 7.1. A complete esterification of all phenols was achieved.

For room temperature experiments, a set of samples was prepared initially and then every 12 hours one sample was measured. With this schedule, at least 4 data points within 168 hours of preparation for the decrease in concentration were obtained for every compound in the consecutive determination of the hydrolysis constant $k_{h}$.

The measurements at elevated temperatures were carried out by heating the samples within the autosampler of the GC. The hydrolysis constants $k_{h}$ of every compound were measured at 50,60, and $70{ }^{\circ} \mathrm{C}$ to determine the Arrhenius parameters $E a$ and $A$ from the Arrhenius plot. Using this temperatures, a significant decrease in concentration could be investigated for all substances within two weeks and the sensitivity and accuracy of the GC method was not affected.

The hydrolysis constant $k_{h}$ was determined by plotting the time on the x-axis and the logarithmic concentration of the ester on the y-axis. According to Eq. (4), the slope of the linear partial regression line is $k_{h}$ for concentrations down to approximately. $10 \%$ of the initial concentration.

Also, the Arrhenius parameters $E_{a}$ and $A$ of several phenolic esters at three different $\mathrm{pH}$ values ranging from $\mathrm{pH} 6$ to 8 were also investigated. The selected esters for this test were phenol acetate, o-cresol acetate, 2-ethylphenol acetate, phenyl benzoate, and phenyl propionate. To identify the hydrolysis constants $k_{h}$, these experiments were conducted by the method of different initial concentrations. Within these experiments, four samples with different initial ester concentrations were prepared by adding a subsequent volume of ester standard to $4 \mathrm{ml}$ buffer solution containing $2 \mathrm{~g} / \mathrm{L}$ phosphate buffer in $5 \mathrm{ml}$ glass vials for every investigated $\mathrm{pH}$. The vials were incubated in a temperature-controlled oven at the temperature of investigation. After sufficient hydrolysis time of approximately one half-life, the samples were cooled down in icy water and the hydrolysis product phenols were measured immediately using a Cary Eclipse 50 fluorescence spectrometer from Varian. The hydrolysis constant $k_{h}$ was calculated by plotting the initial concentration of the ester versus the concentration at constant and identical reaction time $t$ using a linear regression, $y=a x$. According to Eq. (4), $a=e^{-k h t}$. 


\subsubsection{Hydrolysis of hydroxynaphthalene sulfonic esters}

In order to achieve the lowest possible detection limit of the reactive tracer, several hydroxynaphthalene sulfonates were investigated with respect to their fluorescence. From these substances 2-hydroxy-6-naphthalene sulfonate showed the lowest detection limit and was therefore chosen as the reaction product (Table 5.1). The limit of detection is $5 \mu \mathrm{g} / \mathrm{L}$ with direct fluorescence and $<1 \mu \mathrm{g} / \mathrm{L}$ with high pressure liquid chromatography using fluorescence detection. Furthermore, the esters formed with the hydroxyl groups of these compounds are not fluorescing and therefore not affecting the fluorescent detection of the hydrolysis products.

Table 5.1: Fluorescence intensity for six naphthol sulfonates and two naphthol disulfonates. Abbr.: Conc. = concentration, Ex.: Extinction maximum, Em.: Emission maximum, xol: Position of the hydroxy group, xsulf.: Position of the sulfonate group

\begin{tabular}{ccccc}
\hline Substance & $\begin{array}{c}\text { Conc. } \\
\text { [ } \mathbf{~ g ~ L}^{-\mathbf{1}} \text { ] }\end{array}$ & $\begin{array}{c}\text { Ex. } \\
\text { [nm] }\end{array}$ & $\begin{array}{c}\text { Em. } \\
{[\mathbf{n m}]}\end{array}$ & $\begin{array}{c}\text { Intensity } \\
\text { [a.u.] }\end{array}$ \\
\hline 1ol3sulf & 100 & 230 & 460 & 120 \\
1ol4sulf & 100 & 230 & 430 & 145 \\
1ol5sulf & 2000 & 340 & 530 & 310 \\
1ol8sulf & 2000 & 340 & 440 & 40 \\
2ol6sulf & 100 & 230 & 430 & 170 \\
2ol7sulf & 100 & 230 & 460 & 70 \\
1ol36disulf & 2000 & 340 & 480 & 420 \\
2ol36disulf & 100 & 235 & 470 & 195 \\
\hline
\end{tabular}

\subsection{2.a Synthesis and purifying of naphthalene sulfonic esters}

The synthesis of the hydroxynaphthalene sulfonic esters was conducted by the Schotten-Baumann method (Einhorn variation): $10 \mathrm{~g}$ of 2-naphthol-6-sulfonate potassium salt were dissolved in $175 \mathrm{ml}$ of dimethyl formamide. Afterwards, $31 \mathrm{ml}$ of pyridine and $30 \mathrm{ml}$ of 2-ethylbutyric chloride were added. For esterification, this solution was stirred for $10 \mathrm{~h}$ at $90{ }^{\circ} \mathrm{C}$ in an oil bath by using a Dimroth condenser. Within all the steps, the system was kept under an argon atmosphere to ensure high yields.

For purification, the resulting solution was separated by column chromatography and the resulting different fractions were investigated by thin-layer chromatography (silica gel) with respect to their relative purity. A primary eluent of pure ethyl acetate was used and then switched to acetone, ethyl acetate, and water 
(50:38:12, v:v:v). Different fractions were collected and washed with toluene. Afterwards the solutions were concentrated by evaporation using a rotary evaporator. LC/MS measurements of the purest fraction confirmed a purity of $>95 \%$.

\subsection{2.b Stability tests}

The investigation of $k_{h}$ of the hydroxynaphthalene sulfonate ester, where the hydroxyl group is esterified and the sulfonic group is ionic (Fig. 5.2), was conducted by the method of different initial concentrations as described in Section 3.1. The character of the reaction is given in Fig. 2. For the calculation of the Arrhenius parameters $E a$ and $A, k_{h}$ was determined at four different temperatures, ranging from 80 to $100^{\circ} \mathrm{C}$, and at seven different $\mathrm{pH}$ values, ranging from 5.0 to 8.0 . The samples were prepared in the same way as described in Section 3.1. For the experiments under the presence of rock material or salinity, $1 \mathrm{~g}$ of pulverized typical reservoir rock (red sandstone) was added to the sample and the respective buffer solution was prepared with the addition of $100 \mathrm{~g} / \mathrm{L} \mathrm{NaCl}$. The first order hydrolysis constants $k_{h}$ and the Arrhenius parameters Ea and $A$ were determined for each $\mathrm{pH}$. For the calculation of the second order rate constants, the respective $\mathrm{OH}^{-}$ concentration at the specific temperature and $\mathrm{pH}$ was calculated using PHREEQC version 2.13.04. Then, $k_{2}$ was calculated by Eq. (3) from $k_{h}$ and $\left[\mathrm{OH}^{-}\right]$.

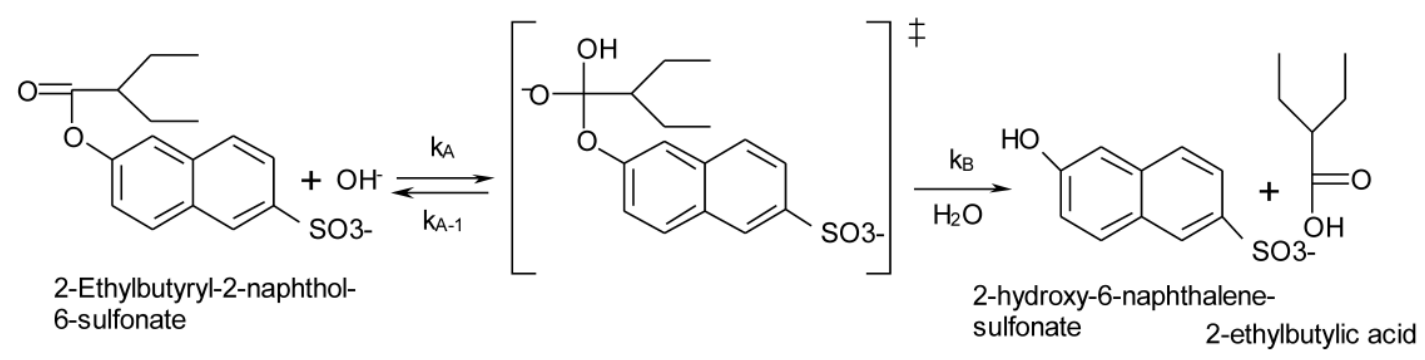

Figure 5.2: Hydrolysis reaction of 2-ethylbutyryl-2-napthol-6-sulfonate

\subsection{Results and discussion}

\subsubsection{Hydrolysis of phenolic esters as acetates}

The ambient temperature experiments of the phenol acetates show a strong relationship between the $\mathrm{pK}_{\mathrm{a}}$ of the phenolic reaction product and the respective reaction kinetics. This correlation is linear for at least three groups of substances (Fig. 5.3) and covers a range of four units of hydrolysis constants $k_{h}$ with increasing 
$\mathrm{pK}_{\mathrm{a}}$ by three units. That implies Hammet's law is valid for this kind of reaction. The esters located within the same group have several similarities concerning their molecular structures. In the first group of compounds (sterically doubly hindered), the reactive ester group is protected from both sides with a chlorine atom or an alkyl group (acetates from: 2,6-dichlorophenol, 2,4,6-trichlorophenol, 2,3,6-trichlorophenol, 2,3,4,6-tetrachlorophenol, 2,3,5,6-tetrachlorophenol, pentachlorophenol, 2,6-dimethylphenol, 2,4,6-trimethylphenol, and 2,3,6-trimethylphenol). The reactive group of the second group of esters is protected only from one side by a chlorine atom or an alkyl group (acetates from: 2,3,4,5-tetrachlorophenol, 2,3,5-trichlorophenol, 2,3,4-trichlorophenol, 2,4,5-trichlorophenol, 2,3-dichlorophenol, 2,4/2,5-dichlorophenol, 2-chlorophenol, 2-propylphenol, 2,5-dimethylphenol, 2,4-dimethylphenol, 2-n-propylphenol, 2-isopropylphenol, 2,3,5-trimethylphenol, 2-ethylphenol 3,5-dimethylphenol, and 3,4-dimethylphenol). The third group consists of esters with no sterical hindrance (acetates from: 3,4,5-trichlorophenol 3,4-dichlorophenol, 3,5-dichlorophenol, 3-chlorophenol, and 4-chlorophenol, phenol, 4iso-propylphenol, 4n-propylphenol, 3iso-propylphenol, 3n-propylphenol, 3-ethylphenol, and p-cresol). It is remarkable that 1-Napthol acetate plots on the same regression line as the non-sterically hindered phenolic esters, thus making the concept transferable to a wider range of compounds.

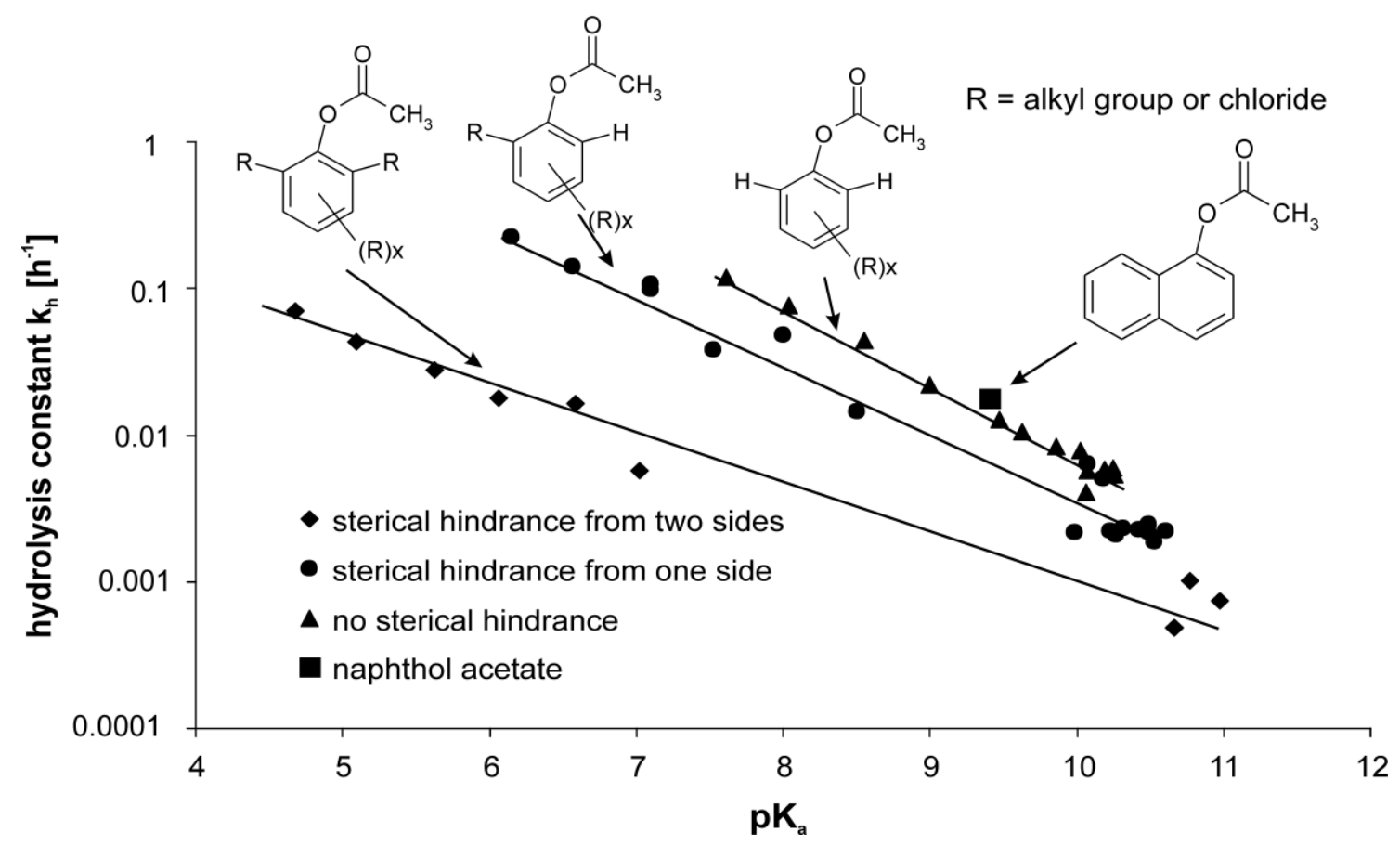

Figure 5.3: Linear relationship of the acid constant $p K_{a}$ of the phenol acetates versus hydrolysis constant $k$ at $25^{\circ} \mathrm{C}$ 
Mesomeric and inductive effects on the reaction rate were also investigated. Additional groups having negative inductive effects, such as chloride result in a higher electron density in the aromatic ring. The result is a lower $\mathrm{pK}_{a}$ of the phenolic reaction product (Table 5.2). As the $\mathrm{pK}_{\mathrm{a}}$ of the phenolic substructure in the ester is a dominant control factor of the reaction speed (Fig. 5.3), the reaction rates of chlorophenol acetates are naturally higher. Concurrently, additional groups that have a positive inductive effect, such as methyl, lead to slower hydrolysis rates. By increasing the number of substituents, this effect is intensified.

Table 5.2: Arrhenius parameters and calculated half-life for $30^{\circ} \mathrm{C}$ and $110^{\circ} \mathrm{C}$ for 42 phenolic esters. Abbreviations (all as esters): DMP: dimethylphenol, TMP: trimethylphenol, EP: ethylphenol, PP: propylphenol, Cre: cresol, CP: chlorophenol, DCP: dichlorophenol, TrCP: trichlorophenol, TeCP: tetrachlorophenol, PCP: pentachlorophenol, $\mathbf{p K}_{\mathrm{a}}$ values were calculated using SciFinder Scholar ${ }^{\mathrm{TM}}$

\begin{tabular}{|c|c|c|c|c|c|c|c|}
\hline Substance & $\mathbf{p K} \mathbf{K}_{\mathbf{a}}$ & $\begin{array}{c}\text { Ea } \\
{\left[\mathrm{kJ} \mathrm{mol}^{-1}\right]}\end{array}$ & $\begin{array}{c}\operatorname{In} A \\
{\left[h^{-1}\right]}\end{array}$ & $\begin{array}{c}\text { Ea/A } \\
\text { [kJ mol h] }\end{array}$ & $\begin{array}{c}t_{1 / 2} \text { at } \\
30^{\circ} \mathrm{C}[\mathrm{h}]\end{array}$ & $\begin{array}{c}t_{1 / 2} \text { at } \\
110^{\circ} \mathrm{C}[\mathrm{h}]\end{array}$ & $\begin{array}{c}k_{h} \text { at } 25^{\circ} \mathrm{C} \\
{\left[h^{-1}\right]}\end{array}$ \\
\hline PCP & 4.7 & 61.9 & 22.3 & $6.3 \times 10^{-6}$ & 8.9 & 0.05 & 0.108 \\
\hline $2,3,4,5 \mathrm{TeCP}$ & 6.2 & 58.4 & 21.4 & $1.2 \times 10^{-4}$ & 5.4 & 0.04 & 0.224 \\
\hline $2,3,5,6 \mathrm{TeCP}$ & 5.1 & 72.2 & 25.9 & $8.0 \times 10^{-4}$ & 15.0 & 0.03 & 0.0436 \\
\hline $2,3,4,6 \mathrm{TeCP}$ & 5.6 & 80.5 & 28.8 & $2.2 \times 10^{-3}$ & 23.9 & 0.03 & 0.0277 \\
\hline 2345TeCP & 6.2 & 58.4 & 21.4 & $1.2 \times 10^{-4}$ & 5.4 & 0.04 & 0.224 \\
\hline $3,4,5 \operatorname{TrCP}$ & 7.6 & 71.1 & 25.9 & $2.5 \times 10^{-4}$ & 9.8 & 0.02 & 0.120 \\
\hline $2,4,5 \operatorname{TrCP}$ & 7.1 & 71.8 & 26.1 & $9.8 \times 10^{-4}$ & 10.0 & 0.02 & 0.108 \\
\hline $2,3,4 \operatorname{TrCP}$ & 7.1 & 72.6 & 26.4 & $4.8 \times 10^{-3}$ & 10.8 & 0.02 & 0.0978 \\
\hline $2,3,5 \operatorname{TrCP}$ & 6.6 & 71.3 & 26.0 & $2.3 \times 10^{-4}$ & 9.1 & 0.02 & 0.140 \\
\hline $2,4,6 \operatorname{TrCP}$ & 6.6 & 79.9 & 27.9 & $1.9 \times 10^{-3}$ & 41.7 & 0.05 & 0.0164 \\
\hline $2,3,6 \operatorname{TrCP}$ & 6.1 & 82.7 & 29.2 & $8.4 \times 10^{-3}$ & 37.6 & 0.04 & 0.0179 \\
\hline $3,4 \mathrm{DCP}$ & 8.6 & 81.5 & 29.4 & $3.9 \times 10^{-3}$ & 18.8 & 0.02 & 0.0440 \\
\hline $2,4 / 2,5 \mathrm{DCP}$ & 8.0 & 82.6 & 29.8 & $9.4 \times 10^{-3}$ & 18.4 & 0.02 & 0.0484 \\
\hline $2,3 \mathrm{DCP}$ & 7.5 & 87.1 & 31.4 & $6.3 \times 10^{0}$ & 22.9 & 0.01 & 0.0378 \\
\hline $2,6 \mathrm{DCP}$ & 7.0 & 95.7 & 33.3 & $2.8 \times 10^{1}$ & 109.5 & 0.03 & 0.00568 \\
\hline $3 \mathrm{CP}$ & 9.0 & 88.5 & 31.4 & $7.1 \times 10^{0}$ & 42.2 & 0.02 & 0.0218 \\
\hline $4 \mathrm{CP}$ & 9.5 & 89.3 & 31.6 & $1.4 \times 10^{0}$ & 47.7 & 0.03 & 0.0127 \\
\hline $2 \mathrm{CP}$ & 8.5 & 93.3 & 33.0 & $5.4 \times 10^{1}$ & 56.4 & 0.02 & 0.0146 \\
\hline 3.4.5TMP & 10.5 & 93.3 & 31.8 & $5.2 \times 10^{-2}$ & 187.0 & 0.07 & 0.00394 \\
\hline
\end{tabular}




\begin{tabular}{|c|c|c|c|c|c|c|c|}
\hline 2.3.5TMP & 10.5 & 87.4 & 28.8 & $1.2 \times 10^{-2}$ & 370.0 & 0.23 & 0.00185 \\
\hline 2.3.6TMP & 10.8 & 65.6 & 19.4 & $6.3 \times 10^{-3}$ & 690.2 & 2.73 & 0.00101 \\
\hline 2.4.6TMP & 11.0 & 77.5 & 24.3 & $4.6 \times 10^{-5}$ & 621.4 & 0.90 & 0.000744 \\
\hline 3.5DMP & 10.2 & 91.2 & 31.3 & $3.7 \times 10^{-2}$ & 139.4 & 0.06 & 0.00508 \\
\hline 3.4DMP & 10.2 & 92.3 & 31.7 & $1.3 \times 10^{-1}$ & 140.6 & 0.06 & 0.00221 \\
\hline 2.5DMP & 10.4 & 85.6 & 28.1 & $3.5 \times 10^{-2}$ & 353.5 & 0.26 & 0.00224 \\
\hline 2.4DMP & 10.6 & 87.6 & 28.9 & $1.8 \times 10^{-2}$ & 340.1 & 0.21 & 0.00222 \\
\hline 2.6DMP & 10.7 & 72.4 & 21.8 & $4.0 \times 10^{-4}$ & 937.7 & 2.09 & 0.000486 \\
\hline $3 n P P$ & 10.1 & 91.5 & 31.2 & $7.3 \times 10^{-3}$ & 175.5 & 0.08 & 0.00567 \\
\hline 3iPP & 10.0 & 85.2 & 28.9 & $3.5 \times 10^{-1}$ & 136.8 & 0.10 & 0.00786 \\
\hline $4 \mathrm{iPP}$ & 10.2 & 89.8 & 30.4 & $5.5 \times 10^{-2}$ & 178.0 & 0.09 & 0.00590 \\
\hline 2iPP & 10.5 & 79.4 & 25.6 & $3.1 \times 10^{-3}$ & 358.6 & 0.44 & 0.00422 \\
\hline $2 n P P$ & 10.5 & 81.5 & 26.4 & $1.4 \times 10^{-3}$ & 351.6 & 0.36 & 0.00219 \\
\hline $3 E P$ & 10.1 & 86.3 & 28.8 & $5.4 \times 10^{-2}$ & 233.3 & 0.08 & 0.00405 \\
\hline 4EP & 10.3 & 86.9 & 29.7 & $5.4 \times 10^{-2}$ & 115.8 & 0.08 & 0.00592 \\
\hline $2 \mathrm{EP}$ & 10.3 & 81.7 & 26.4 & $2.1 \times 10^{-4}$ & 383.8 & 0.39 & 0.00207 \\
\hline m-Kre & 10.1 & 97.0 & 33.5 & $6.5 \times 10^{-2}$ & 154.8 & 0.04 & 0.00642 \\
\hline p-Kre & 10.3 & 99.6 & 34.5 & $1.2 \times 10^{-1}$ & 164.6 & 0.04 & 0.00535 \\
\hline o-Kre & 10.3 & 91.8 & 30,7 & $3.5 \times 10^{-2}$ & 307.5 & 0.13 & 0.00232 \\
\hline $4 \mathrm{Cl}-3-\mathrm{Cre}$ & 9.6 & 91.1 & 31.7 & $5.3 \times 10^{-1}$ & 81.8 & 0.04 & 0.0106 \\
\hline 2PhenylP & 10.0 & 100.0 & 33.8 & $3.3 \times 10^{-1}$ & 363.8 & 0.08 & 0.00218 \\
\hline Phenol & 9.9 & 96.4 & 33.6 & $1.2 \times 10^{0}$ & 113.2 & 0.03 & 0.00834 \\
\hline Naphthol & 9.4 & 53.9 & 17.5 & $1.1 \times 10^{-5}$ & 42.4 & 0.45 & 0.0179 \\
\hline
\end{tabular}

The sterical hindrance effect of the alkyl chain length next to the reacting group shows only small influences on reaction kinetics. This can be studied by comparing the acetate esters of 2n-propylphenol, 2i-propylphenol, 2-ethylphenol, and ocresol. For these substances, the calculated half-life ranges from 307 to $383 \mathrm{~h}$ at $30^{\circ} \mathrm{C}$. Varying the number of the substituents next to the reactive group, the effect on the half-life is clearly pronounced. Therefore, 2,6-dimethylphenol acetate is much more stable than the respective ester of 2,5-dimethylphenol and 2,3,6dimethylphenol acetate is more stable than 2,3,5-trimethylphenol acetate. 


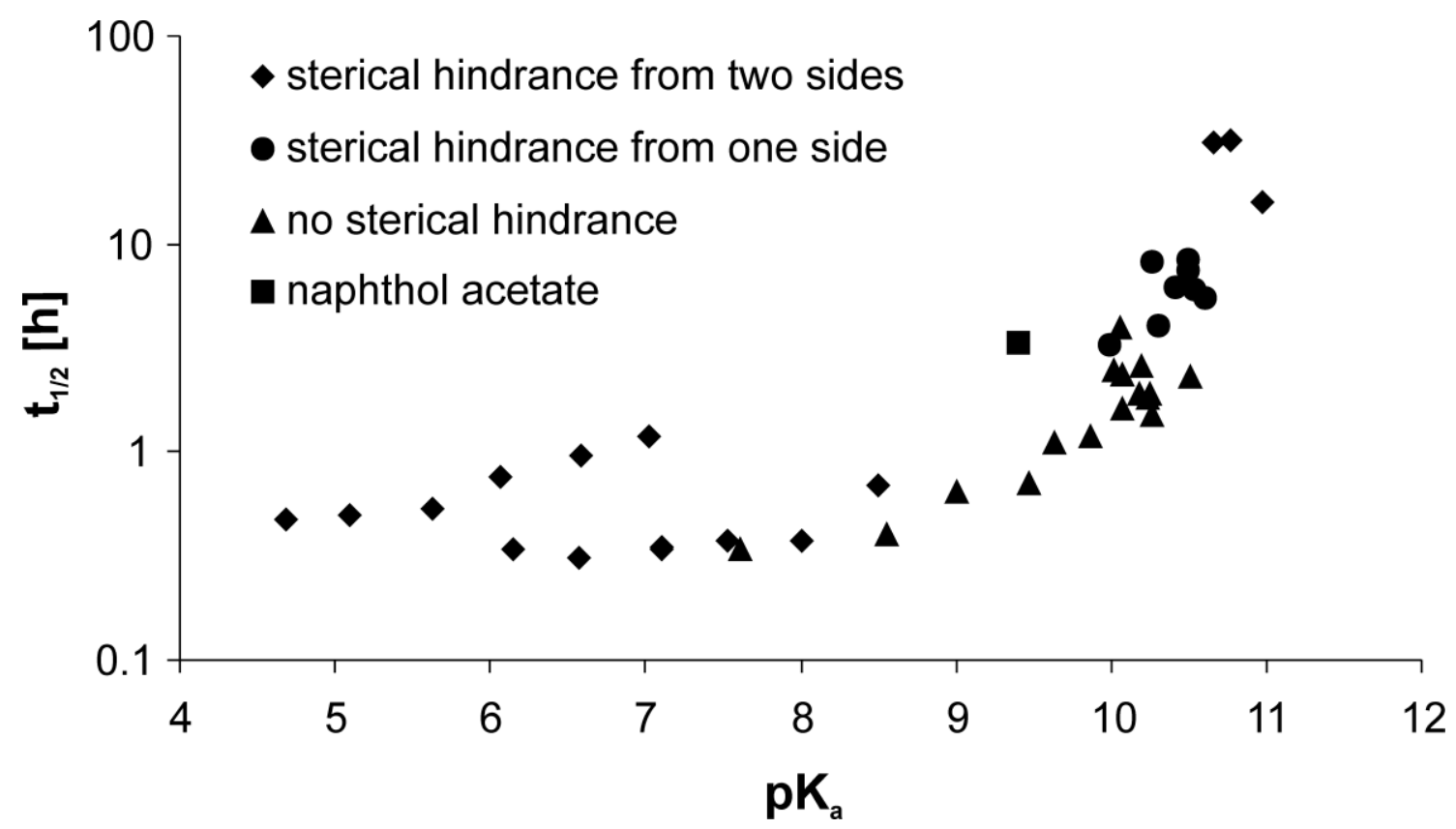

Figure 5.4: $p K_{a}$ of the phenolic reaction product versus half-life of 44 phenol acetate esters at $80^{\circ} \mathrm{C}$, calculated from Arrhenius parameters

For the experiments at elevated temperatures, results indicate that the mechanisms influencing the reaction kinetics at elevated temperatures are almost the same as for room temperature. There is a strong relationship between $\mathrm{pK}_{\mathrm{a}}$ of the reaction product and the half-life (Fig. 5.4). Also, the mechanisms between sterical hindrance and mesomeric and inductive effects are similar.

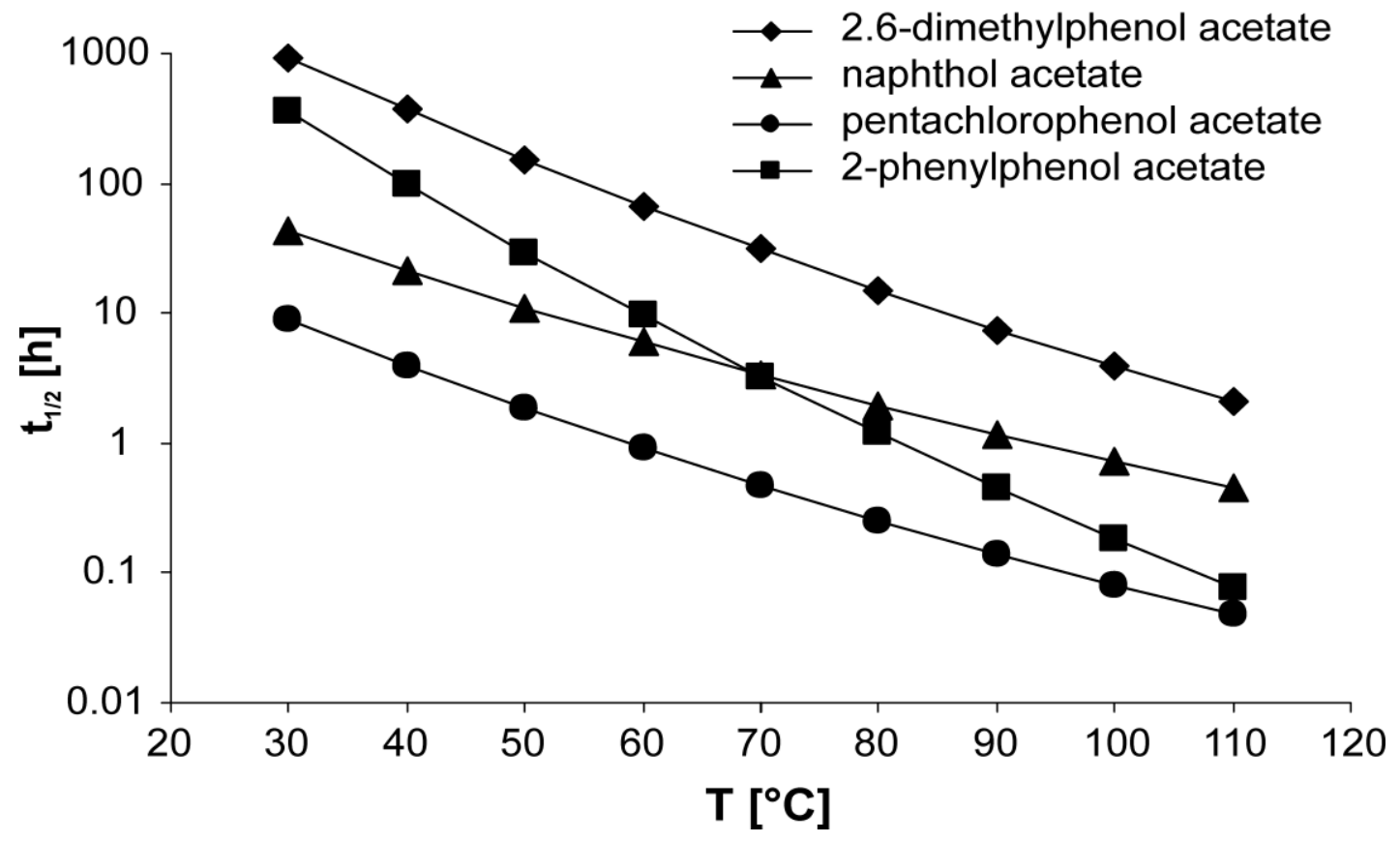

Figure 5.5: Half-life versus temperature for the acetates of 2.6-dimethylphenol, naphthol, pentachlorophenol, and 2-phenylphenol 
All of the substances show a strong sensitivity of the reaction kinetics on temperature. Half-life decreases, on average, three to four orders of magnitude when raising the temperature from 30 to $110{ }^{\circ} \mathrm{C}$ (Table 5.2). This highlights their potential to be used as thermo-sensitive tracers. Depending on the Ea and $A$ values, there are variations in the decrease of half-life with temperature. An example of some selected substances is given in Fig. 5.5. Also, there is a linear relationship between $E a$ and $A$ for substances with the same basic structure. In this case, the chlorophenol acetates and the alkylphenol acetates, each plot on their own regression lines (Fig. 5.6). This empiric enthalpy-entropy relationship is well known under several names, for example as the Barkley-Butler rule (Liu and Guo, 2001).

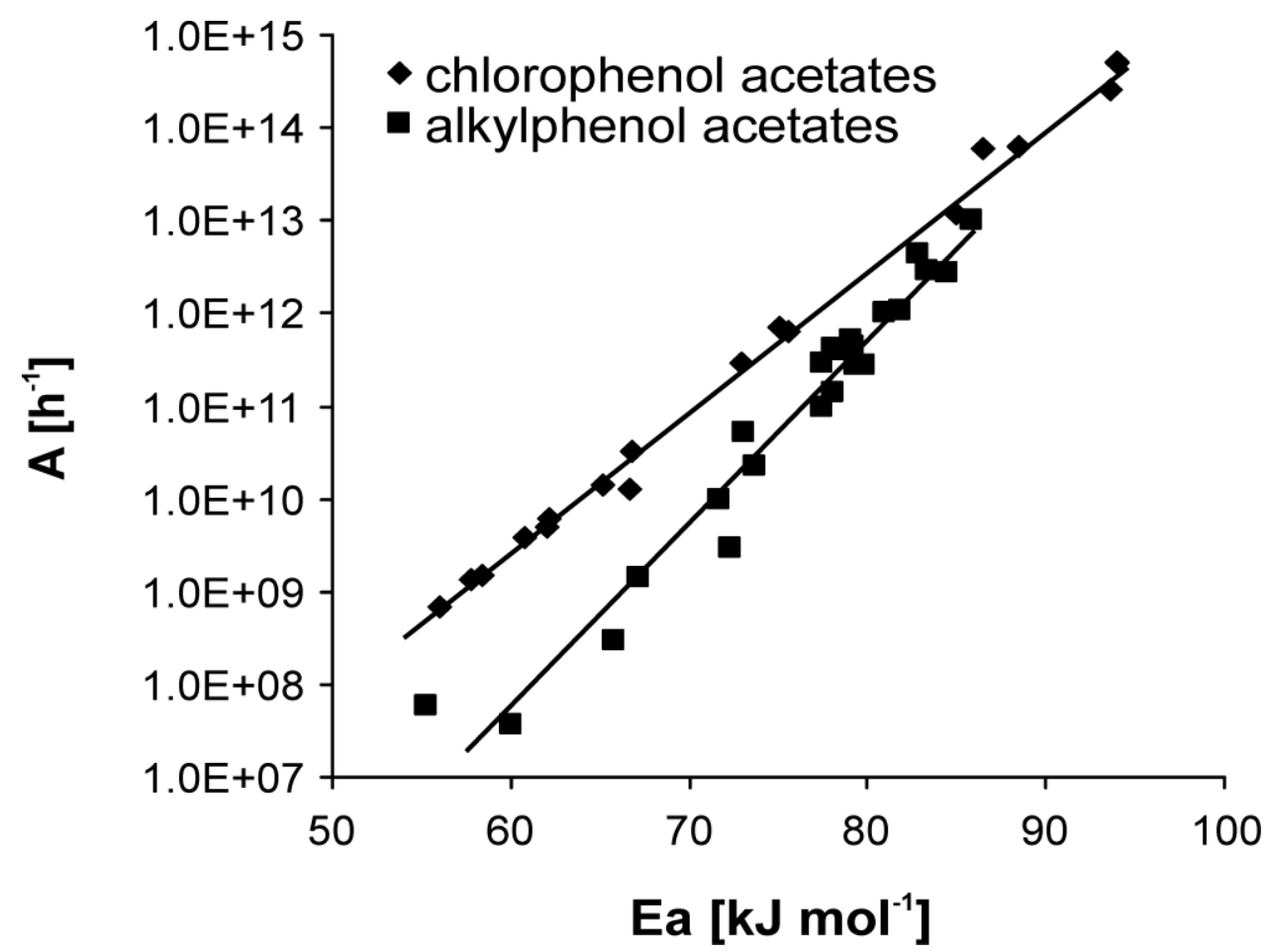

Figure 5.6: Activation energy Ea versus pre-exponential factor $A$ for the acetates of chlorophenols and alkylphenols

For the experiments investigating the influence of $\mathrm{pH}$ and the availability of a catalyst to form the transition complex, the reaction is almost fully catalyzed by the $\mathrm{OH}^{-}$concentration. This results in a decrease of half-life approximately by a factor of 10 when increasing the $\mathrm{pH}$ by one unit (Table 5.3). Also, the findings of the sterical-hindering effects as described before could be confirmed, showing that o-cresol acetate is more stable than phenol acetate, and 2-ethylphenol acetate is more stable than o-cresol acetate. The influence of varying the leaving carboxyl groups is comparatively low for the investigated substances. But it can be clearly 
seen that longer carbon chains or groups with higher molecular weight have a significant influence on reaction kinetics (Table 5.3). Due to this fact, phenyl propionate is more stable than phenyl acetate and less stable than phenyl benzoate.

Table 5.3: Arrhenius parameters and half-lives at $100{ }^{\circ} \mathrm{C}$ for $\mathrm{pH} 6,7$, and 8 of different phenol acetates

\begin{tabular}{|c|c|c|c|c|c|c|c|c|c|}
\hline \multirow[b]{2}{*}{ Substance } & \multicolumn{3}{|c|}{ pH 6} & \multicolumn{3}{|c|}{ pH 7} & \multicolumn{3}{|c|}{ pH 8} \\
\hline & $\begin{array}{l}\mathrm{Ea}[\mathrm{kJ} \\
\left.\mathrm{mol}^{-1}\right]\end{array}$ & $\begin{array}{l}\text { In A } \\
{\left[h^{-1}\right]}\end{array}$ & $\begin{array}{c}t_{1 / 2} \text { at } \\
100{ }^{\circ} \mathrm{C} \\
{[\mathrm{h}]}\end{array}$ & $\begin{array}{l}\mathrm{Ea}[\mathrm{kJ} \\
\left.\mathrm{mol}^{-1}\right]\end{array}$ & $\begin{array}{l}\text { In } A \\
{\left[h^{-1}\right]}\end{array}$ & $\begin{array}{c}t_{1 / 2} \text { at } \\
100{ }^{\circ} \mathrm{C} \\
{[\mathrm{h}]}\end{array}$ & $\begin{array}{l}\mathrm{Ea}[\mathrm{kJ} \\
\left.\mathrm{mol}^{-1}\right]\end{array}$ & $\begin{array}{l}\operatorname{In} A \\
{\left[h^{-1}\right]}\end{array}$ & $\begin{array}{c}t_{1 / 2} \text { at } \\
100{ }^{\circ} \mathrm{C} \\
{[\mathrm{h}]}\end{array}$ \\
\hline $\begin{array}{l}\text { o-cresol } \\
\text { acetate }\end{array}$ & 79.5 & 22.7 & 13.1 & 90.7 & 28.8 & 1.1 & 90.5 & 30.8 & 0.1 \\
\hline $\begin{array}{c}\text { phenyl } \\
\text { benzoate }\end{array}$ & 104.5 & 31.2 & 8.5 & 79.0 & 24.0 & 3.0 & 102.1 & 34.7 & 0.1 \\
\hline $\begin{array}{l}\text { phenol } \\
\text { acetate }\end{array}$ & 78.0 & 22.9 & 6.5 & 77.0 & 25.5 & 0.4 & 97.5 & 34.2 & 0.1 \\
\hline $\begin{array}{l}\text { 2- } \\
\text { ethylphenol } \\
\text { acetate }\end{array}$ & 77.9 & 21.9 & 16.7 & 84.4 & 26.1 & 2.0 & 88.7 & 29.8 & 0.2 \\
\hline $\begin{array}{c}\text { phenyl } \\
\text { propionate }\end{array}$ & 77.5 & 22.7 & 7.3 & 85.6 & 27.6 & 0.7 & 85.6 & 29.6 & 0.1 \\
\hline
\end{tabular}

\subsubsection{Hydrolysis of hydroxynaphthalene sulfonic esters}

The reaction kinetics of the 2-ethylbutyl-2-naphthol-6-sulfonate ester shows a strong connection to the $\mathrm{pH}$ of the solution. The half-life calculated from the Arrhenius parameters $E a$ and $A$ increases from $4 \mathrm{~h}$ at $100^{\circ} \mathrm{C}$ and $\mathrm{pH} 8$ to $500 \mathrm{~h}$ at $100^{\circ} \mathrm{C}$ and $\mathrm{pH} 5$ in buffer with no additional $\mathrm{NaCl}$ (Table 5.4). Additives consisting of a highly salty matrix of $100 \mathrm{~g} / \mathrm{L} \mathrm{NaCl}$ and/or rock of powdered sandstone showed no significant effect (Fig. 5.7) on the hydrolysis. 
Table 5.4: Arrhenius parameters and half-life of the 2-ethylbutyryl-2-naphthol6-sulfonate ester at different $\mathrm{pH}$.

\begin{tabular}{|c|c|c|c|c|c|c|}
\hline $\begin{array}{l}\text { pH at } \\
25^{\circ} \mathrm{C}\end{array}$ & $\begin{array}{c}A \\
{\left[h^{-1}\right]}\end{array}$ & $\begin{array}{l}\mathrm{EA}[\mathrm{kJ} \\
\left.\mathrm{mol}^{-1}\right]\end{array}$ & $\begin{array}{c}{\left[\mathrm{OH}^{-}\right] \text {at }} \\
100{ }^{\circ} \mathrm{C} \\
{\left[\mathrm{mol} \mathrm{L}^{-1}\right]}\end{array}$ & $\begin{array}{c}t_{1 / 2}[\mathrm{~h}] \text { at } \\
100{ }^{\circ} \mathrm{C} \text { calc. } \\
\text { from } k_{2}\end{array}$ & $\begin{array}{c}t_{1 / 2}[\mathrm{~h}] \text { at } \\
100{ }^{\circ} \mathrm{C} \\
\text { measured }\end{array}$ & $\begin{array}{c}t_{1 / 2}[\mathrm{~h}] \text { at } \\
100^{\circ} \mathrm{C} \mathrm{calc} . \\
\text { from } k_{h}\end{array}$ \\
\hline 5.0 & $3.67 \times 10^{+1}$ & 53.1 & $4.35 \times 10^{-8}$ & 1895.5 & 495.2 & 525.7 \\
\hline 5.5 & $2.60 \times 10^{+1}$ & 67.0 & $1.29 \times 10^{-7}$ & 639.2 & 320.8 & 279.7 \\
\hline 6.0 & $5.89 \times 10^{+3}$ & 88.2 & $4.05 \times 10^{-7}$ & 203.6 & 124.2 & 109.6 \\
\hline 6.5 & $1.5 \times 10^{+7}$ & 114.9 & $1.28 \times 10^{-6}$ & 64.4 & 70.5 & 41.9 \\
\hline 7.0 & $5.61 \times 10^{+9}$ & 136.1 & $4.11 \times 10^{-6}$ & 20.1 & 27.0 & 20.4 \\
\hline 7.5 & $6.53 \times 10^{+6}$ & 118.1 & $1.30 \times 10^{-5}$ & 6.3 & 5.9 & 4.9 \\
\hline 8.0 & $4.22 \times 10^{+5}$ & 111.5 & $3.92 \times 10^{-5}$ & 2.1 & 3.9 & 4.0 \\
\hline $\begin{array}{l}\text { pH at } \\
25^{\circ} \mathrm{C}\end{array}$ & $\begin{array}{c}A \\
{\left[h^{-1}\right]}\end{array}$ & $\begin{array}{l}\mathrm{EA}[\mathrm{kJ} \\
\left.\mathrm{mol}^{-1}\right]\end{array}$ & $\begin{array}{c}{\left[\mathrm{OH}^{-}\right] \text {at }} \\
80{ }^{\circ} \mathrm{C} \\
{\left[\mathrm{mol} \mathrm{L}^{-1}\right]}\end{array}$ & $\begin{array}{c}t_{1 / 2}[h] \text { at } \\
80{ }^{\circ} \mathrm{C} \text { calc. } \\
\text { from } k_{2}\end{array}$ & $\begin{array}{c}\mathrm{t}_{1 / 2}[\mathrm{~h}] \text { at } 80^{\circ} \mathrm{C} \\
\text { measured }\end{array}$ & $\begin{array}{c}t_{1 / 2}[\mathrm{~h}] \text { at } \\
80^{\circ} \mathrm{C} \text { calc. } \\
\text { from } k_{h}\end{array}$ \\
\hline 5.0 & $3.67 \times 10^{+1}$ & 53.1 & $2.09 \times 10^{-8}$ & 17297.8 & 5636.6 & 4032.1 \\
\hline 5.5 & $2.60 \times 10^{+1}$ & 67.0 & $6.33 \times 10^{-8}$ & 5733.0 & 3635.9 & 2417.7 \\
\hline 6.0 & $5.89 \times 10^{+3}$ & 88.2 & $1.99 \times 10^{-7}$ & 1819.5 & 1767.0 & 1317.9 \\
\hline 6.5 & $1.5 \times 10^{+7}$ & 114.9 & $6.32 \times 10^{-7}$ & 571.6 & 636.4 & 341.5 \\
\hline 7.0 & $5.61 \times 10^{+9}$ & 136.1 & $2.02 \times 10^{-6}$ & 178.7 & 125.7 & 102.1 \\
\hline 7.5 & $6.53 \times 10^{+6}$ & 118.1 & $6.44 \times 10^{-6}$ & 56.1 & 38.0 & 16.7 \\
\hline 8.0 & $4.22 \times 10^{+5}$ & 111.5 & $2.00 \times 10^{-5}$ & 18.1 & 21.9 & 10.5 \\
\hline
\end{tabular}

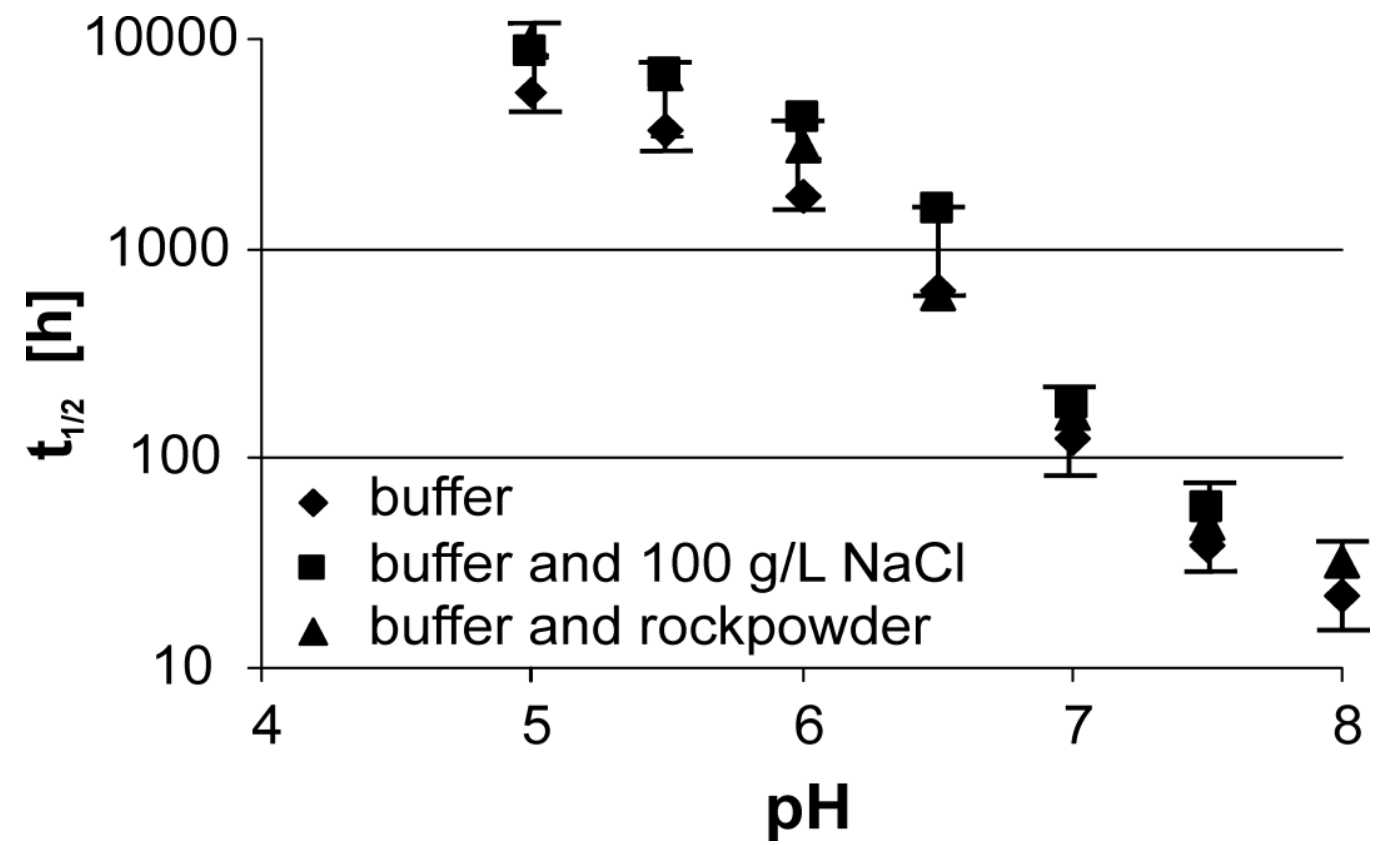

Figure 5.7: Half-life of the 2-ethylbutyryl-2-naphthol-6-sulfonate ester at $80^{\circ} \mathrm{C}$ versus $\mathrm{pH}$ in pure buffer, buffer with $100 \mathrm{~g} / \mathrm{L} \mathrm{NaCl}$, and buffer with rockpowder. 
By plotting the $\mathrm{OH}^{-}$concentration vs. the logarithm of the hydrolysis constant $k_{h}$, the slope of the regression line was between 1.06 and 1.13 for every investigated temperature (Fig. 5.8). This result shows that the reaction is alkaline-catalyzed within the investigated $\mathrm{pH}$ range.

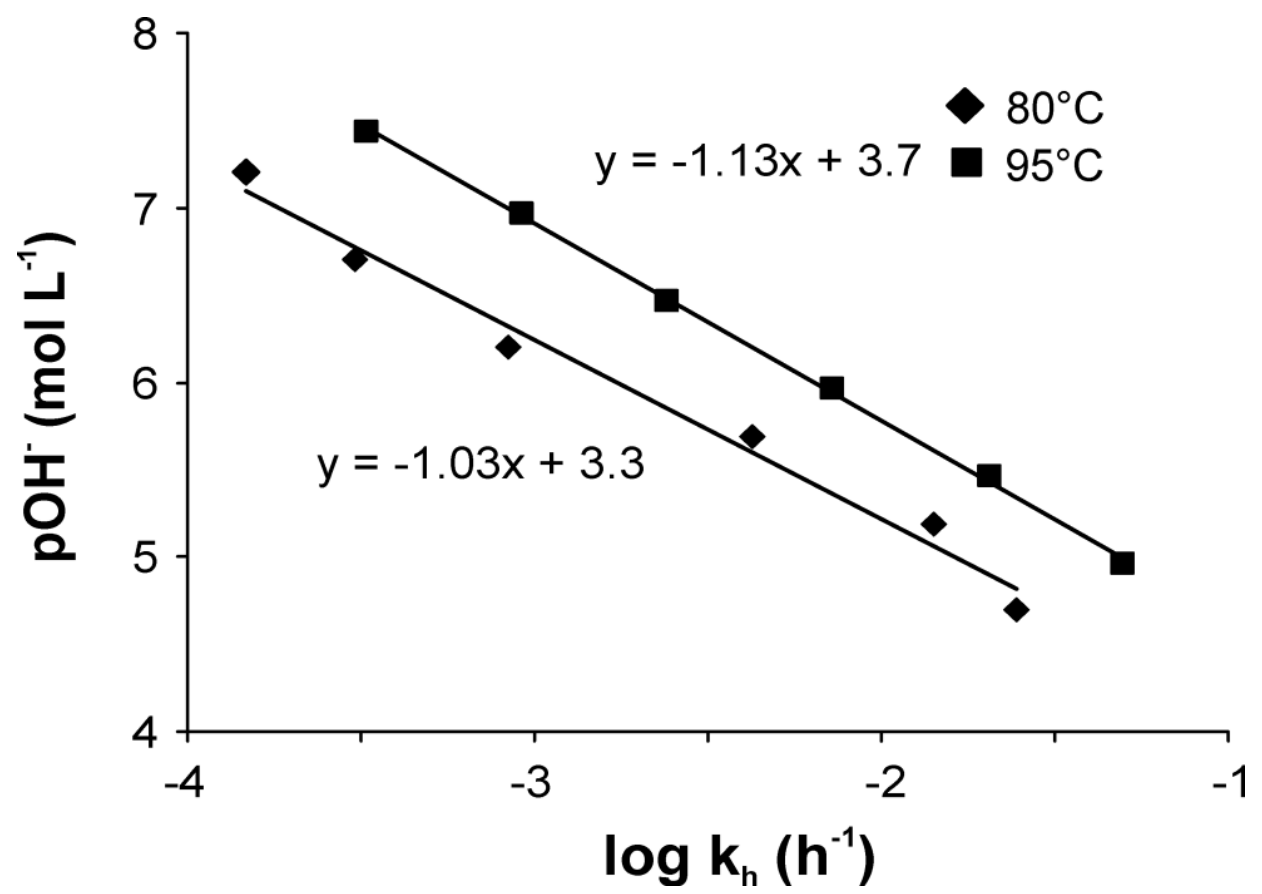

Figure 5.8: Pseudo first-order reaction kinetics of the 2-ethylbutyryl-2-naphthol6-sulfonate ester at different $\mathrm{OH}^{-}$concentrations for 80 and $95{ }^{\circ} \mathrm{C}$

Assuming an alkaline-catalyzed hydrolysis mechanism, the second-order rate constant $k_{2}$ can be calculated by Eq. 3 from $k_{h}$ and $\left[\mathrm{OH}^{-}\right]$. The Arrhenius plot for the estimation of Ea and $A$ is shown in Fig. 5.9. The calculated activation energy is 80.9 $\mathrm{kJ} / \mathrm{mol}$, and the value of the pre-exponential factor is $7.14 * 10^{11}\left[\mathrm{~L} \mathrm{~mol}^{-1} \mathrm{~s}^{-1}\right]$. Comparing the half-life calculated by the pseudo first-order reactions for every single $\mathrm{pH}$ and the calculated values from the second-order rate constant $k_{2}$, results are consistent (Table 5.4).

\subsubsection{Considerations of potentially suitable reactive tracers in geothermal reservoirs}

Based on the findings of Sections 4.1 and 4.2, other potentially suitable thermal reactive tracers may be considered. Furthermore, it is possible to predict the kinetic properties of substances not yet manufactured so as to design tracers for the special specifications of different test sites and test designs, such as those that may have varying temperature regimes and/or residence times. 


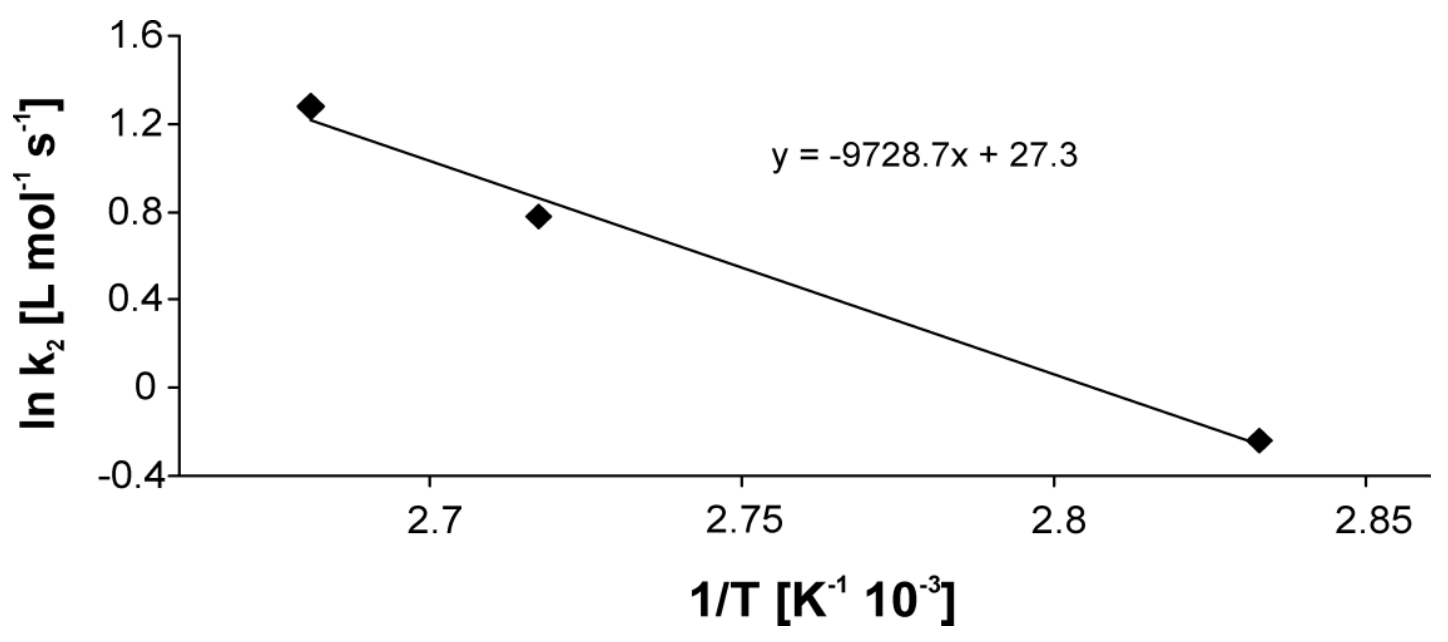

Figure 5.9: Arrhenius plot for alkaline catalyzed second order rate constants of the 2-ethylbutyryl-2-naphthol-6-sulfonate ester

Considering the comparatively short half-life of the 2-ethylbutyl-2-naphthol6-sulfonate ester, the reaction rates have to be slowed down for most typical applications and reservoir temperatures. As described in Section 4.1, there are several possibilities to slow down hydrolysis reactions by adding functional groups to the basic molecular structure. Furthermore, it is possible to make variations of the ester group. Functional groups on the basic structure have several effects. Substituents with a positive mesomeric effect would decrease the acidity of the hydroxide, thereby leading to slower reaction rates. This could be achieved by adding, as an example, alkyl groups. Substituents with a positive inductive effect, such as alkyl groups, decrease the acidity as well. Large effects on slowing down the hydrolysis reaction could be achieved by adding groups, which exhibit sterical hindrance. As seen in Section 4.1, the reaction rates decrease approximately by a factor of three when adding one methyl group next to the reactive group (phenol acetate compared to o-cresol acetate), and by a factor of 10 when adding two methyl groups next to the ester group (phenol acetate compared to 2,6-dimethylphenol acetate). The chain length of the hindering groups has further effects on reaction kinetics.

As seen in Section 4.1, the $\mathrm{pK}_{\mathrm{a}}$ of the alcoholic component has strong influences on reaction kinetics. According to Zollinger and Büchler (1950), the $\mathrm{pK}_{\mathrm{a}}$ of hydroxynaphthalene sulfonates range from 8.2 to 9.2 , which unfortunately gives only little variation possibility from the base molecular structure on the reaction speed. Moreover, the highest $\mathrm{pK}_{\mathrm{a}}$ of the phenolic group was reported for substances having their sulfonic group not on the same aromatic ring of the naphthalene as the hydroxyl substituent. The $\mathrm{pK}_{\mathrm{a}}$ of the investigated 2-hydroxy-6-naphthalene sulfonic acid is 9.1. Therefore, it is not possible to decrease reaction rates by choosing other 
kinds of hydroxynaphthalene sulfonic isomers, as long as no functional groups are additionally substituted for hydrogen on the aromatic rings.

Additionally, estimations of the temperature sensitivity can be made. Depending on the $E a$ and $A$ values of the tracer, the increase of reactivity with temperature is different. Substances having a low pre-exponentional factor $A$ and a high activation energy Ea can have the same half-life as substances with a high $A$ and a low Ea. As Plummer (2010) suggested, the sensitivity of the tracer with respect to temperature changes in the reservoir is much more significant when using tracers with a high Ea. Considering the linear relationship of Ea and $A$ for molecules within the same substance class, it would be advisable to choose substances having a comparatively low $A$ to Ea ratio. As shown in 4.1, the alkylphenolic esters have comparatively high Ea values and would therefore be a good choice as thermosensitive tracers. Also, it can be seen that the sterically-hindered molecules are much more sensitive with respect to temperature gradients than molecules without any hindrance groups (Fig. 5.5).

\subsection{Conclusions}

In the investigations of the thermal decay of the phenolic esters, several structure element effects on hydrolysis reaction kinetics could be identified. The influence of sterical hindering groups and mesomeric and/or inductive effects could be evaluated. Some of these effects are linear and therefore the changes in reaction kinetics by adding functional groups on the basic structure are predictable. Also, chain length of the carboxyl groups influences hydrolysis reaction times. Considering all these findings, a target variation of the hydrolysis constants $k_{h}$ by at least of a factor of 100 is possible.

The first investigated compound based on a naphthalene sulfonate shows high potential as a practical thermo-sensitive tracer in geothermal applications. Considering the comparatively short half-life of approximately $1500 \mathrm{~h}$ at $80^{\circ} \mathrm{C}$ and $\mathrm{pH} 6$ of the 2-ethylbutyl-2-napthol-6-sulfonate ester, this substance is proposed to be used for low temperature push-pull experiments. For circulation tests or tracer tests in reservoirs, having significantly higher temperatures than $80^{\circ} \mathrm{C}$, tracers with sterical hindering groups adjacent to the reacting group can be used. Another possibility to decrease reactivity is to esterify the hydroxyl group by longer or branched alkyl chains. 
Because the hydrolysis reaction is highly dependent on $\mathrm{OH}^{-}$concentration, exact downhole measurements of $\mathrm{pH}$ are needed to interpret results. Considering the normally high buffering capacity of geothermal brines, it is expected there is no change in $\mathrm{OH}^{-}$concentration within one formation. It has also been shown in this paper that high salty matrix of $100 \mathrm{~g} / \mathrm{L}$ or the presence of powdered sandstone has no effect on reaction kinetics. Therefore, influences of salinity or the presence of different kind of rock seems to be negligible. However, due to the large spectrum of rock types and fluid chemistry compositions in geothermal reservoirs, this may be proven for the exact hydrochemical and mineral characteristics of the respective test site.

The main advantage of the hydrolysis reaction is that the reaction kinetics strongly depends on temperature. Therefore, thermo-sensitive tracers are able to track thermal changes with high sensitivity. Also, there is a wide range of the Arrhenius parameters Ea and $A$. Within the two investigated groups of alkyl- and chlorophenol acetate esters, these range from approximately 50 to 100 for Ea [kJ mol$\left.{ }^{-1}\right]$ and from 15 to 35 for $\ln A\left[h^{-1}\right]$. Varying the combination of these parameters results in different thermo-sensitivities. Because of the wide variance of hydroxynaphthalene sulfonate isomers, it is possible to use these tracers with different reaction kinetics and reaction products simultaneously within one tracer test.

\section{Acknowledgements}

The authors gratefully acknowledge the financial support of parts of this work by the German Federal Ministry of Environment (BMU, 0327579 and 0325111 ) and by the European Commission MUSTANG project (Project Reference: 227286), seventh framework program. The authors would like to thank the working group of Prof. Ulf Diderichsen (University of Göttingen) for their help during the ester synthesis.

\subsection{References}

Adams, M. C., Davis, J., 1991. Kinetics of fluorescein decay and its application as geothermal tracer. Geothermics 20 (1/2), 53-66.

Behrens, H., Ghergut, I., Sauter, M., Licha, T., 2009. Tracer properties and spiking results from geothermal reservoirs. In: Proceedings of the 31th Workshop of Geothermal Reservoir Engineering, Stanford University, Stanford, California, USA, February 9-11, 2009, SGP-TR-187, 7 pp.

Bender, M. L., 1960. Mechanisms of catalysis of nucleophilic reactions of carboxylic acid derivatives. Chem. Rev. 60 (1), 53-113. 
DuTeaux, R., Callahan, T.J., 1996. Comparing reactive and non-reactive tracers to measure changes in liquid dominated, fractured geothermal reservoirs. Geotherm. Resour. Counc. Trans. 20, 447-451.

Ghergut, I., Sauter, M., Behrens, H., Licha, T., McDermott, C.I., Herfort, M., Rose, P., Zimmermann, G., Orzol, J., Jung, R., Huenges, E., Kolditz, O., Lodemann, M., Fischer, S., Wittig, U., Güthoff, F., Kühn, M., 2007. Tracer tests evaluating hydraulic stimulation at deep geothermal reservoirs in Germany. In: Proceedings of the 31th Workshop on Geothermal Reservoir Engineering, Stanford University, Stanford, Calfornia, USA, January 22-24, 2007, SGP-TR-183, 8 pp.

Greim, H., Ahlers, J., Bias, R., Broecker, B., Hollander, H., Gelbke, H. P., Klimisch H. J., Mangelsdorf, I., Paetzig, A., Schön, N., Stropp, G., Vogel, R., Weber, C., ZieglerSkylakakis, K., Bayer, E., 1994. Toxicity and ecotoxicity of sulfonic acids: structureactivity relationships. Chemosphere 28, 2203-2236.

Haggerty, R., Argerich, A., Marti E., 2008. Development of a smart tracer for the assessment of microbiological activity and sediment-water interaction in natural waters: The resazurin- resorufin system. Water Resour. Res. 44, W00D01, doi:10.1029/2007WR006670.

Kwakwa, K. A., 1988. Tracer measurements during long-term circulation of the Rosemanowes HDR geothermal system. In: Proceedings of the 13th Workshop on Geothermal Reservoir Engineering, Stanford University, Stanford, California, USA, January 19-21, 1988, SGP-TR-113, 8 pp.

Laughton, P. M., Robertson, R. E., 1955. Reactions of arylsulphonic esters: II. The alkyl group. Can. J. Chem. 33 (7), 1207-1215.

Liu, L., Guo, Q.-X., 2001. Isokinetic relationship, isoequilibrium relationship and enthalpyentropy compensation. Chem. Rev. 10, 673-695.

Nottebohm, M., Licha, T., Ghergut, I., Nödler, K., Sauter, M., 2010. Development of thermosensitive tracers for push-pull experiments in geothermal reservoir characterization. In: Proceedings World Geothermal Congress 2010 Bali, Indonesia, April 25-29, 2010, 6 pp.

O'Sullivan, M., Yeh, A., Mannington, W., 2010. Renewability of geothermal resources. Geothermics 39, 314-320

Plummer, M. A., Palmer, C. D., Hull, L. C., Mattson, E. D., 2010. Sensitivity of a reactivetracer based estimate of thermal breakthrough in an EGS to the properties of the reservoir and tracer. In: Proceedings of the 35th Workshop on Geothermal Reservoir Engineering, Stanford University, Stanford, California, USA, February 1-3, 2010, SGP-TR188, $7 \mathrm{pp}$.

Redden, G., Stone, M., Wright, K. E., Mattson, E., Palmer, C. D., Rollins, H., Harrup, M., Hull, L. C., 2010. Tracers for characterizing enhanced geothermal systems. In: Proceedings, 35 Workshop on Geothermal Reservoir Engineering, Stanford University, Stanford, California, USA, February 1-3, 2010, SGP-TR-188, 7 pp. 
Robinson, B. A., Birdsell, S. A., 1987. Tracking thermal fronts with temperaturesensitive, chemically reactive tracers. Fifth Geothermal Program Review, Washington, DC, USA, April 14-15, 1987.

Rose, P., Benoit, W. R., Kilbourn, P. M., 2001. The application of polyaromatc sulfonates as tracers in geothermal reservoirs. Geothermics 30, 617-640.

Rose, P., Johnson, D. S., Kilbourn, P., Kastelen, C., 2002. Tracer testing at Dixie Valley, Nevada using 1-naphthalene sulfonate and 2,6-naphthalene disulfonate. In: Proceedings, 27 Workshop on Geothermal Reservoir Engineering, Stanford University, Stanford, Calfornia, USA, January 28-30, 2002, SGP-TR-171, 6 pp.

Sanjuan, B., Pinault, J.-L., Rose, P., Gérard, A., Brach, M., Braibant, G., Couzet, C., Foucher, J.-C., Gautier, A., Touzelet, S., 2006. Tracer testing of the geothermal heat exchanger at Soultz-sous-Forêts (France) between 2000 and 2005. Geothermics 35, 622-653.

Sanjuan, B., Millot, R., Brach, M., Asmundsson, R., Giroud, N., 2010. Use of a new Sodium/Lithium ( $\mathrm{Na} / \mathrm{Li})$ geothermometric relationship for high-temperature dilute geothermal fluids from Iceland. In: Proceedings World Geothermal Congress 2010 Bali, Indonesia, April 25-29, 2010, 12 pp.

Schwarzenbach, R. P., Gschwend, P. M., Imboden, D. M., 2003. Environmental Organic Chemistry, second edition, Wiley-Interscience Publishers, Chapter 13.3.

Shook, G. M., 2001. Predicting thermal breakthrough in heterogeneous media from tracer tests. Geothermics 30, 573-589.

Sykes, P., 1988. A Guidebook to Mechanism in Organic Chemistry, 6 ed, Longman, London, Chapter 8.6.

Tester, J. W., Robinson, B. A., Ferguson, J. H., 1986. Inert and reacting tracers for reservoir sizing in fractured, Hot Dry Rock Systems. In: Proceedings of the 11th Workshop on Geothermal Reservoir Engineering, Stanford University, Stanford, California, USA, January 21-23, 1986, SGP-TR-93, 11 pp.

Zollinger, H., Büchler, W., 1950. Einfluss der Sulfongruppen auf den Dissoziationsgrad der Hydroxyle in Naphtholsulfonsäuren. Helv. Chim. Acta 33, 2002-2010. 


\section{Chapter 6}

\section{General conclusions and perspectives}

Tracer techniques show a high potential to apply various characterization methods of deep reservoirs in geothermal applications. Some of these techniques are the only way for the estimation of essential characteristics such as flow paths and longterm sustainability. However, the investigation of appropriate tracer substances need research. The choice of the tracer that is used may also depend on the physicochemical properties of the reservoir such as temperature, salinity, and $\mathrm{pH}$. These properties affect the transport behavior of the tracer in the reservoir, its stability, and the choice of the analytical methods. While some substances like naphthalene sulfonates have been shown to be an excellent choice as conservative liquid phase tracers, the investigation of thermosensitive substances has to be extended. The first steps in the development of a new class of thermosensitive tracers have been done within this work.

\section{Analytical techniques for the detection and quantification of fluorescence tracers}

An analytical technique for the detection of highly polar substances in brines which have a high ion strength has been developed. The method bases on ion-pair chromatography in conjunction with solid phase extraction and fluorescence detection. The main advantage of this method is that the detection limits could be significantly improved. Also, this method is highly specific to the analytes (in this case naphthalene sulfonates) and the influences of overlapping effects are therefore minimized. The method has been explicitly developed for the detection of analytes from highly saline fluids. Therefore, it is applicable for the highly saline brines that are present in the northern European basin, but it can also be applied for most other geothermal matrices.

Using high-performance liquid chromatography with fluorescence detection and solid-phase extraction combines a low detection limit, a sufficient selectivity, and moderate efforts in time and costs. While direct measurements are often not selective to the analyte and the detection limit is poor, the drawback of HPLC applications is that online measurements are not possible. However, in some cases the use of this analytical method is essential. For example, naturally occurring organic phases as well as additives given to the circulating fluid, can generate background signals that overlays the tracer signal significantly. Also, the use of the 
tracer amount is restricted in some locations, making a low detection limit essential. Because this method is able to separate isomers, it is possible to use very similar substances at the same test site without the risk of overlapping signals.

\section{Investigation of a thermosensitive reaction for the target design of thermally reacting tracers}

The first steps in the development of thermosensitive substances have been done within this work. This includes the investigation of the kinetic parameters of naphthalene sulfonic esters that undergo a thermosensitive reaction by hydrolysis. The experiments have been conducted in the lab under the physicochemical boundary conditions of a typical geothermal reservoir. Also, the mechanisms affecting hydrolysis rates that are caused by different substituents on the molecule have been studied in detail. It has been shown that the reaction rates can be varied at least by the factor of 100 . All these variations are predictable. Therefore, the target design of a thermally reactive tracer can be done with respect to the thermal regime of the considered test site. However, this has its limitations. The reaction rates of the hydrolysis reaction are comparatively fast for high temperature geothermal reservoirs. To decrease reaction rates, several possibilities have been shown by adding substituents to the molecule that causes sterical hindrance and/or mesomeric and inductive effects. Also, the leaving group can be varied by using longer chained or branched alkyl chains. Because the reaction rates depends on the concentration of the hydroxide ion concentration, the $\mathrm{pH}$ of the reservoir fluid has to be considered as well as the different intrinsic dissociation constants of water at varying temperatures. By assuming a second order rate constant, this effect can be considered in the reaction kinetic formulas. The estimation of the absolute hydroxide ion concentration in the "in situ" reservoir fluid may be done by using hydro-chemical modeling software like, for example, PHREEQC.

The reaction rates of the 2-ethylbutyryl-2-hydroxynaphthalene-6-sulfonic ester seems to be suitable for short-term push-pull experiments in comparatively low tempered geothermal systems. Beside this limitation, the tracer seems to be an excellent choice, because its reaction product has been proofed in geothermal applications for many years. Also, different compounds of this substance class can be used simultaneously because it is possible to detect different isomeres of (hydroxy-) naphthalene sulfonates by the method described in this work. 


\section{General remarks for the development of "smart" tracers}

The target design of tracers that possess the specific requirements of a reacting tracer is a new and very innovative concept. The interactions of organic molecules with natural systems are known in many ways. Therefore, the properties of molecules can be specifically modified to construct a tracer that fulfills the requests of a "smart" tracer test under the given boundary conditions of the respective test site. Beside the application as thermal reactive tracers, this concept may be extended to design tracers that sorbs on rock for example, or for tracers that partitions between different phases such as oil and water, or $\mathrm{ScCO}_{2}$ and water.

However, the target design of molecules is only the first step in the development of a reacting tracer. It has to be proven by lab experiments that the reaction is selective and specific to the boundary condition that has to be determined by the tracer test. If the reaction is not unique, the influences of other factors have to be evaluated and quantified. Also the interpretation of the resulting breakthrough curves needs further research. The development of transport and flow modeling techniques is in progress, leading to a better understanding of the results. This can also help to give recommendations for the requests on the tracer that has to be designed before its synthesis. As a result, lab experiments have to be performed, and modeling approaches have to be developed in parallel for the development of reliable and appropriate "smart" tracers. 


\section{Appendix A}

\section{Results of Purity Identification of the Ester- synthesis described in Chapter 2.8}

Table A.1: Ion-chromatographic measurements of the synthesized 2-ethylbutyryl2-naphthol-6-sulfonic ester. Ester A: Purified by one-step recrystallization; Ester B: Purified by two-step recrystallization; Ester C: not purified

\begin{tabular}{ccccccc} 
& $\mathbf{C l}^{-}[\mathbf{m g} / \mathbf{g}]$ & $\begin{array}{c}\mathbf{S O}_{4}{ }^{2-} \\
{[\mathbf{m g} / \mathbf{g}]}\end{array}$ & $\begin{array}{c}\mathbf{N a}^{+} \\
{[\mathbf{m g} / \mathbf{g}]}\end{array}$ & $\begin{array}{c}\mathbf{K}^{+} \\
{[\mathbf{m g} / \mathbf{g}]}\end{array}$ & $\begin{array}{c}\mathbf{M g}^{2+} \\
{[\mathbf{m g} / \mathbf{g}]}\end{array}$ & $\begin{array}{c}\mathbf{C a}^{2+} \\
{[\mathbf{m g} / \mathbf{g}]}\end{array}$ \\
\hline Ester A & 6.91 & 2.41 & 4.10 & 81.84 & 0.25 & 1.66 \\
Ester B & 1.12 & 0.97 & 1.30 & 80.63 & $<0.28$ & $<0.28$ \\
Ester C & 49.39 & $<1.5$ & $<0.8$ & 134.85 & $<0.28$ & $<0.28$
\end{tabular}

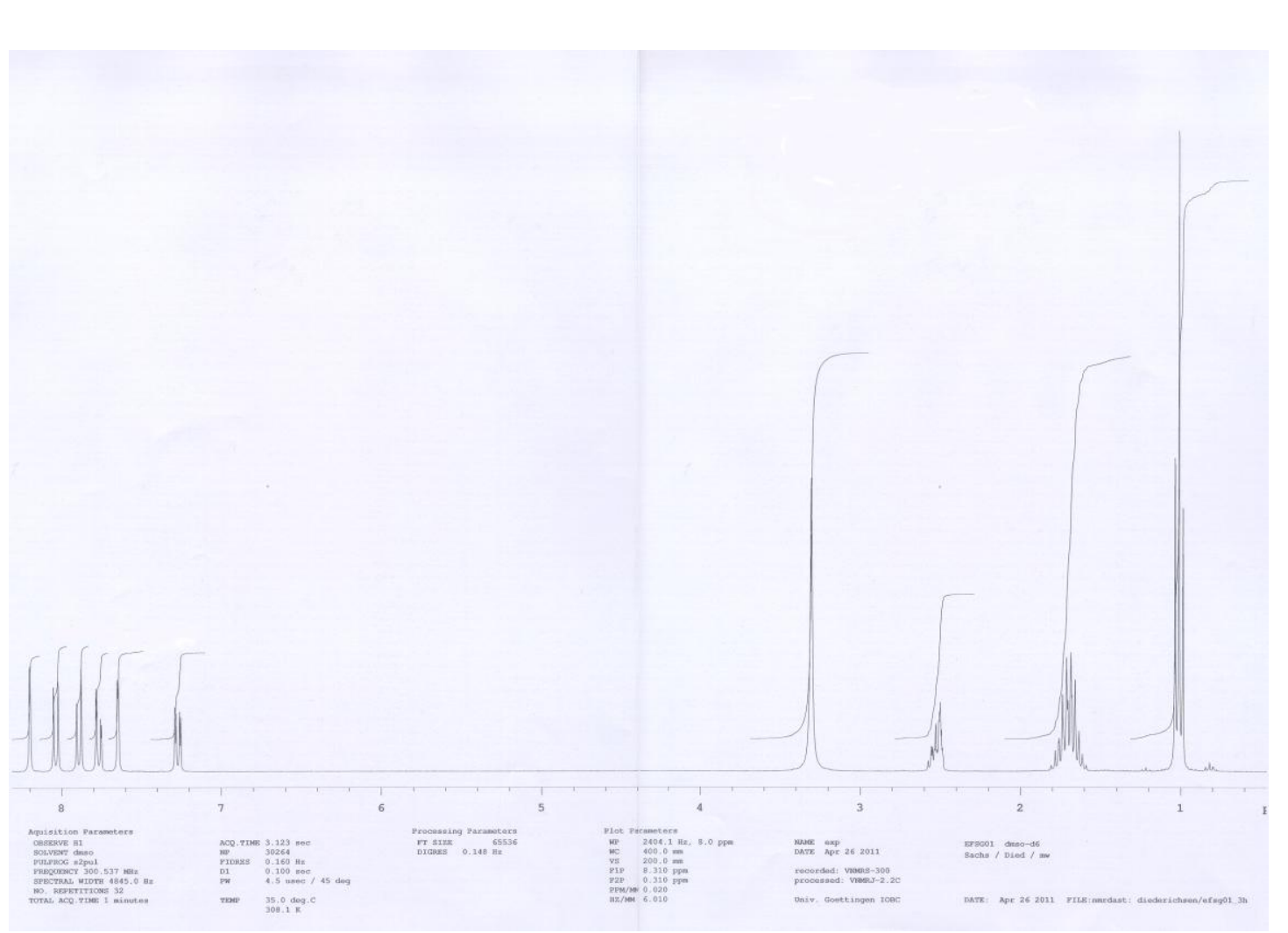

Figure A.1: H-NMR-Spectrum of Ester C 


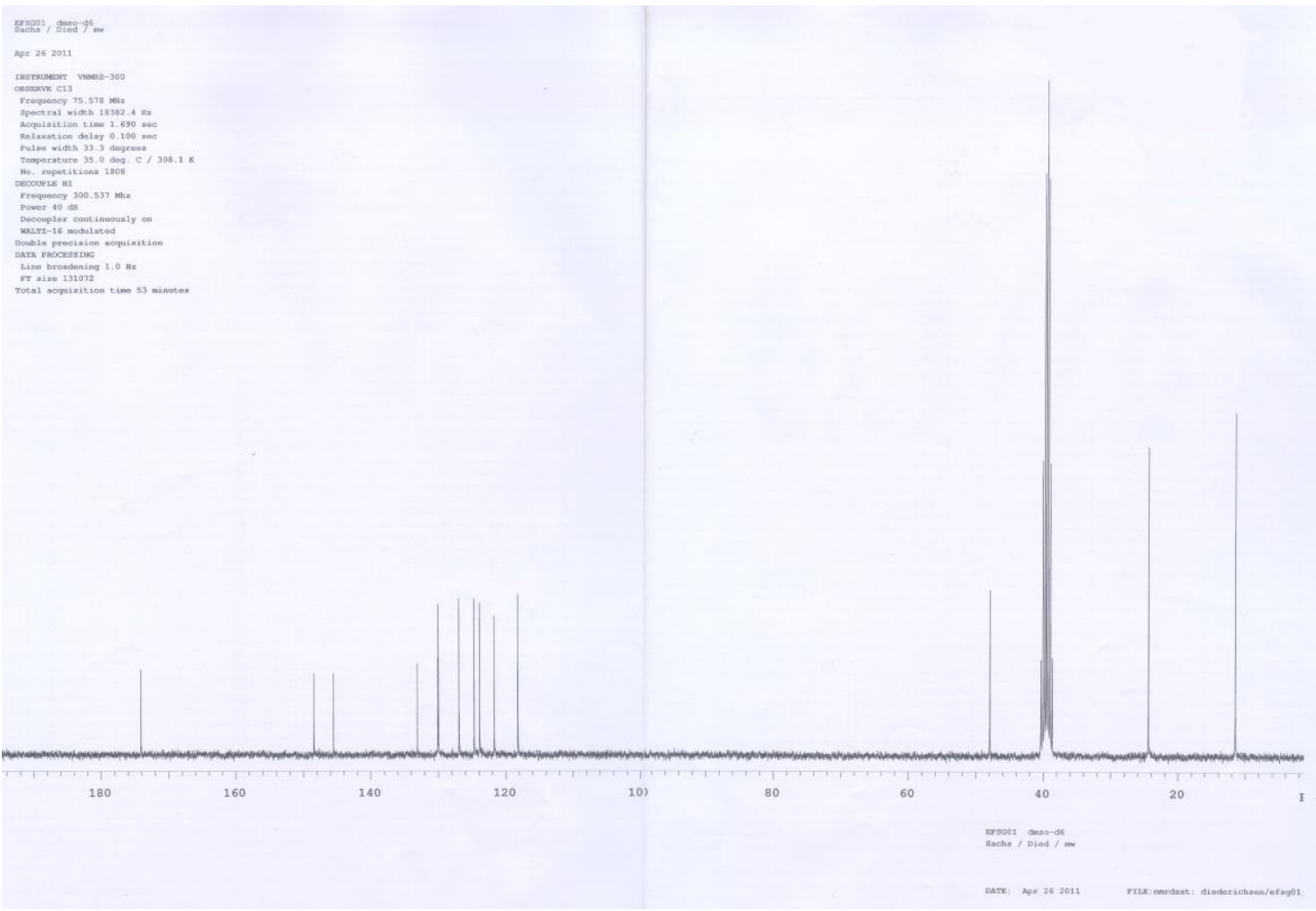

Figure A.2: C13-NMR Spectrum of Ester C

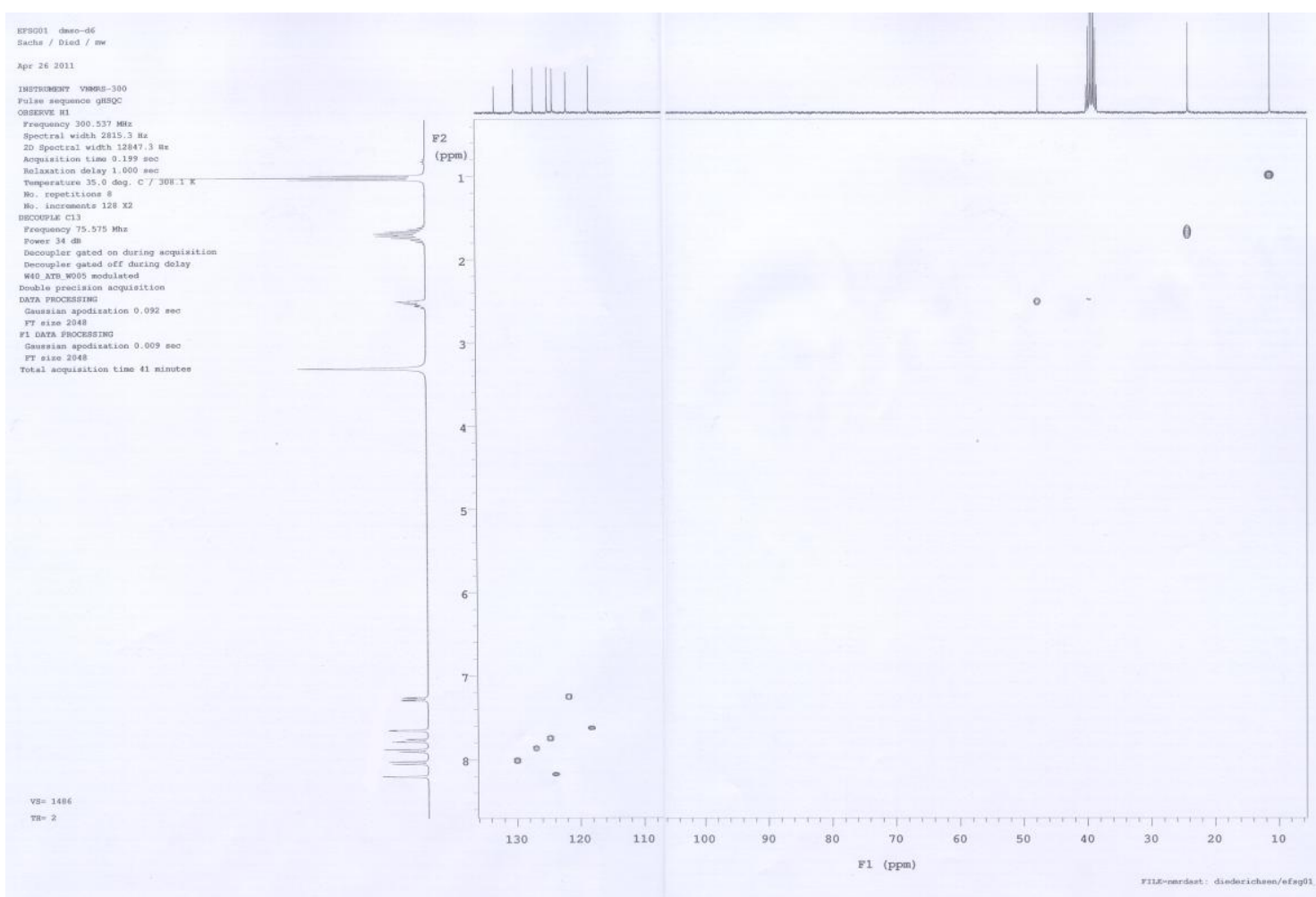

Figure A.3: NMR-Spectrum of Ester C 


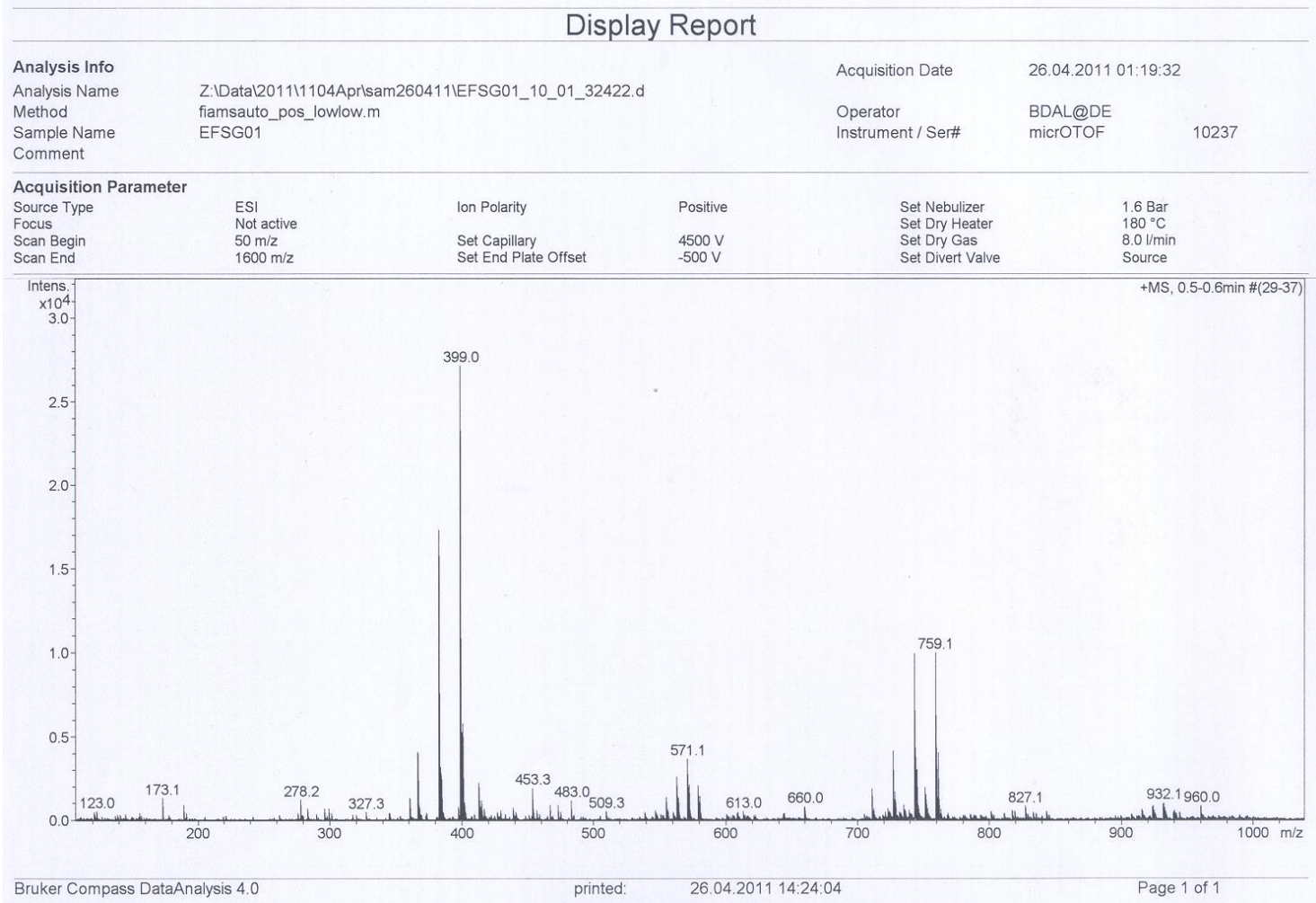

Figure A.4: m-TOF chromatogram of Ester C (positive, m/z 100-1050)

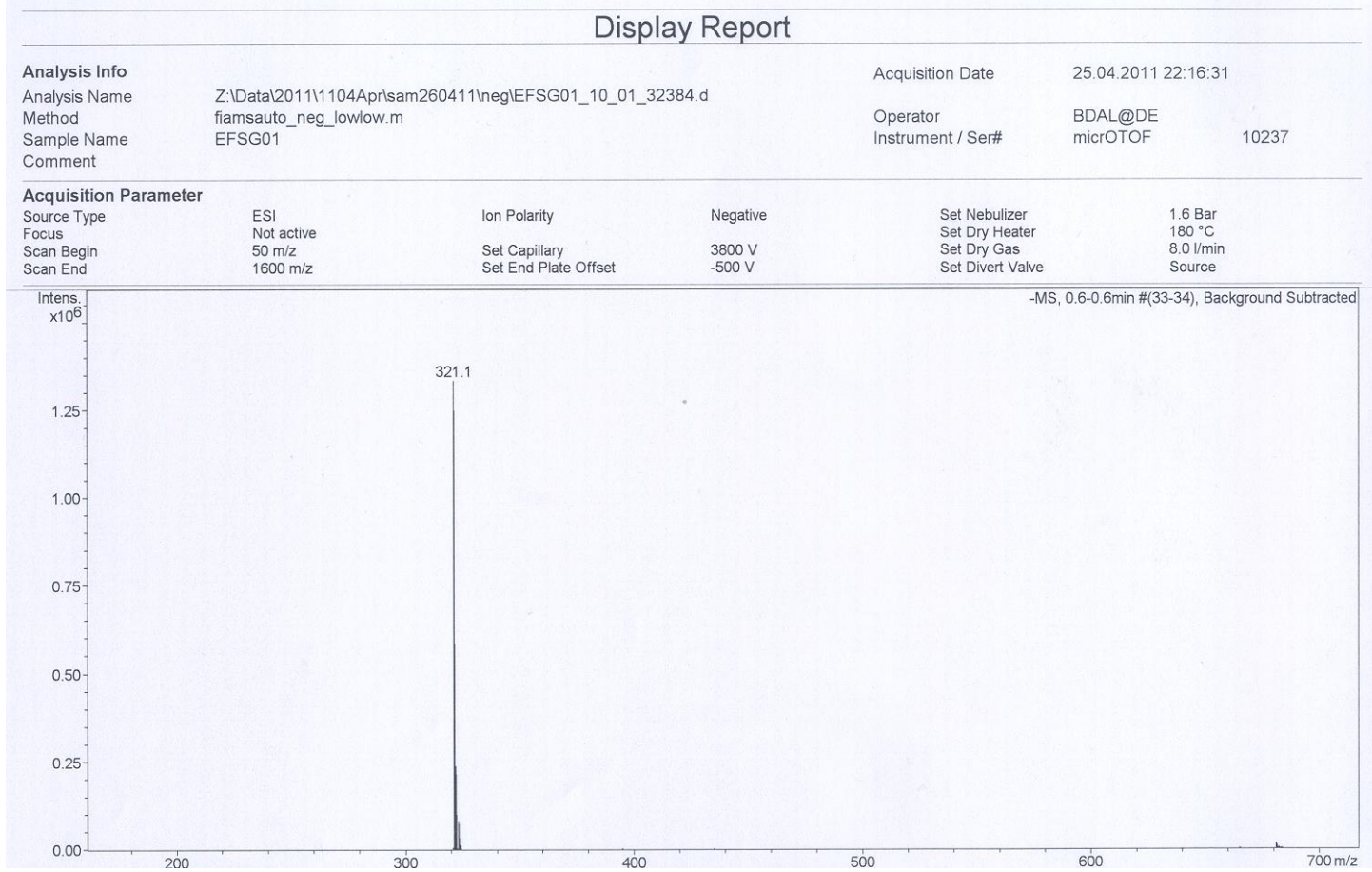

Figure A.5: m-TOF chromatogram of Ester C (negative, $\mathrm{m} / \mathrm{z}$ 180-720) 


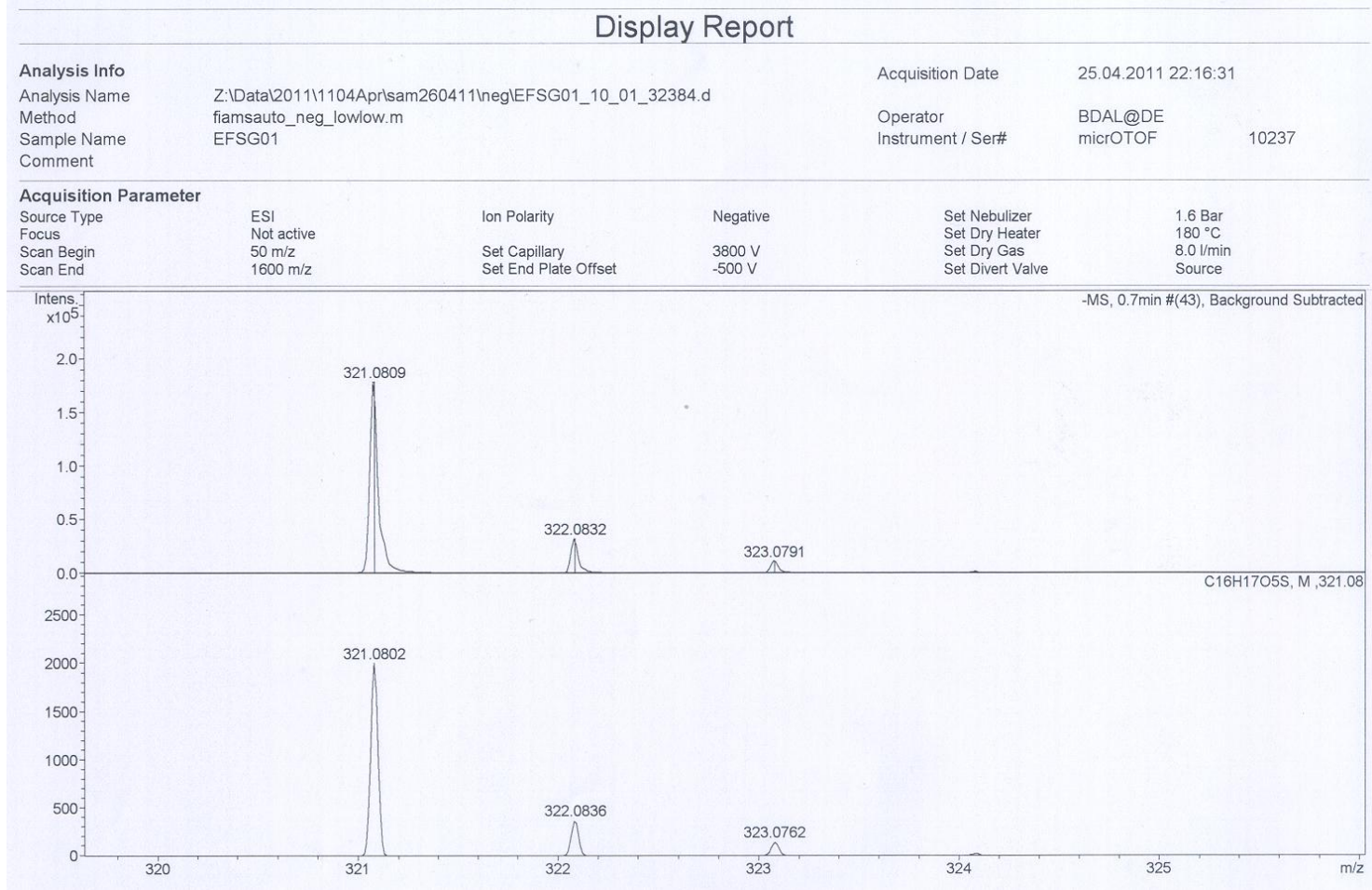

Figure A.6: $\mathrm{m}$-TOF chromatogram of Ester C (negative, $\mathrm{m} / \mathrm{z}$ 319.6-326) 


\section{Appendix B}

List of publications authored or co-authored by me, and related to the present work

\section{Journal paper}

Nottebohm, M., Licha, T.: Detection of Naphthalene sulfonates from highly saline brines with high-performance liquid chromatography in conjunction with fluorescence detection and solid-phase extraction (accepted by Journal of Chromatographic Science)

Nottebohm, M., Licha, T. and Sauter, M.: Tracer design for tracking thermal fronts in geothermal reservoirs (accepted pending minor revisions by Geothermics)

\section{Peer reviewed conference paper (english)}

Nottebohm, M., Licha, T., Ghergut, I., Nödler, K., Sauter, M. (2010): Development of Thermosensitive Tracers for Push-Pull Experiments in Geothermal Reservoir Characterization, Proceedings World Geothermal Congress 2010 Bali, Indonesia, 25-29 April 2010

Nottebohm, M., Licha, T., Sauter, M. (2010): Thermal Decay of Selected Organic Substances as "Smart Tracers" in Geothermal Reservoirs PROCEEDINGS, Thirty-Fifth Workshop on Geothermal Reservoir Engineering, Stanford University, Stanford, California, February 13, 2010, SGP-TR-188

\section{Conference paper (english)}

Nottebohm M, Licha T (2011): Investigation of thermosensitive tracers for the investigation of the thermal regime in $\mathrm{CO} 2$ sequestration reservoirs. Geophys Res Abstr 13, 8754

Nottebohm, M. Licha, T. (2010): Thermal decay of selected organic substances for using them as "smart tracers" in geothermal reservoirs. European geothermal PhD Day, 12.02.2010, Potsdam

\section{Conference paper (german)}

Nottebohm, M., Licha, T. (2010): Untersuchungen des thermischen Zerfalls von organischen Substanzen zum Einsatz als thermosensitive Tracer in Geothermalreservoiren. Tagung der Fachsektion Hydrogeologie in der DGG (FH-DGG), 12-16.05.2010, Tübingen

Nottebohm, M. Licha, T. (2009): Bestimmung von Naphthalinsulfonaten in geothermischen Reservoirfluiden. Kongressband der Geothermischen Vereinigung, Bundesverband Geothermie e. V, Geothermiekongress Karlsruhe, 17-19.11.09, Karlsruhe 
Nottebohm, M., Licha, T. (2009): Bestimmung von Naphthalinsulfonaten in geothermischen Reservoirfluiden. Tagung der Gesellschaft deutscher Chemiker, Anakon 2009, 1720.03.09, Berlin

Nottebohm, M., Licha, T. (2008): Bestimmung von Naphthalinsulfonaten in geothermischen Reservoirfluiden. Kongressband der Geothermischen Vereinigung, Bundesverband Geothermie e. V, Geothermiekongress Karlsruhe, 11-13.11.08, Karlsruhe

Nottebohm, M., Licha, T. (2008): Bestimmung von Naphthalinsulfonaten in geothermischen Fluiden. Tagung der Fachsektion Hydrogeologie in der DGG (FH-DGG), 21-25.05.2008, Göttingen

\section{Reports}

Ghergut, I., Nottebohm, M., Licha, T. and Sauter, M. (2011): Verbundprojekt zur Charakterisierung von sedimentären Geothermalreservoiren (SmartTracer), FKZ: 0327579, final report, $35 \mathrm{p}$. 


\section{Curriculum Vitae}

\section{Martin Breer genannt Nottebohm}

(as at November 2011)

\section{Personal Data:}

Born 17 April 1977 in Itzehoe, Germany

\section{Academic Qualifications:}

Dipl. Geoscientist, University of Göttingen, Applied Geology (2007)

BSc. Geosciences, University of Göttingen, Applied Geology (2003)

\section{Major Professional Experience:}

Research associate, University of Göttingen (2007-Current)

Student assistance, University of Göttingen (2004-2007)

Engeneering offices (2004-2007, part-time) 